\title{
Effects of Genistein Following Fractionated Lung Irradiation in Mice
}

\author{
By
}

\section{Andrea Ellen Para}

A thesis submitted in conformity with the requirements

for the degree of Master of Science

Graduate Department of Medical Biophysics

University of Toronto

C Copyright by Andrea Ellen Para 2009 
Effects of Genistein Following Fractionated Lung Irradiation in Mice, Master of Science 2009, Andrea Ellen Para, Department of Medical Biophysics, University of Toronto

\begin{abstract}
Radiation therapy for lung cancer and cancers of the upper thorax is limited by side effects to normal tissue of the lung. An understanding of mechanisms leading to radiation induced lung damage is essential to developing protective agents. In this thesis an anti-oxidant and anti-inflammatory agent Genistein was investigated for its potential to affect DNA damage, tissue inflammation, functional deficits and survival. We hypothesized that chronic oxidative stress and the subsequent inflammatory response play a key role in the development of major lung complications, radiation pneumonitis and fibrosis. If side effects of radiation could be reduced, then larger doses could be delivered to the tumor with a better chance of eradicating the disease.
\end{abstract}




\section{Acknowledgements}

Thank you to my supervisor Dick for hiring me into your lab and for all you guidance and support during the course of my degree. For being a mentor and motivating me to do the best science we could.

Thank you to my supervisory committee members Dr. Andrea Bezjak, Dr. Ivan Yeung and Dr. Rob Bristow for your thoughts, insights, and direction.

Thank you to Dr. Jake Van Dyk and members of the lung group (Ivan Yeung, Victoria Calveley, Javid Mahmood, Asif Zaidi, Salomeh Jelveh) for your input and collaborations. Especially to Victoria who taught me all the lung assays and got me started on the project.

Thank you to the Excellence in Radiation Research for the $21^{\text {st }}$ Century (EIRR) program for supplying my funding for two years.

Thank you to all the past and present members of the Hill lab (Asif Zaidi, Bob Kuba, Carine Laurent, Javed Mahmood, Li Zhang, Mary-Claire Kavanagh, Naz Chaudary, Patrick Subarsky, Pavel Kaspler, Sarah Jane Lunt, Salomeh Jelveh, Tamara Marie-Egyptienne, Tuula Kalliomäki, Victoria Calveley). A special thanks to Bob, for your patience in doing hundreds of difficult mouse tail vein injections for me.

Thank you to all my family, Mom, Dad, Pat, Kennedy, Lisa, and Rebecca for supporting me no matter what I decide to do and how many long years I stay in school. Thank you to all my friends for being there when I was stressed out, especially Courtney McIntosh and Matthew Lincoln - I wouldn't have made it without you. 
Table of Contents

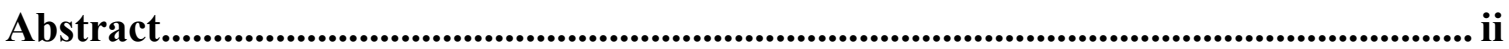

Acknowledgements ............................................................................................................... iii

List of Figures................................................................................................................................. v

List of Abbreviations ...................................................................................................vi

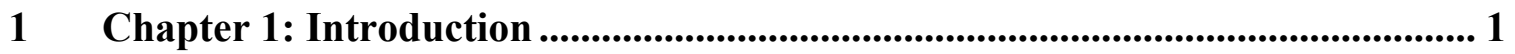

1.1 Normal lung response to radiation ............................................................. 2

1.2 Direct and Indirect Effects of Radiation ................................................... 3

1.3 Pulmonary Response to Radiation Therapy ................................................ 3

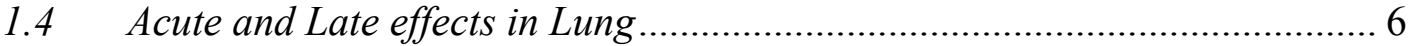

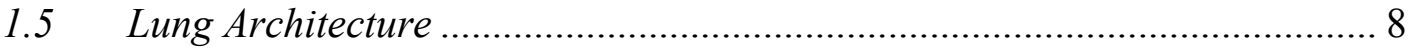

1.6 Volume and Regional Effects .............................................................. 9

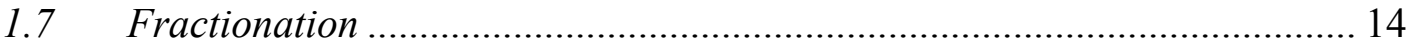

1.8 Universal Reaction - Acute Respiratory Distress Syndrome (ARDS).......... 16

1.9 Lung Inflammation Post Irradiation (PI) - Cell Adhesion Molecules ........ 20

1.10 Lung Inflammation Post Irradiation (PI) - Inflammatory Cytokines .......... 20

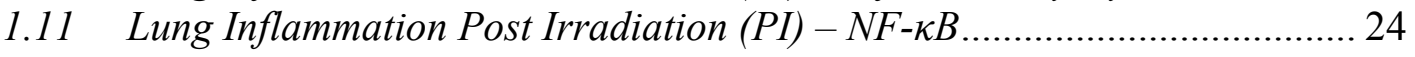

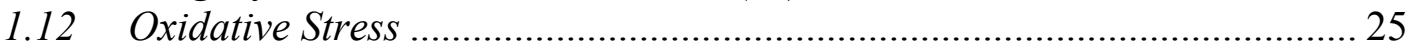

1.13 Protection Against Oxidative Damage - SOD and SOD mimetics............. 30

1.14 Protection Against Lung Inflammation ........................................................ 32

1.15 Protection Against Radiation-Induced Lung Damage by Genistein............ 34

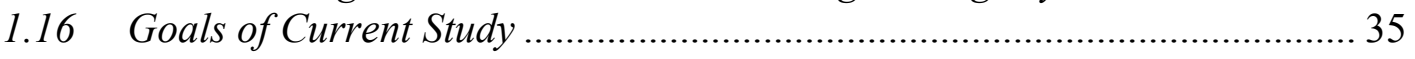

2 Chapter 2: Mitigation of radiation-induced lung damage by Genistein........... 38

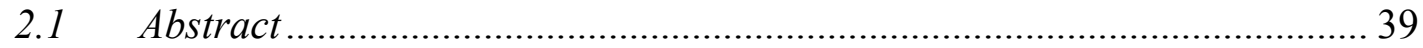

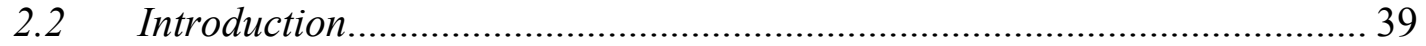

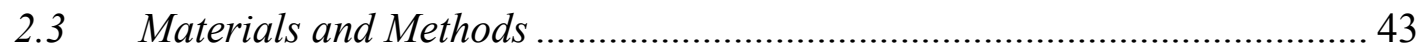

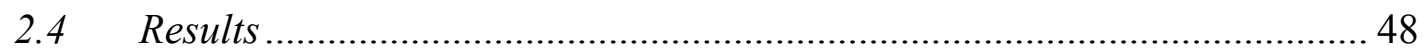

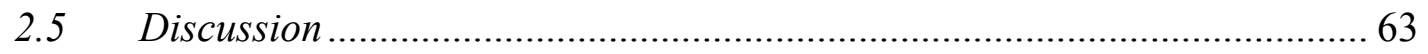

3 Chapter 3: Discussion and future directions ................................................... 71

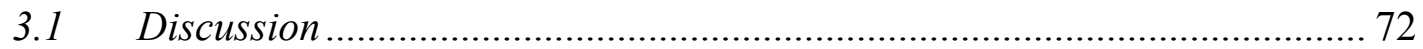

3.2 Future Directions........................................................................... 78

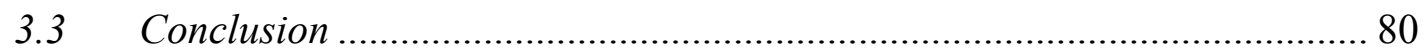




\section{List of Figures}

Figure 1-1: Possible cellular communication following irradiation ............................... 5

Figure 1-2: Possible cycle of inflammatory mediators post irradiation............................ 7

Figure 1-3: Breathing rate and lethality as a function of partial volume irradiated.......... 11

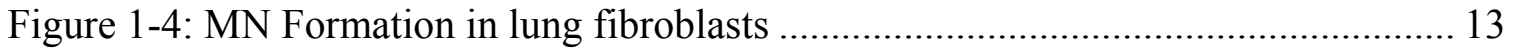

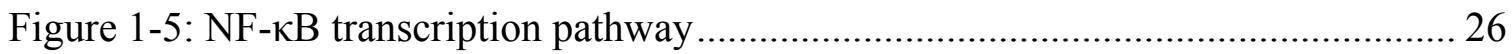

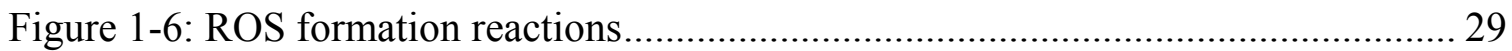

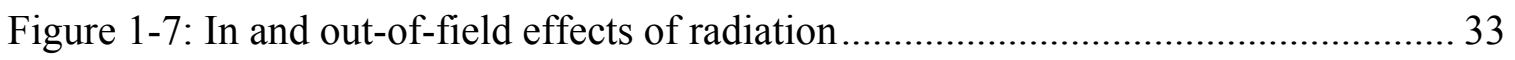

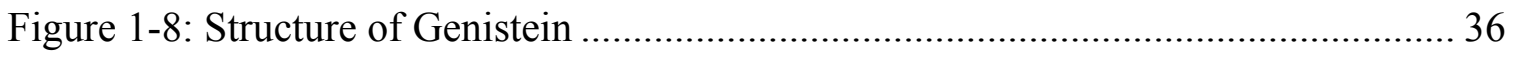

Figure 2-1: Weight of mice following irradiation.................................................... 49

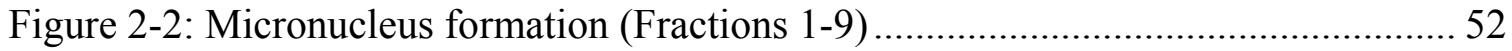

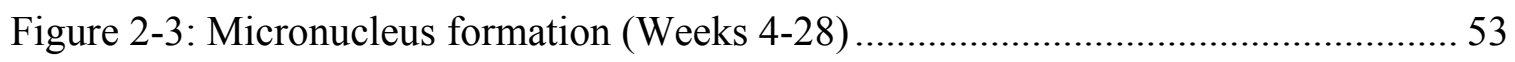

Figure 2-4: Representative images of MAC3 stain..................................................... 54

Figure 2-5: Representative images of MAC3 stain (from moribund mice)..................... 55

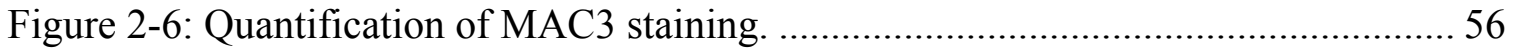

Figure 2-7: Quantification of MAC3 staining (from moribund mice) ............................ 57

Figure 2-8: Representative images of Masson's Trichrome stain .................................59

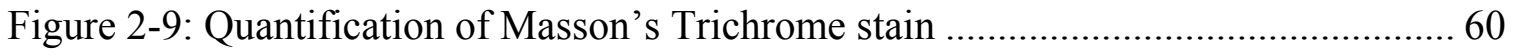

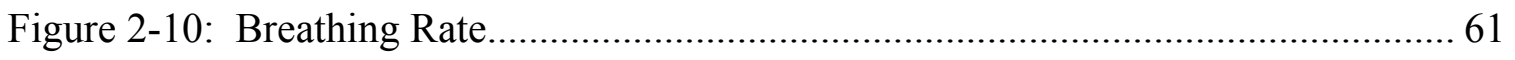

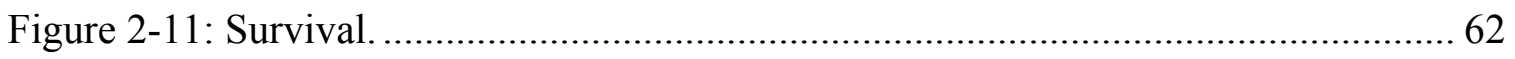

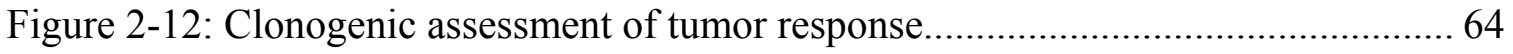

Figure 3-1: Survival data from previous experiments in rats .................................... 76

Figure 3-2: Breathing rate data from previous experiments in rats .............................. 77 


\section{List of Abbreviations}

ARDS - Acute Respiratory Distress Syndrome

ACE - angiotensin converting enzyme

BALF - bronchiolar lavage fluid

CAM - Cell adhesion molecule

$\mathrm{ED}_{50}$ - effective dose for $50 \%$ of subjects

EC-SOD - extracellular superoxide dismutase

FSU - functional subunit

Gy - Gray

IL - interleukin

I $\kappa$ B - inhibitory protein of NF- $\kappa$ B

ICAM-1 - intercellular adhesion molecule-1

IP - intraperitoneally

IV - intravenous

IKK - kinase that phosphorylates inhibitory I $\mathrm{B}$ protein

$\mathrm{LD}_{50}$ - lethal dose for $50 \%$ of subjects

LPS - lipopolysaccharide

$\mathrm{MN}$ - micronuclei

NF- $\kappa \mathrm{B}$ - nuclear factor-kappa B

L -NAME - nitro-L-arginine methyl ester

NTCP - normal tissue complication probability

PDGF - platelet derived growth factor

PI - post irradiation

RNOS - reactive nitrogen oxide species

ROS - reactive oxygen species

SBRT - stereotactic body radiation therapy

SOD - superoxide dismutase

TGF- $\beta$ - transforming growth factor $\beta$

TNF- $\alpha$ - tumor necrosis factor $\alpha$

$\mathrm{V}_{20}$ - dose delivered to $20 \%$ of lung volume

VCAM-1 - vascular cell adhesion molecule-1 


\section{Chapter 1: Introduction}




\subsection{Normal lung response to radiation}

There were an estimated 159,900 new cases of cancer in Canada in 2007 [1] and at least half of all patients will undergo radiation therapy as part of their cancer treatment [2]. Lung cancer is the most common cancer, with 23,300 new cases in Canada in 2007 and has one of the lowest five year survival ratios of $16 \%$ resulting in 19,900 deaths in 2007 [1]. The lung is a relatively radiosensitive organ [3] and normal tissue toxicity is a dose limiting factor for radiotherapy of tumors in the upper thorax such as lung cancer, breast cancer, thymoma and lymphoma [4]. The main side effects of radiotherapy in the lung are pneumonitis and fibrosis, characterized by symptoms of congestion, cough, shortness of breath, chest pain, and reduced diffusion capacity/volume. Five to twenty percent of patients will develop severe pulmonary side effects from radiation treatment [4]. These effects reduce the functional capacity of the lung and may even lead to death. The severity of radiation pneumonitis and fibrosis depends upon the dose, fractionation schedule, volume and region irradiated [5]. Currently there is little that can be done in terms of prevention and thus there is a need for effective measures to mitigate and treat damage associated with exposure to ionizing radiation. The ability to prevent radiationinduced toxicity without affecting antitumour efficacy has the potential to enhance the therapeutic benefit for cancer patients while decreasing their risk of serious adverse effects. Reducing or preventing the development of radiation-induced functional deficits would allow for dose escalation which in turn would lead to better chances of tumor eradication and for potentially better patient quality of life following radiotherapy. The exact mechanisms of radiation-induced damage are complex; however, an agent capable of mitigating these effects would be highly beneficial to treatment strategy. 


\subsection{Direct and Indirect Effects of Radiation}

DNA is considered the critical target in the irradiation of biological tissue. Radiation may interact directly with the critical target where an atom of the DNA is ionized or excited that initiates a chain of events leading to biological effects. Radiation may also interact indirectly by interacting with other molecules or atoms in the cell to produce free radicals that may then diffuse within the cell to reach and damage critical targets [5]. Water is a likely target of the indirect action since the cell is composed of about $80 \%$ water. In this case a photon interacts with the water molecule to produce an ion radical and a secondary electron. The ion radical is highly reactive but has an extremely short half life and decays to form a free radical. The ion radical reacts with another water molecule to form a hydronium ion and a hydroxyl free radical. The hydroxyl radical can then diffuse within the cell to react with the critical target DNA. It is this indirect action of ionizing radiation that may be modified by means of radical scavengers to reduce the biological effect of radiation. This is an important area of research to reduce the side effects of radiation therapy.

\subsection{Pulmonary Response to Radiation Therapy}

The lung response to radiation is a complex and dynamic response with many interactions at the cellular and molecular levels. The response to radiation involves many cell types including macrophages, epithelial pneumocytes, endothelial cells, and fibroblasts [6]. Damage to these cells and corresponding normal tissue from radiation involves cell death, production of reactive oxygen species, alterations in gene expression, 
and the production of cytokines [7]. This multicellular reaction is modulated by the production of specific cytokines and growth factors $[8,9]$. A simplified schematic of the cellular interactions due to growth and inhibitory factors is shown in Figure 1-1.

The alveolar epithelium consists of type I and II epithelial cells. Type I cells are flat epithelial cells that cover $90 \%$ of the alveolar surface. Type II cells replicate and mature to produce type I cells, and also produce surfactant [10]. Following radiation, type I cells are damaged and lost from the alveolar surface and type II cells rapidly proliferate to reepithelialize the alveolar surface. Type II cells may also be injured by radiation and this triggers a release of surfactant $[11,12]$. A large number of cytokines, growth factors and cytokines regulate this response [13]. Alveolar macrophages are a major source of cytokine signalling driving the inflammatory process following irradiation. Cellular injury of the macrophage causes altered gene expression and a subsequent release of cytokines such as tumor necrosis factor $\alpha(\mathrm{TNF}-\alpha)$ and transforming growth factor $\beta$ (TGF- $\beta$ ). In the target cell, the fibroblast, cytokine receptors are activated and signal transduction occurs stimulating collagen genes $[8,14]$. The cytokine cascade is persistent during the months following radiation and results in a chronic inflammatory state during the time leading up to and during the expression of functional damage $[14,15]$. In addition to being a source of inflammatory cytokines, macrophages are also a large source of reactive oxygen species (ROS) generated in response to the inflammatory signals following radiation [16]. Radiation causes an initial burst of ROS production due to the ionization of water molecules, but the activation of inflammatory cells and induction of inflammatory cytokines causes persistent changes in cell signalling and continued production of ROS at late times (Figure 1-2). The normal tissue response 


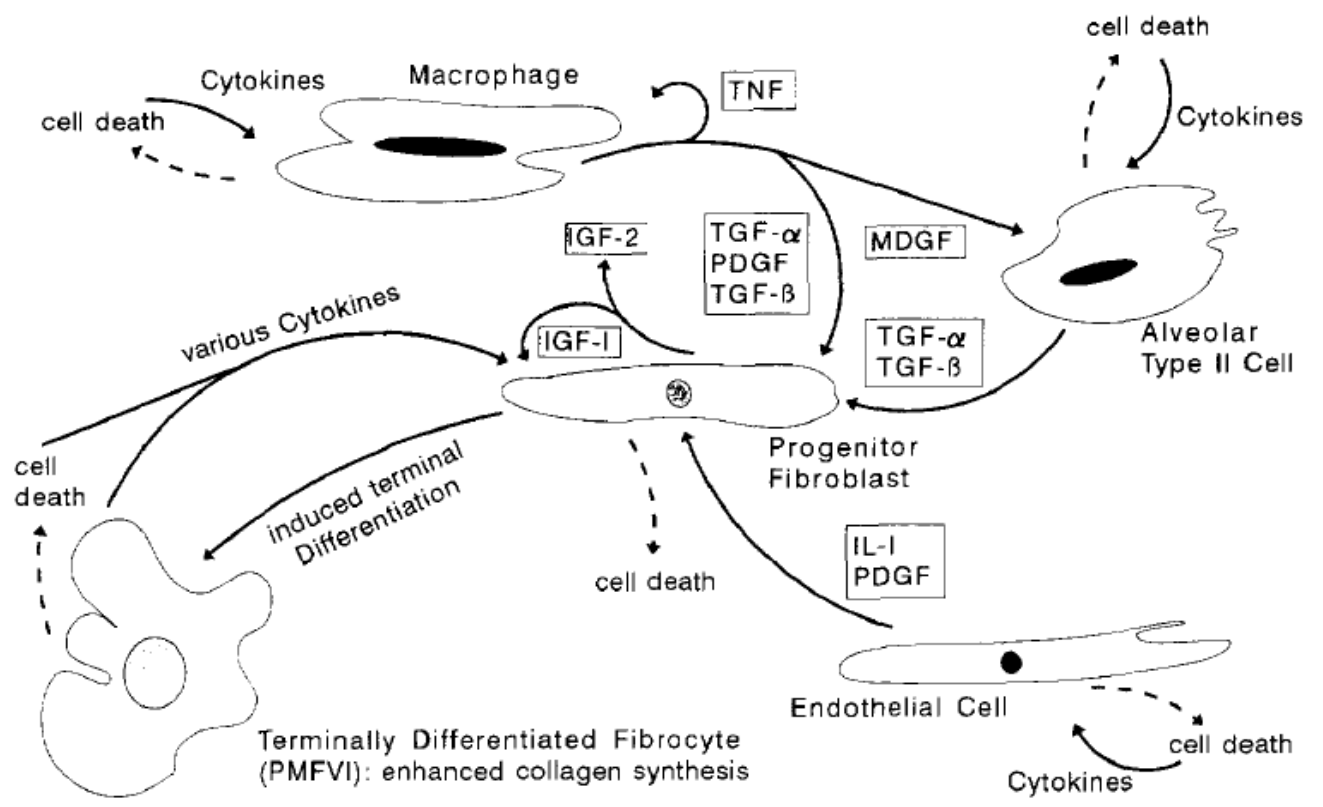

Fig. 2. Possible cellular communication and events after irradiation injury in lung tissue.

Figure 1-1: Possible cellular communication following irradiation. The lung response is a complex and dynamic interaction between many different lung cell types. Cytokines play a key role in signalling between cells. From [9] 
including the propagation of ROS and oxidative stress is an active process that leads to the development of clinically evident early and late lung damage $[13,14]$.

\subsection{Acute and Late effects in Lung}

Radiation-induced lung injury has classically been separated into two phases: radiation pneumonitis and radiation fibrosis. Following radiation there is a latent period before clinical symptoms arise. However, during this time there are changes at the cell and molecular level leading to the development of pneumonitis and fibrosis. Changes in cytokine expression have been detected as early as one hour following radiation [15]. Acute radiation pneumonitis usually occurs between 1-6 months following irradiation with symptoms of cough, dyspnea, chest pain and occasional fever. Radiographic changes are variable and may reveal local infiltrate within the radiation field or diffuse infiltrate outside the radiation field [16]. Histopathology following irradiation shows a loss of type I pneumocytes and endothelial cells, release of surfactant and fibrin in alveoli, a decrease in macrophages, and interstitial oedema. During radiation pneumonitis there is tissue inflammation with an increase in type II pneumocytes, leukocytes, fibroblasts, alveolar macrophages and oedema [17].

Radiation pneumonitis may resolve after a few weeks and can also be followed by chronic inflammation and fibrosis that usually develops by 6 months but can continue to progress for 1-2 years following irradiation. Radiation fibrosis is characterized by vascular damage and collagen deposition [18]. Fibrotic changes in the lung are a result of interactions between many cell types involving the production of inflammatory and fibrotic cytokines by cells such as macrophages and fibroblasts [6]. 


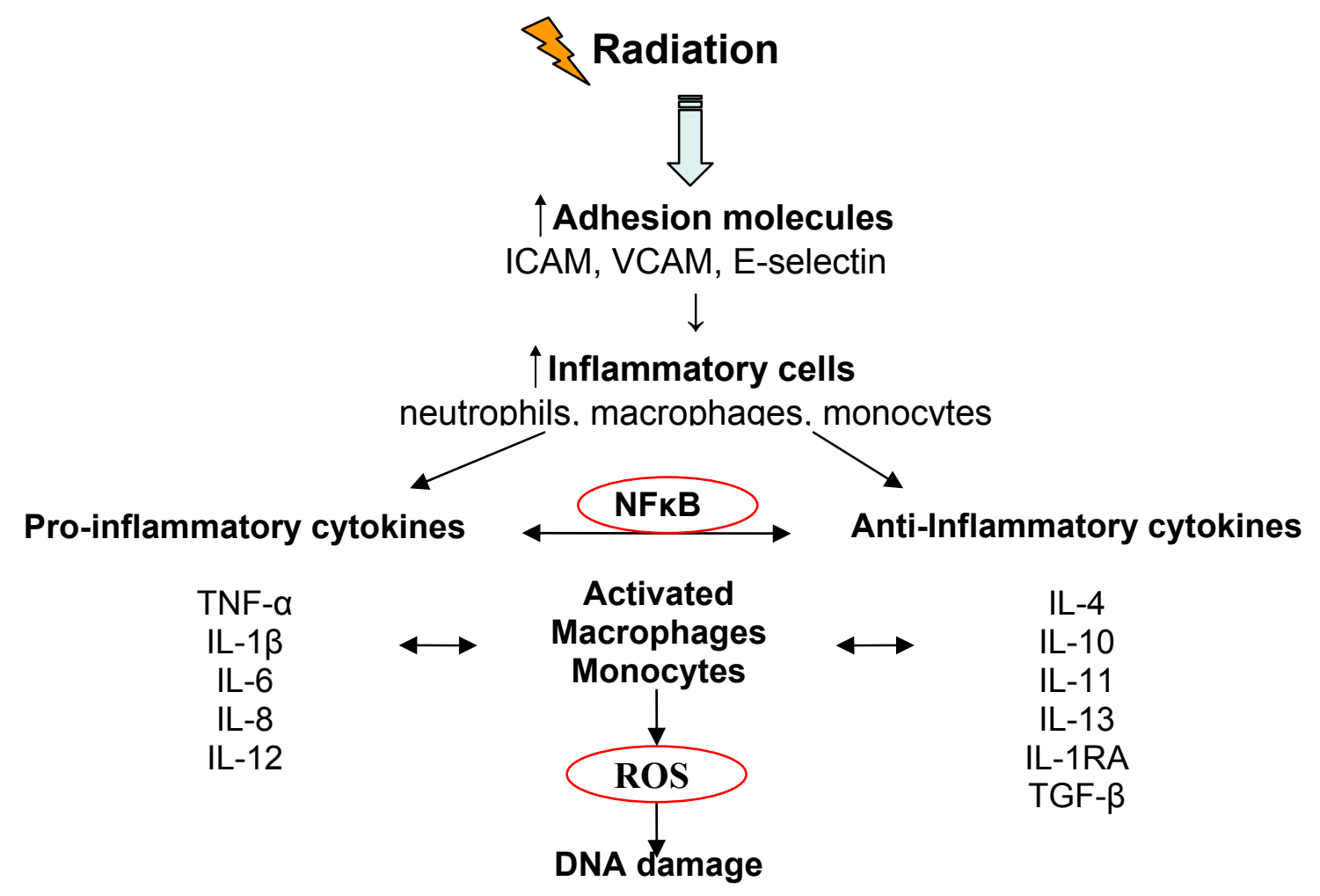

Figure 1-2: Possible cycle of inflammatory mediators post irradiation. Radiation causes an increase in cellular adhesion molecules, allowing for increased extravasation and arrest of inflammatory cells in lung tissue. Inflammatory cells secrete pro- and anti-inflammatory cytokines, and the balance is regulated by $\mathrm{NF}-\kappa \mathrm{B}$. Inflammatory cells such as monocytes and activated macrophages produce high levels of ROS that can lead to DNA damage. 
Radiographic evidence of scarring associated with fibrosis can be seen within the irradiated field. Symptoms related to radiographic changes and fibrosis depend upon the extent of lung parenchyma involved and the pre-existing pulmonary reserves [18]. If the lung volume irradiated is small, the patient may not exhibit symptoms. For larger irradiated volumes there may be symptoms of cough, progressive chronic dyspnea, and chest pain due to reduced diffusion capacity similar to those observed during pneumonitis [19]. Histopathology during fibrosis shows loss of capillaries, thickening of alveolar septa, and narrowing of alveoli [17]. The defining feature of fibrosis is the increasing rigidity of tissue due to increased collagen deposition stimulated by pro-fibrotic cytokines such as TGF- $\beta[10,20]$. Increased expression of pro-inflammatory and pro-fibrotic cytokines play a key role in the development of fibrosis. Inflammation is initiated as a mechanism to protect and repair damage to normal tissue from radiation. When the balance between pro- and anti-inflammatory processes becomes disturbed, a state of chronic inflammation can result in further damage to tissue. Both pneumonitis and fibrosis can severely impact upon the quality of life for patients. There is a need to better understand the mechanisms contributing to the development of normal tissue damage and clinical symptoms as well as effective measures to prevent and mitigate radiation induced-lung injury.

\subsection{Lung Architecture}

The lung has a large diffusion area for gas exchange created by a series of branching airways. The trachea branches into two main bronchi that enter each lung, which branch into lobar and segmental bronchi down to terminal bronchioles. Terminal bronchioles divide into respiratory bronchioles with occasional alveoli and then into 
alveolar ducts fully lined with alveoli [18]. The portion distal to the terminal bronchiole is the region where gas exchange occurs and forms a functional subunit (FSU) called the pulmonary lobule or acinis. The FSUs in the lung are arranged in parallel and many bronchi and acinis work together [5]. Normal tissue tolerance is the dose required to produce a functional deficit, and depends upon the number and radiosensitivity of the target cells in the FSU, the functional reserve of the organ and structural organisation of the FSU [21]. If small volumes of lung are irradiated, the remaining FSU can still perform their function. The parallel arrangements of the FSU in the lung give rise to a graded dose response [22]. However, the lung becomes dose limiting when large volumes of lung are irradiated and there is not sufficient reserve capacity in the remaining FSU [5, 23]. Furthermore, low doses to large lung volumes are more damaging than the same mean lung dose to small lung volumes(eg. 9-12 Gy to $100 \%$ of lung volume produces more functional lung damage than $27-36$ Gy to $25 \%$ of lung volume) [24, 25]. Clinically it is recommended that no more that $30-35 \%$ of the lung receive a dose larger than $20 \mathrm{~Gy}$ ( $\mathrm{V}_{20}$ parameter), and that the mean lung dose is less than 20-23 Gy [26].

\subsection{Volume and Regional Effects}

In addition to dose and volume the lung response is dependent upon the location of the irradiated sub volume within the organ $[7,23,27-30]$. Several studies have shown the base of the lung to be more sensitive than the apex. Using either breathing rate or lethality for the endpoint, studies in mouse lung by Travis, Liao and Tucker [23, 29, 30] investigated the relationship between dose, volume and region of irradiated lung on the probability of radiation induced complications. Irradiation of a smaller volume in the 
base of the lung than in the apex was required to achieve a given effect $\mathrm{ED}_{50}$ for breathing rate or $\mathrm{LD}_{50}$ for lethality (Figure 1-3). The $\mathrm{ED}_{50}$ is the effective dose required to produce a functional effect in $50 \%$ of subjects. The $\mathrm{LD}_{50}$, is the dose lethal to $50 \%$ of subjects. Clinically it has also been reported that patients who undergo irradiation of tumours in the lower lung are at increased risk of developing pneumonitis than those with tumours in the upper lobe [31-33]. The difference in regional sensitivity is not fully understood but is presumed to be due to differences in the number and location of FSUs as there are more FSUs in the base of the lung than the apex [30].

Inclusion of the heart within the irradiation field has also been reported to increase lung damage[34, 35] but this effect was not confirmed in other studies [25, 33].

Previous studies in our lab have used a rat model to demonstrate the regional sensitivity of the lung to radiation $[27,28]$. Radiation-induced lung damage was assessed in fibroblasts using a cytokinesis block micronucleus assay to evaluate DNA damage. Following whole lung irradiation there was a large increase in micronuclei formation compared to unirradiated controls. Following lower lung irradiation, there were comparable levels of DNA damage within the irradiation field to that observed during a whole lung irradiation and also a high amount of damage in the shielded upper lung. When the apex of the lung was irradiated, the in-field damage was approximately half that seen during whole lung irradiation and in the out-of-field lower lung there was only a slight increase in damage seen above background levels (Figure 1-4).

The level of damage in the upper irradiated lung was similar to the out-of-field damage in the upper lung when the lower lung was irradiated. These findings suggest that irradiation of the base of the lung produces larger amounts of damage in-field and 

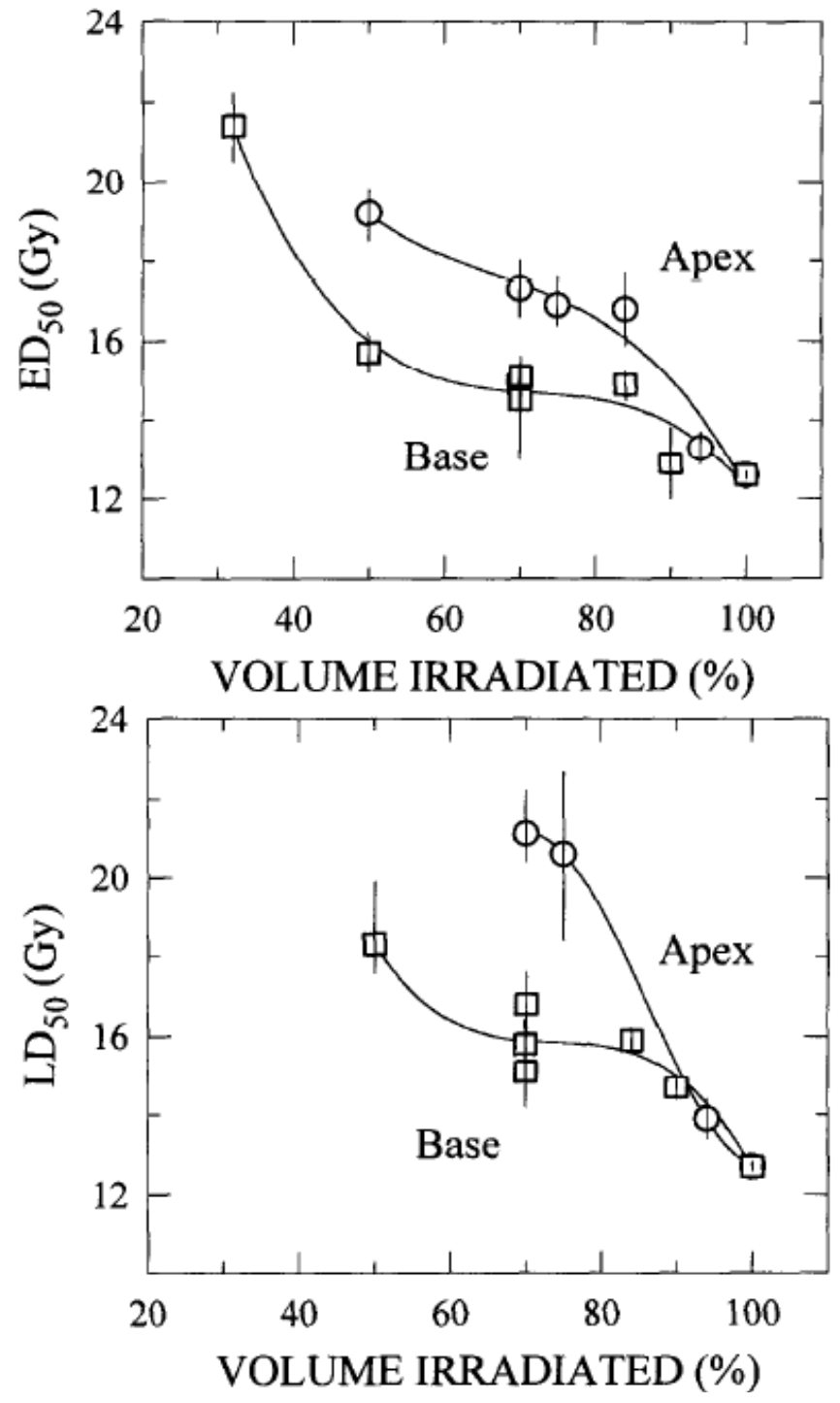

Figure 1-3: Breathing rate and lethality as a function of partial volume irradiated. The base of the lung is more sensitive than the apex. From [30] 
out-of-field than irradiation of the apex. The administration of radical scavengers $\mathrm{Mn}$ superoxide dismutase (MnSOD) or CuZnSOD or nitro-L-arginine methyl ester (L NAME) 30 minutes prior to irradiation was effective in reducing the damage in field by $10-30 \%$ and $50-60 \%$ out of field. This suggests that damage created in field may generate signals to produce superoxide radicals, and inflammatory cytokines that are transported by diffusion or blood circulation to cause damage in the whole organ including out-of-field regions. Following irradiation there is an induction of an inflammatory response meant to protect and aid in repair of damage. However, this in turn causes the production of additional reactive oxygen species (ROS) that can also cause DNA damage. Increases in inflammatory cytokines interleukin $1 \beta$ (IL-1 $1 \beta$ ) and transforming growth factor- $\beta 1$ (TGF- $\beta 1$ ) were measured in the plasma following irradiation. The anti-oxidant agents were more effective in protecting against indirect damage caused by tissue reactions (inflammation) than the direct action of the radiation itself. The more radiosensitive lower lung was able to generate a greater inflammatory response than the upper lung. An analysis of these data in combination with mouse functional data from Travis et al. [23, 29, 30] proposed a model that incorporated in-field and out-of-field effects to better predict lung response [36]. The model predicted that for a given proportion of target cells, greater damage would be expected when the base of the lung was irradiated. Thus, when predicting the likelihood of complications arising from standard dose and volume data, one must also consider the additional impact of where the irradiated sub-volume is located within the lungs and out-of-field effects. 


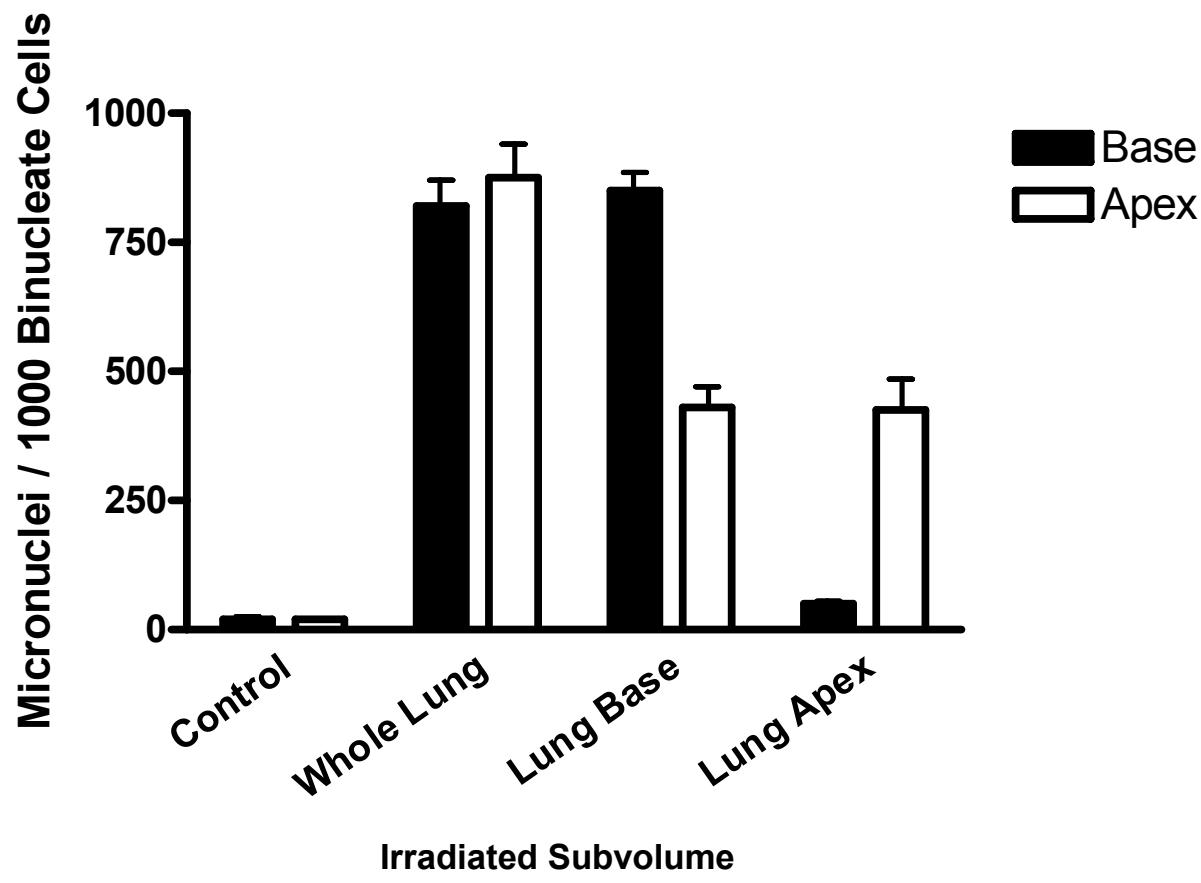

Figure 1-4: Micronuclei Formation in lung fibroblasts following whole and partial lung irradiation. Irradiation of the whole lung shows high levels of damage in and out-of-field. When only the lung base was irradiated, there were similar levels of damage in-field compared to the whole lung irradiation, and a large amount of damage also seen in the upper unirradiated lung out-of-field. When the apex of the lung was irradiated, there was lower damage seen in-field than when the whole lung was irradiated, and there was very little additional damage seen out-of-field in the lower lung. Data from [28] 


\subsection{Fractionation}

Radiation is sometimes delivered as a single dose, but it is more often administered in a series of fractions. Dividing a radiation dose into fractions spares normal tissues because it allows for repair of sublethal damage and repopulation between treatments. Fractionation increases tumor damage over multiple doses due to reoxygenation of the tumor as hypoxic cells are more radioresistant than well oxygenated cells. It also allows reassortment of cells through out the cell cycle (cells are most resistant during S phase, and most sensitive during $M$ and $G_{2}$ ) making them more sensitive to subsequent radiation doses $[5,37]$. A balance is achieved to minimize damage to normal tissues while maximizing damage to tumor tissue. Each fraction progressively adds to the tumor cell kill.

Cell survival (S) following radiation is often described by the linear quadratic (LQ) model

$$
S(D)=\ell^{-\left(\alpha D+\beta D^{2}\right) n}
$$

where $\mathrm{D}$ is the dose, and $\alpha$ is the constant describing the initial linear slope of the survival curve, $\beta$ is the constant describing the quadratic component of cell kill, and $n$ is the number of fractions[38]. This assumes that there is complete repair of sublethal damage, and that each fraction has equal effect. With respect to damage to normal lung tissue, this model was extended to the linear quadratic with time (LQT) to take proliferation of lung cells between fractions into account

$$
S(D)=\ell^{-\left(\alpha D+\beta D^{2}\right) n+\gamma T}
$$

(Equation 2) 
where $\gamma$ is the overall time dependence and $\mathrm{T}$ is the overall treatment time[38]. The effect of a treatment fraction does not depend upon the time (its position) within the treatment in which it is given[39]. To compare two fractionation regimes an isoeffective dose formula of functional damage is used

$$
E=\left[\alpha\left(1+\varepsilon T+\eta T^{2}\right) D+\beta D^{2}\right] n \quad \text { (Equation 3) }
$$

where $\varepsilon$ and $\eta$ modify the effect of $\alpha / \beta$ over time, parameters derived from modeling of clinical data are $\alpha / \beta=4.1 \mathrm{~Gy}, \varepsilon=-0.025 /$ day, and $\eta=28 \times 10^{-5} /$ day $^{-2}[40]$.

Clinically, fractionated treatment delivers smaller therapeutic doses of radiation daily, usually less that 2Gy. Palliative treatments may deliver fewer doses in larger fractions (ie 5 fractions of $4 \mathrm{~Gy}$, or a single $10 \mathrm{~Gy}$ dose). Many studies have examined the effect of treatment schedules on the development of radiation pneumonitis and fibrosis [41-43]. The studies focused on single versus fractionated and hyperfractionated radiation treatments. It was shown that a single dose of $15 \mathrm{~Gy}$ of ${ }^{60} \mathrm{Co}$ gamma rays produced greater histological damage than 10 daily fractions of $3 \mathrm{~Gy}$, or 30 fractions of 1Gy three times per day to the same volume. Fractionation reduced the percent of lung parenchyma involved in pneumonitis from $70-80 \%$, to $40-50 \%$ and $30-50 \%$ respectively. There was no difference in fibrosis at later times depending upon treatment [42]. Radiation pneumonitis and fibrosis may be independent damage events but recent data suggest that a cyclic inflammatory response and chronic inflammation is responsible for the development for the spectrum of radiation induced lung damage from pneumonitis to fibrosis $[44,45]$.

However, new advancements in treatment planning using stereotactic body radiation therapy (SBRT) allows for increased precision in tumor targeting and this has revived the 
use of hypofractionation [46]. The large dose per fraction assumes that tumor and surrounding healthy tissue would be eradicated (i.e. ablated as during surgery), volumes of normal tissue obliterated are small, volumes beyond the tumor that receive a lower dose are below the threshold dose and will recover, and that there is sufficient reserve capacity in the organ to maintain organ function. For example, at Princess Margaret Hospital in Toronto they are investigating the use of 3 fractions of 15-20Gy to small lesions to examine if it results in better local control while maintaining reasonable levels of side effects. The use of agents capable of protecting against side effects would be highly beneficial to this treatment strategy as well.

\subsection{Universal Reaction - Acute Respiratory Distress Syndrome (ARDS)}

The lung response to radiation is similar to that of its response to other types of injury such as lipopolysaccharide(LPS), bleomycin, endotoxins, many chemotherapeutics and hyperoxia $[7,8,47]$. The similar lung inflammatory response to various damaging agents suggests that the aspects of normal tissue response are universal and independent of the damaging agent [7].

Mechanisms associated with radiation-induced lung damage may be better understood by examining the universal lung response to various damaging agents. Bleomycin is a chemotherapeutic agent that causes an inflammatory lung response similar to that of radiation. Superoxide dismutase (SOD) is part of normal cellular defence against oxidative damage that leads to pulmonary fibrosis. When mice knocked out for extracellular SOD were treated with bleomycin there was a marked increase in 
inflammation, hydroxyproline content and interstitial fibrosis at 14 days post treatment [48].

Direct lung injury (pulmonary infection, aspiration, or toxic inhalation) or indirect lung injury (sepsis, shock, or trauma) results in an inflammatory response called acute respiratory distress syndrome (ARDS). ARDS is a condition of inflammation and increased vascular permeability in response to pulmonary parenchymal injury and ends with tissue repair and fibrosis [49]. Symptoms in ARDS patients are similar to those with radiation induced lung damage such as dyspnea, decreased lung compliance, and diffuse alveolar infiltrates on chest radiographs [50]. These clinical symptoms are evident within days of lung injury $[49,50]$ whereas radiation induced lung damage is not apparent until months following radiation. It is understood that cellular and molecular changes are occurring during this apparent latent period.

ARDS is characterized by three phases of cellular changes in the lung: acute exudative phase, proliferative phase, and a fibrotic phase [49-51]. The first exudative phase is characterized by the activation and infiltration of inflammatory cells and occurs 24-48 hours following lung injury [50]. There is widespread necrosis of type I alveolar cells and infiltration of neutrophils from the capillaries into the pulmonary interstitium and air space [49]. Plasma proteins and fibrin accumulate on the denuded basement membranes forming hyaline membranes [51]. The proliferative phase is initiated within 3-10 days characterized by infiltration of the interstitium with fibroblasts and continued exuberant infiltration with inflammatory cells [52]. Type II pneumocytes proliferate and replace type I pneumocytes on the basement membrane. Fibroblasts begin to deposit collagen thickening the alveolar walls at the site of inflammation. Macrophages 
phagocytose the hyaline membranes and other cellular debris [51]. The fibrotic phase results in consolidation and fibrosis of the pulmonary parenchyma 7-14 days following lung injury $[49,51,52]$.

Activation of NF- $\kappa \mathrm{B}$ is a signature event of ARDS. NF- $\kappa \mathrm{B}$ is a transcription factor for a variety of factors that are directly or indirectly involved in the development of ARDS including pro-inflammatory cytokines (IL-1, IL-6, IL-8, TNF- $\alpha$ ), chemokines, colony-stimulating factors, and interferons [52]. A positive feedback loop exists as NF$\kappa \mathrm{B}$ can be activated by IL-1 and TNF- $\alpha$ to further amplify the signal [53]. Negative feedback of NF- $\kappa$ B occurs at the extracellular level where IL-1 and TNF- $\alpha$ also cause production of the regulatory anti-inflammatory cytokine IL-10 to attenuate the signal [54]. High binding activity of NF- $\mathrm{kB}$ and concentration of inflammatory mediators has been shown in bronchoalveolar lavage fluid (BALF) of ARDS patients. The level of NF$\kappa \mathrm{B}$ binding activity correlates with the degree of respiratory dysfunction [55].

Inflammatory mediators play a key role in the pathogenesis of ARDS. Proinflammatory cytokines tumour necrosis factor alpha (TNF- $\alpha$ ) and interleukin-1 $\beta$ (IL-1 $\beta$ ) are derived from activated macrophages and are found in BALF during the exudative phase [50,55-57]. The ratios of cytokine concentrations in BALF fluid compared to serum levels suggest a pulmonary origin $[56,58,59]$. Both TNF- $\alpha$ and IL-1 $\beta$ act via specific cell membrane-bound receptors and activate neutrophils and induce an upregulation of adhesion molecules [50]. A similar response occurs in animal models following LPS exposure. TNF- $\alpha$ and IL- $1 \beta$ are released and in turn activate a second level of inflammatory cytokines, lipid mediators, reactive oxygen species, and upregulate cellular adhesion molecules resulting in inflammatory cell recruitment [50]. The plasma 
levels of TNF- $\alpha$ and IL-1 $\beta$ peak within hours of the insult leaving a narrow window for therapeutic intervention [49]. Additional inflammatory cytokines IL-6 and IL-8 have been shown to be elevated in ARDS patients [49-51, 55, 60]. IL-6 plays a role in the acute exudative phase of ARDS and is also raised in other acute conditions such as burn, surgery and sepsis. IL-8 is a main chemotactic factor for neutrophils [61]. The concentrations of these cytokines correlate with the severity of ARDS disease, and high levels are indicative of a poor prognosis [52].

A state of chronic inflammation can result from the self-propagating ability of many cytokines which can lead to the development of tissue damage in ARDS. The balance between pro and anti-inflammatory cytokines is a critical mechanism to limit the biological response. IL-10 is an anti-inflammatory cytokine that inhibits the release of pro-inflammatory cytokines (IL-1 $\beta, \mathrm{TNF}-\alpha$, IL-6) from macrophages and monocytes thus regulating the balance between pro-inflammatory versus anti-inflammatory response [62]. Lower levels of IL-10 in plasma and BALF of patients correlated with ARDS development [63]. Administration of anti-inflammatory IL-10 showed protective effects in animal models of ARDS and higher levels of IL-10 correlate with better clinical outcome in patients [50]. A study of the balance of pro and anti-inflammatory cytokines showed specific temporal patterns of expression with anti-inflammatory cytokines peaking at early times (1-3 days) and pro-inflammatory cytokines rising during the course of study up to 3 weeks [56]. This supports the idea that the biological changes in ARDS are dependent upon the net cytokine balance and these patterns are critical to disease progression. 


\subsection{Lung Inflammation Post Irradiation (PI) - Cell Adhesion Molecules}

Cell adhesion molecules (CAMs) are expressed on the surface of endothelial cells and play an important role in inflammation in the lung following irradiation by aiding in leukocyte migration from the microvasculature into the surrounding lung tissue [64]. Radiation also directly induces expression of intercellular adhesion molecule-1 (ICAM-1) and E-selectin on endothelial cells within a few hours following irradiation $[65,66]$. Following adhesion of leukocytes, such as neutrophils, to the vascular endothelium, inflammatory cells extravasate and migrate into the injured lung tissue. Inflammatory cells cause an upregulation of proinflammatory cytokines, such as TNF- $\alpha$ and IL-1, that can also stimulate induction of a wider variety of CAMs including E-selectin, P-selectin, ICAM-1, and vascular cell adhesion molecule-1 (VCAM-1). ICAM expression has been found to be elevated in BAL of patients who develop pneumonitis compared to those who do not [67]. Similar results were also seen in a rat model [68]. Mice knocked out for ICAM-1 gene expression show a reduced inflammatory response, and less infiltration of inflammatory cells into the lung tissue [47, 69]. Together these results emphasize the importance of CAMs immediately following irradiation in recruiting inflammatory cells into lung tissue causing inflammation.

\subsection{Lung Inflammation Post Irradiation (PI) - Inflammatory Cytokines}

The progression of inflammation in the lung following irradiation is similar to the inflammatory process observed in ARDS. Several studies have investigated the changes in inflammatory cells and mediators in lung tissue following irradiation such as transcription factors, cytokines, and cell adhesion molecules [10, 11, 44, 70-76]. Several 
of these studies have shown that there is a cyclic pattern of cytokine upregulation following irradiation and that the temporal patterns of expression are critical in the development of radiation pneumonitis and fibrosis [8-11, 15, 44, 71-73, 77].

Several studies have also investigated the genetic component of susceptibility to radiation-induced lung damage to elucidate further the association between inflammation and tissue response [78-86]. Travis [87] compared quantitative measurements of lung fibrosis to the survival at $2 \mathrm{~Gy}$ of skin and lung fibroblasts from $\mathrm{C} 3 \mathrm{H}$ fibrosis resistant mice and C57BL/6 fibrosis prone mice. Data showed differences in the severity of radiation-induced lung fibrosis; however, the radiosensitivity of the fibroblasts did not correlate with the differences seen in radiation response between the fibrosis prone and resistant mice. This provides support for the idea that factors other than intrinsic radiosensitivity must exist to account for the differences in fibrosis response. It is currently thought that a cyclic expression of pro-inflammatory cytokines is a major contributing factor to the development of radiation-induced lung damage.

Initially it was thought that there was a latent period between the time of irradiation and when symptoms manifested clinically $[10,88]$. However, more recently it has been shown that cytokine signalling and changes in gene expression can be seen within hours of irradiation [15]. Rubin et al. [10] demonstrated early changes in cytokine production underlie the pulmonary radiation response. Radiation fibrosis prone C57/BL6 mice were irradiated with $12.5 \mathrm{~Gy}$ and their lungs examined at various times post irradiation (PI). RNA expression of inflammatory cytokines IL-1 $\alpha$, IL-1 $\beta$, and for profibrotic cytokines TGF- $\beta$ and platelet derived growth factor (PDGF) was assessed. Interleukins (IL's) are strong stimulators of inflammatory cells, particularly lymphocytes 
and macrophages. IL-1 $\alpha$ in particular showed significant increases from 2 to 8 weeks post irradiation (PI) and remained elevated with a second peak at 26 weeks PI. These data suggested that a pro-inflammatory stimulus plays a role in the onset and maintenance of the pneumonitis phase from 8 to 16 weeks PI, and then persists into the later fibrotic phase. TGF- $\beta$ and PDGF are cytokines that stimulate extracellular matrix remodelling leading to the development of fibrosis. TGF- $\beta$ and PDGF showed marginal increases in expression above background levels, increasing at later times where they play a larger role in fibrosis. The results of this study provide evidence for the hypothesis that cellular communication between pulmonary and inflammatory cells occurs very early following irradiation and that it continues to contribute to the development of pneumonitis and fibrosis.

Rube et al. [72] demonstrated a significant radiation-induced increase in TNF- $\alpha$ in lung tissue during pneumonitis. TNF- $\alpha$ is a pro-inflammatory cytokine that plays a role in radiation pneumonitis by inducing expression of adhesion molecules that recruit leukocytes to the sites of tissue damage, and in fibrosis by stimulating growth of fibroblasts and collagen deposition. C57/BL6 mice were irradiated with 12Gy and their lungs were analysed during the latent and pneumonic phases. Within 1 hour of irradiation mRNA levels and protein levels of TNF- $\alpha$ were elevated and correlated with increases in inflammatory cells, particularly macrophages, into the lung parenchyma. TNF- $\alpha$ was also elevated at later times from 2 to 24 weeks PI reaching a peak at 8 weeks PI at the onset of pneumonitis. These data suggest that TNF- $\alpha$ plays a critical role in the time immediately following irradiation and leading up to the development of symptoms. An additional study [44] further investigated the time course of the pro-inflammatory 
cytokine upregulation following irradiation. Early increases in TNF- $\alpha$ were seen at 1 hour PI, and in IL-1 $\alpha$ and IL- 6 at 6 hours PI and then returned to basal levels for up to 2 weeks PI. During the pneumonitis phase TNF- $\alpha$, IL- $1 \alpha$, and IL-6 were again all elevated and reached a peak at 8 weeks PI. This further confirmed the temporal pattern of proinflammatory cytokine expression leading up to the development of histological discernable pneumonitis. A further study showed the bronchiolar epithelium as a prominent source of these inflammatory cytokines [74].

Hong et al. [11] found similar time dependent increases in TNF- $\alpha$ gene expression following radiation of $\mathrm{C} 57 / \mathrm{BL} 6$ (fibrosis prone) and $\mathrm{C} 3 \mathrm{H} / \mathrm{HeJ}$ (fibrosis resistant) mice. Following a 20Gy irradiation there was upregulation of TNF- $\alpha$, and IL- $1 \alpha$ and IL-1 $\beta$ at 1 hour PI that persisted for 16 hours and subsided by 24 hours PI in the C57/BL6 mice. The $\mathrm{C} 3 \mathrm{H} / \mathrm{HeJ}$ mice showed a similar response, and IL- $1 \beta$ showed the greatest increases in expression within the first hour, peaked at 8 hours and subsided by 16 hours PI. These data again support a rapid induction of cytokine response following irradiation. It also shows differences in cytokine response between strains that may account for differences seen in the development of pneumonitis and fibrosis.

TGF- $\beta$ is another important cytokine that plays a role in the radiation response in lung [73, 89-92]. TGF- $\beta$ is widely expressed in normal and tumor tissue [92]. Following irradiation TGF- $\beta$ is produced locally in addition to circulating TGF- $\beta$ which may be activated by ROS. TGF- $\beta$ acts as a chemoattractant for fibroblasts, macrophages and monocytes. It can also increase production of IL-1, IL-6, TNF- $\alpha$, and growth factors $[73,92,93]$. TGF- $\beta$ can inhibit epithelial cell proliferation, stimulate excess production 
of collagen from fibroblasts, and decrease collagen degradation thus contributing to fibrosis.

Rube et al. [73] investigated the expression of TGF- $\beta$ in C57/BL6 mice following 6 and 12Gy irradiation. After 12Gy mRNA expression of TGF- $\beta$ was increased within one hour and increased significantly above controls by $12 \mathrm{hrs}$, and then subsequently declined. It later peaked again at 2 and 4 weeks PI. Levels of TGF- $\beta$ correlated with immunohistochemical staining of macrophages. Finkelstein et al. [20] also has shown increases in TGF- $\beta$ in C57/BL6 mice 14 days following 5 and 12.5 Gy irradiation. Anscher et al. [90, 92] investigated the prospects of using TGF- $\beta$ as a marker for development of pneumonitis in lung cancer patients treated with radiation therapy. Plasma samples were obtained before, during and after each radiotherapy treatment. The findings suggest that patients with lower levels of plasma TGF- $\beta$ were less likely to develop radiation pneumonitis. More recently, it was also shown that a small molecule inhibitor of the type I TGF- $\beta$ receptor was effective in reducing the extent of radiation induced lung injury as assessed by breathing rate and histology [94]. These studies of cytokine expression levels demonstrate that the radiation induced inflammatory response follows a temporal pattern of expression that may be responsible for the development of clinically apparent symptoms. The balance between pro and anti-inflammatory cytokines may help to better understand the timing of the waves of inflammation.

\subsection{Lung Inflammation Post Irradiation (PI) $-N F-\kappa B$}

Transcription factors also play an important role in the progression of the inflammatory lung response following irradiation [71, 95, 96]. Nuclear factor kappa B 
(NF-kB) has been shown to be continuously activated following irradiation and is involved in initiating and sustaining the inflammatory response $[97,98]$. NF- $\kappa \mathrm{B}$ can be activated by a wide variety of stimuli, such as oxidative stress, radiation, LPS exposure, cytokines, bacterial and viral antigens, many of which are involved in the inflammatory response. It also modulates a variety of cell functions including immune responses, stress

responses, cell cycle and survival, apoptosis and regulating inflammation. NF- $\mathrm{KB}$ is involved in inflammation by regulating transcription of genes for pro and antiinflammatory cytokines [99-101]. NF- $\mathrm{kB}$ exists in a latent form in the cytoplasm as a

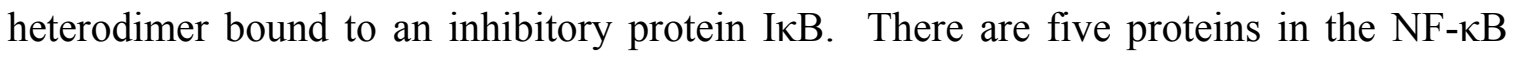
family; p50 and p65 are the most commonly found heterodimer. When NF- $\mathrm{kB}$ is

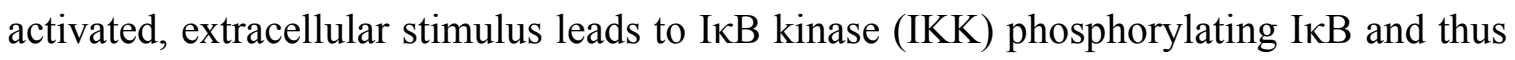
targeting it for ubiquitination and degradation by the proteasome (Figure 1-5). Free NF$\mathrm{\kappa B}$ can then translocate to the nucleus and activate target genes by binding with high affinity to $\kappa \mathrm{B}$ elements in their promoters [102]. NF- $\mathrm{BB}$ is activated by radiation, oxidative stess, and many products of the inflammatory lung response (cytokines, macrophages, ROS) and further promotes the inflammatory response itself, thus playing a key role in the regulation of the radiation response in lung. NF- $\mathrm{KB}$ activation is controlled by a negative feedback loop by upregulating production of inhibitory IкB. NF- $\mathrm{KB}$ activation is also suppressed by anti-oxidants and anti-inflammatory cytokines resulting in decreased pro-inflammatory mediator expression $[103,104]$.

\subsection{Oxidative Stress}

Normal tissue damage involves complex interactions between many cell types as 


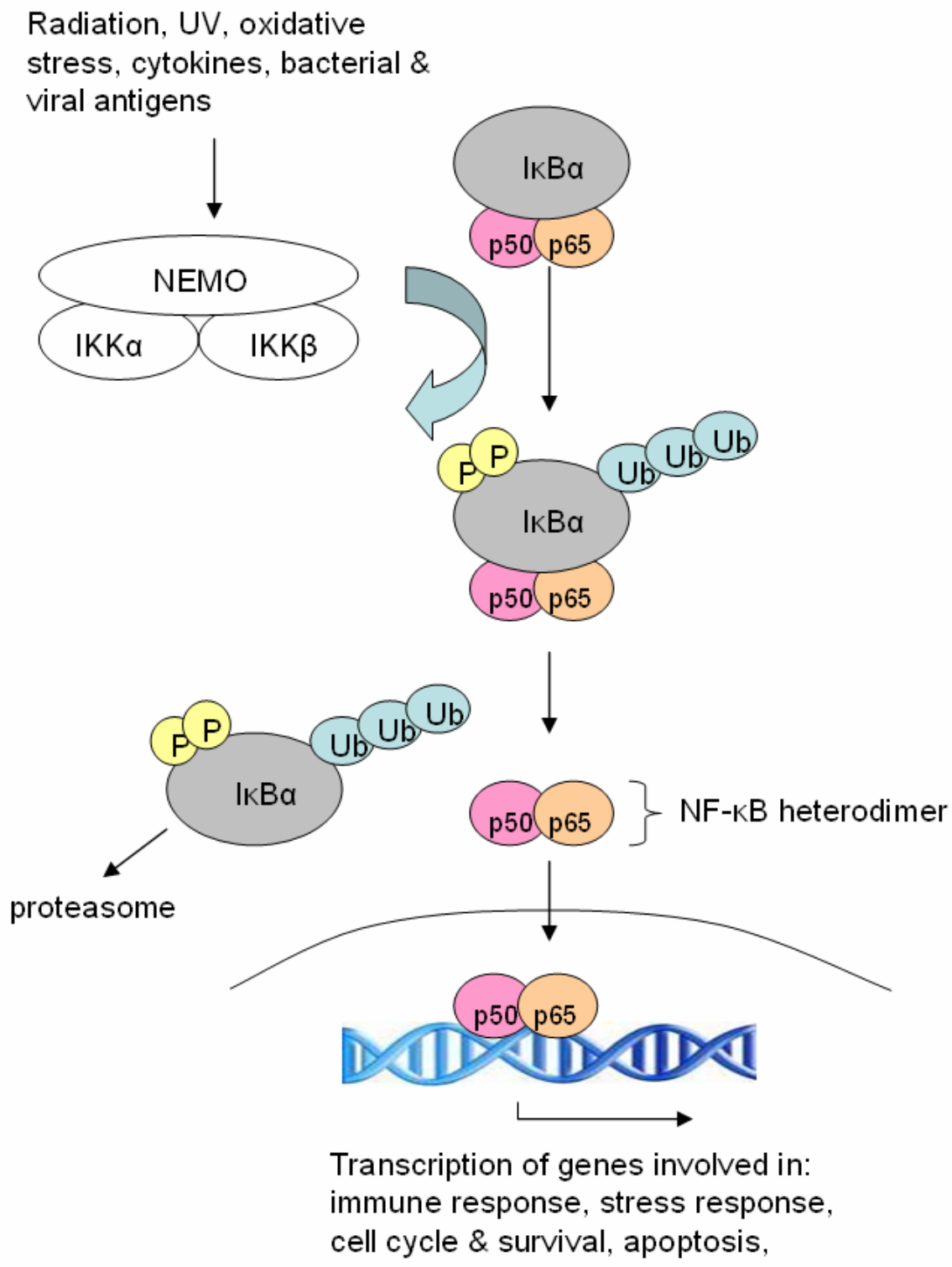

Figure 1-5: NF- $\mathrm{kB}$ transcription pathway. There are five proteins in the NF- $\kappa \mathrm{B}$ family, it is commonly found as heterodimer composed of subunits p50 and p65 bound to inhibitory protein $\mathrm{\kappa B}$ (I $\mathrm{I} B$ ). Radiation and other factors can initiate the NF- $\kappa B$ pathway by activating inhibitory $\kappa B$ kinase (IKK). IKK is a multisubunit enzyme composed of a heterdomer of IKK $\alpha$ and IKK $\beta$, and regulatory subunit NEMO. The IKK complex phosphorylates I $\kappa \mathrm{B}$ and targets it for ubiquitination and degradation by the proteosome. The NF$\kappa \mathrm{B}$ heterodimer is only then free to translocate to the nucleus to be transcribed. Figure modified from [105] 
described previously, however many of the mechanisms of interaction are still unknown. One mechanism of cellular interaction following radiation is the bystander effect, which has similarities to the out-of-field effect described by observations in our lab [27, 28]. The out-of-field effect is observed when tissue damage was located beyond the boundaries of the irradiation field, and even within a different unirradiated lobe of the lung. This is also similar to abscopal effects that are significant responses seen in tissues definitively separate from the irradiated area [106]. The bystander effect is observed when unirradiated cells exhibit responses associated with radiation exposure as a result of cell-to-cell contact or through soluble signals [93]. Several experimental approaches have been used to study this phenomenon. In vitro experiments used confluent cell cultures to demonstrate direct intercellular communication through cell-to-cell contact. Precise irradiation of target cells produced DNA mutations and micronuclei (MN) formation in neighbouring unirradiated cells. MN formation occurs when portions of the chromosome are lost due to double strand DNA breaks. A second approach transferred culture medium from irradiated cells to a separate unirradiated flask and still observed the radiation response [107]. This supports the notion that a soluble factor is capable of initiating the radiation response in cells beyond the irradiation field. Both approaches implicated enhanced oxidative metabolism with reactive oxygen species (ROS) and stress response proteins as key factors [106].

One effect of the soluble signals of bystander effects and inflammation is oxidative stress. Bystander effects have been partially attributed to the production of ROS following irradiation that also stimulate cytokine production [108]. ROS are reduced metabolites of molecular oxygen such as the hydroxyl radical $(\mathrm{OH} \cdot)$, hydrogen 
peroxide $\left(\mathrm{H}_{2} \mathrm{O}_{2}\right)$, and superoxide anions $\left(\mathrm{O}_{2}{ }^{-}\right)$that are continuously generated through normal oxidative metabolism (Figure 1-6) and during radiation exposure [13, 107]. ROS are oxidizing agents capable of causing DNA damage. Superoxide is a free radical that is not highly reactive and can not cross lipid membranes and is restricted to the intracellular compartment in which it is generated. Superoxide is primarily generated in the mitochondria due to leakage from the electron transport chain or by direct reduction of molecular oxygen. Superoxide is rapidly dismutated to hydrogen peroxide by the antioxidant enzyme superoxide dismutase (SOD). Hydrogen peroxide is not a free radical and is a weaker oxidizing agent than superoxide; however, it can cross biological membranes. At low concentrations hydrogen peroxide is converted to water by glutathione peroxidases, and at high concentrations it is converted to water and molecular oxygen by catalase localized in peroxisomes. In the presence of transition metals hydrogen peroxide can give rise to the most reactive ROS, the hydroxyl radical, via the Fenton reaction [13]. Reactive nitrogen oxide species (RNOS) are also produced from the reaction of nitric oxide (NO·) with molecular oxygen or superoxide.

Irradiation of biological material leads to a burst of ROS production mainly due to the ionization of water molecules. The hydroxyl radical is highly reactive and reacts within $10^{-9} \mathrm{~s}$ of generation. Superoxide anions and hydrogen peroxide are relatively stable and can persist for $10^{1}-10^{2} \mathrm{~s}$ in water, however the amounts of these radicals produced by radiation (depending on dose) is much lower than those produced by normal cellular metabolism [109]. In addition to the rapid burst of ROS following radiation there is a prolonged increase in ROS up to several days post irradiation [14]. The presence of ROS can cause activation of transcription factors such as NF- $\mathrm{kB}$, induce apoptosis or 
Superoxide formation:

$$
\mathbf{O}_{2}+\mathbf{e}^{-} \rightarrow \mathbf{O}_{2}^{-}
$$

\section{Hydrogen peroxide formation:}

$$
2 \mathrm{O}_{2}^{-}+2 \mathrm{H}^{+} \rightarrow \mathrm{H}_{2} \mathrm{O}_{2}+\mathrm{O}_{2}
$$

\section{Hydroxyl formation (Fenton reaction): \\ $\mathrm{H}_{2} \mathrm{O} \rightarrow \mathbf{O H} \cdot+\mathbf{H}^{\cdot}$ $\mathrm{Fe}^{2+}+\mathrm{H}_{2} \mathrm{O}_{2} \rightarrow \mathrm{Fe}^{3+}+\mathrm{OH}^{-}+\mathrm{OH}^{\cdot}$}

Figure 1-6: Reactive Oxygen Species (ROS) formation reactions 
necrosis, and alter signals regulating cell growth and signalling cascades. ROS can cause damage to DNA, lipids, proteins and endothelial cells, and increase microvascular permeability through their ability to induce biochemical alterations $[110,111]$. This supports the hypothesis that chronic oxidative stress plays a key role in inflammation and tissue damage following irradiation. Irradiation induces production of ROS that cause increased expression of CAMs on inflammatory cells, thus further recruiting inflammatory cells to the site of injury. Macrophages and monocytes themselves are major sources of cytokines and ROS and perpetuate the inflammatory process [110]. In the context of radiation response, inflammation is initiated to try and repair initial damage, but if the response is not regulated it can lead to chronic inflammation and oxidative stress causing further tissue damage.

\subsection{Protection Against Oxidative Damage - SOD and SOD mimetics}

Cells and tissues protect themselves from the damaging effects of radicals and ROS by intracellular defence mechanisms that form a redox buffer network with molecules such as SOD, catalase, glutathione and related enzymes [112]. Many studies have also focused on protecting against oxidative damage and reducing ROS levels using agents similar to SOD. SODs are metalloproteins that can dismutate superoxide anions to less reactive hydrogen peroxide and oxygen without extra input of cellular energy [111]. SOD enzymes exist endogenously in two forms: MnSOD found in the mitochondria, and CuZnSOD found in the cytosol and extracellular space (EC-SOD) [113]. High levels of EC-SOD are produced by type II pneumocytes in the lungs and other pathways [114]. Several studies have investigated the use of SOD to protect against the high levels of 
ROS formed after radiation. In our lab, it was demonstrated that administration of MnSOD or CuZnSOD lowered the MN damage seen out of field, suggesting that MN are produced by ROS and that the oxidative damage detected as MN can be modified by these agents [27]. Transgenic mice over expressing EC-SOD were observed to show greater protection against radiation induced lung damage as assessed by changes in breathing rate frequency, macrophage accumulation, collagen deposition, TGF- $\beta 1$ activity, and lipid oxidation. The mice had an increased anti-oxidant capacity and showed a decreased inflammatory response due to a decreased macrophage and TGF- $\beta 1$ response $[115,116]$. In addition, mice over expressing a transgene for human MnSOD were also protected against radiation induced lung damage and showed decreased levels of mRNA for IL-1, TNF- $\alpha$, and TGF- $\beta$. Histological samples also showed that the mice developed less severe alveolitis and fibrosis, as well as increased survival. Over expression of $\mathrm{CuZnSOD}$ did not confer any additional protection from radiation damage, perhaps as it is not upregulated following irradiation and it is located in the cytosol away from critical targets such as the mitochondria $[117,118]$. The main limitation of endogenous SOD is its large size $(\sim 30 \mathrm{kDa})$ and its inability to cross cell membranes. In a therapeutic approach, administration of endogenous SOD would only offer antioxidant activity in the extracellular space and not within the cell itself. As a result, several smaller molecular mass SOD mimetics that imitate the endogenous SOD functions have been developed [111]. Since radiation creates ROS directly within the cell due to the ionization of water molecules and mitochondria within the cell produce ROS, and inflammation creates ROS outside the cell, it is important that protective agents be effective in both locations (Figure 1-7). SOD mimetics therefore are likely to offer 
greater protection than endogenously administered MnSOD or CuZnSOD that acts against extracellular ROS alone.

Studies in our lab with a manganese-salen SOD-catalase mimetic Eukarion189(EUK-189) showed that administration at early times following radiation lowered the chronic production of ROS and reduced DNA damage seen during this period [119]. Other SOD-catalase mimetics, AEOL 10113 and 10150, have also been reported to alleviate increases in breathing rate, TGB- $\beta 1$ activity, hydroxyproline levels, and collagen content following hemithoracic radiation in rats [120-122]. Two Mn porphyrinbased SOD mimetics also showed protective effects by scavenging ROS [123]. These results suggest that at least some of the DNA damage is caused by oxidative stress induced by the radiation-induced inflammatory response and that DNA damage caused by this mechanism can be scavenged by protective agents.

\subsection{Protection Against Lung Inflammation}

One of the best radioprotectors if given before irradiation is amifostine (WR2721), a thiophosphate compound. Amifostine has been shown to protect against increases in breathing rate, increased plasma TGF- $\beta$, and fibrosis but is also known to interfere with chemotherapeutics [124-127]. Studies of angiotensin converting enzyme (ACE) inhibitors and angiotensin II receptor blockers, such as captopril, have shown significant protection against radiation pneumonitis and fibrosis [128-133]. Captopril is believed to reduce the effects of radiation on endothelial cells, fibroblasts and macrophages, and regulate the blood pressure of the pulmonary artery thus lowering edema in the lung. However, it has a very short half life of 2-3 hours. Pentoxifylline is a 


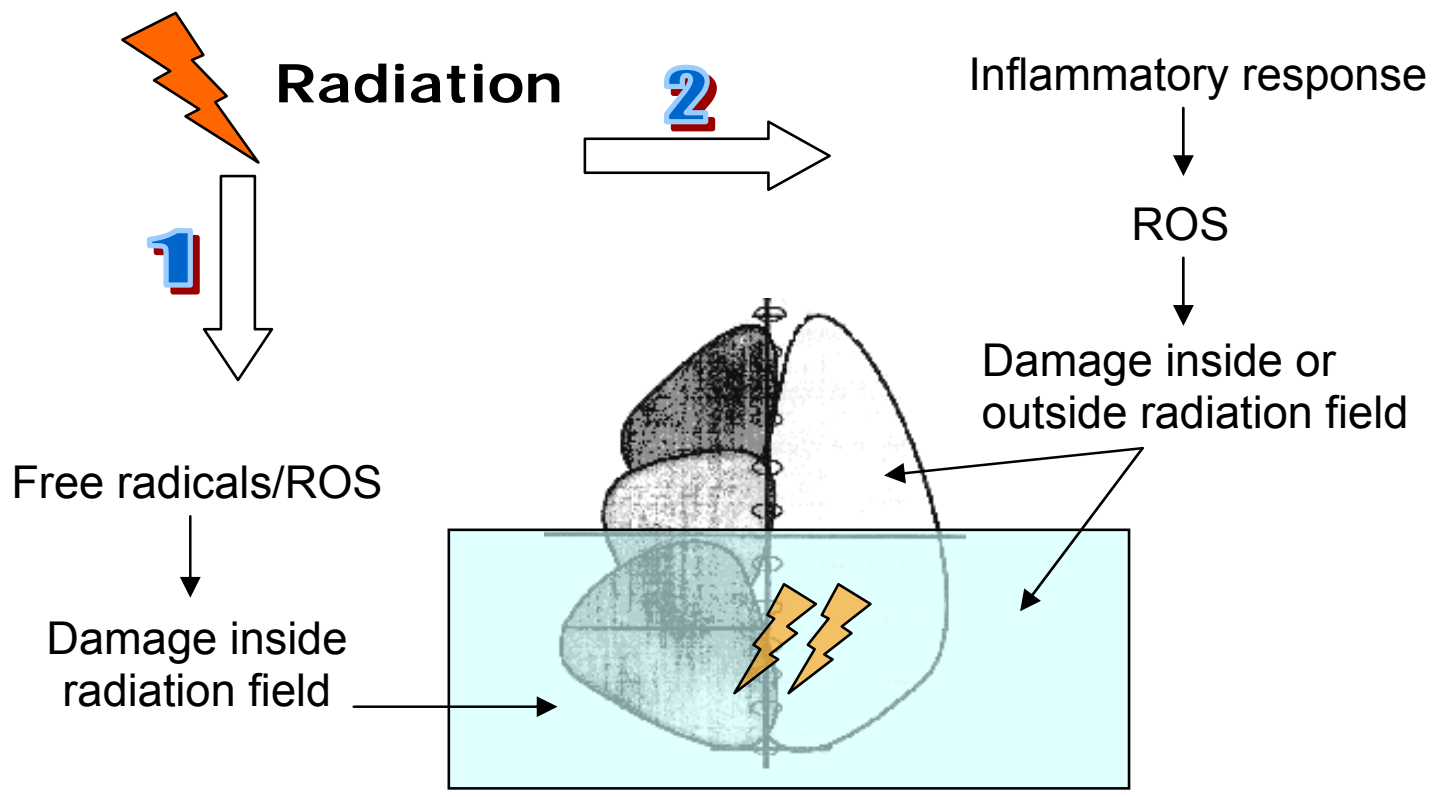

Figure 1-7: In and out-of-field effects of radiation. Radiation may act directly causing DNA damage within the irradiation field (1) by directly ionizing DNA and water molecules. It may also act indirectly by inducing an inflammatory response, that subsequently produces ROS that may cause damage in and out-offield. 
xanthine derivative that has shown potential to reduce radiation toxicity and has been reported to reduce pneumonitis when given during radiotherapy in patients [134]. It has also been shown to maintain perfusion in rats at late times following irradiation but had little effect on pneumonitis or fibrosis $[135,136]$. Given continuously before and after radiation, pentoxifylline was shown to reduce levels of pro-inflammatory TNF- $\alpha$ in mouse lung, and reduce the inflammatory cell infiltrate but it did not have an effect on overall lung damage [72]. These results using amifostine and ACE inhibitors suggest that modulating the inflammatory response could protect against tissue damage but further investigation of other agents may prove to be more effective.

Using gene therapy, a study of soluble TGF- $\beta$ receptor to decrease availability of TGF- $\beta 1$ by competitive inhibition examined if this approach could protect the lung from radiation injury by modulation of the inflammatory response [89]. The study showed a reduction in breathing rates, lower damage visible in histology samples, decreases in macrophage accumulation and plasma TGF- $\beta 1$ in treated animals. Blocking the proinflammatory cytokine's ability to bind to its receptor prevented further signal transduction and generation of late tissue damage. In addition, plasma TGF- $\beta 1$ of patients has been shown to be significantly predictive of radiation-induced lung toxicity, thus further implicating TGF- $\beta 1$ as an important factor in lung radiation response [137].

\subsection{Protection Against Radiation-Induced Lung Damage by Genistein}

Genistein (4'5,7-trihydroxyisoflavone) (Figure 1-8) has anti-oxidant and antiinflammatory properties, has low toxicity and is commonly used as a dietary supplement [138-140]. Genistein acts as an anti-oxidant by directly scavenging ROS [140]. 
Genistein inhibits protein kinase activity and blocks activation of the transcription factor NF- $\kappa B$, a critical mediator of immune and inflammatory responses [141-144]. Genistein has been reported to reduce acute lung injury from inflammation after lipopolysaccharide treatment $[142,144]$. Genistein has also been used as a radioprotector and has been shown to increase survival following whole body irradiation [145]. In addition to radioprotection studies, genistein has been investigated as an anti-cancer therapeutic[146]. Diets high in soy isoflavones have been noted for their role in reducing the incidence of breast and prostate cancers $[147,148]$. Genistein inhibits carcinogenesis in many tumour models through the modulation of genes for cell cycle, survival and apoptosis $[139,146]$ and has been reported to reduce development of metastasis in breast cancer and prostate models [149-151].

Previous work in our lab examined the protective effects of genistein in rats when

given following 18Gy whole lung irradiation. (Calveley et al, in preparation). In this study the rats put on a genistein diet of $\sim 10 \mathrm{mg} / \mathrm{kg} /$ day demonstrated increased survival during the early phase of pneumonitis and were partially protected against an increase in breathing rate during this time. Genistein did not increase survival during the later fibrosis phase and rats showed an increase in breathing rate during this time. However, when examined at 28 weeks the surviving rats on the genistein diet did show reduced levels of collagen in their lungs relative to animals given the control (low soy) diet.

\subsection{Goals of Current Study}

The goal of this study was to investigate the mitigation and treatment potential of genistein combined with fractionated radiation therapy. Chapter 2 describes these 


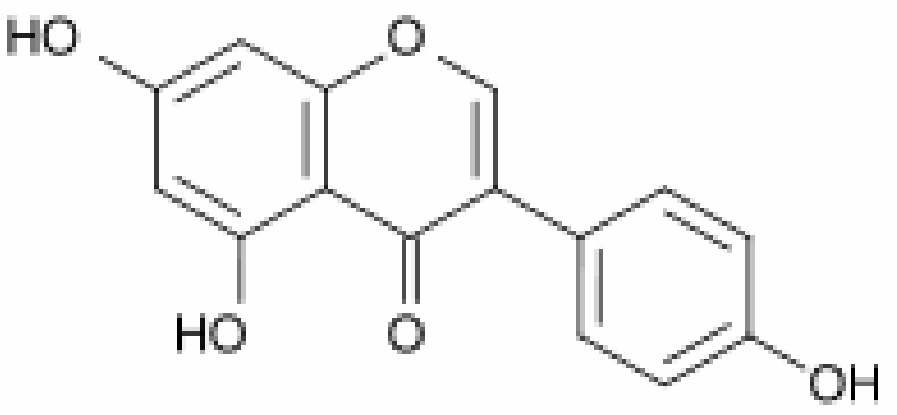

Figure 1-8: Structure of Genistein (4'5,7-trihydroxyisoflavone) 
experiments conducted with genistein. Chapter 3 discusses the relevance and implications of this work and presents future directions. The present study was designed to follow up on the previous findings by investigating the effects of prolonged administration of a genistein diet in mice following a more clinically relevant fractionated irradiation treatment to the lungs. Previous studies had investigated effects following a single dose of radiation, and fractionated doses had not been examined. While the fractionation schedule was expected to be equivalent in terms of functional deficit, based on isoeffect formulas $[39,40]$, the contribution of each fraction to the lung response and the effect of genistein in this case were unknown.

Whenever an agent capable of protecting normal tissue is given, the potential to also protect tumor tissue must also be examined, thus the potential of genistein to protect tumor was also investigated. An ideal agent would protect the normal tissue and not protect, or sensitize tumor to radiation. Previous studies in the lab had always used a rat model, and the impact of genistein on tumor and radiation response had not been examined. We switched to a mouse model for these studies both to allow examination of whether tumour might be protected by the genistein treatment (by an established mouse lung colony assay) and to provide information about the effects of genistein in a different animal model. 


\title{
Chapter 2: Mitigation of radiation-induced lung damage by Genistein
}

\author{
Data from this chapter was submitted for publication to
}

Radiotherapy and Oncology in September 2008 


\section{$2.1 \quad$ Abstract}

Background and Purpose: This study investigated protection of lung injury by genistein following fractionated doses of radiation and its effect on tumor response.

Material and Methods: $\mathrm{C} 3 \mathrm{H} / \mathrm{HeJ}$ mice were irradiated (100 kVp X-rays) with 9 fractions of $3.1 \mathrm{~Gy}$ over 30 days ( $\sim 10 \mathrm{~Gy}$ single dose) and maintained on a genistein diet $(\sim 10$ $\mathrm{mg} / \mathrm{kg}$. Damage was assessed over 28 weeks in lung cells by a cytokinesis block micronucleus (MN) assay and by changes in breathing rate and histology. Tumor protection was assessed using a colony assay to determine cell survival following in situ irradiation of small lung nodules (KHT fibrosarcoma).

Results: Genistein causes about a 50\% reduction in the MN damage observed during the fractionated treatment and continues to decrease at late times to background levels by 16 weeks. Genistein reduced macrophage accumulation by $22 \%$ and reduced collagen deposition by $28 \%$. There was minimal protection against increases in breathing rate or severe morbidity during pneumonitis. No tumor protection by genistein treatment was observed.

Conclusions: Genistein may partially reduce the extent of fibrosis developing in mouse lung caused by irradiation but gives minimal protection against pneumonitis at this dose. There is no evidence that genistein causes protection of small tumors growing in the lung.

\subsection{Introduction}

The thorax is commonly irradiated for treatment of lung cancer, breast cancer, and various lymphomas. The lung is a relatively radiosensitive organ [3] and normal tissue tolerance is a dose limiting factor in radiotherapy of the thoracic region [4]. It is 
desirable to give the highest possible dose to the tumor while sparing the surrounding healthy normal tissue and managing normal tissue complications. Approaches to protecting or mitigating the effects of radiation on lung tissue might improve the therapeutic ratio and have been investigated in a number of centres $[45,119,121,123$, 133]. Radiation-induced lung injury has classically been separated into two phases: pneumonitis and fibrosis. Pneumonitis is an acute inflammatory reaction that occurs two to four months following irradiation where there is an increase in oedema and inflammatory cells causing cough and dyspnea. Fibrosis begins four to six months post irradiation characterized by progressive scarring of the lung, with vascular cell damage and collagen deposition causing chronic dyspnea [4]. Fibrosis increases over time and reduces the functional capacity of the lung. In thoracic radiotherapy, dose escalation is limited by the normal tissue complication probability (NTCP). Using current treatment protocols, the risk of radiation pneumonitis is of most concern as it has considerable impact on patient morbidity and mortality [16, 137, 152-155].

Before symptoms are clinically evident there are molecular changes in response to radiation that are believed to underlie the development of pneumonitis and fibrosis. Direct radiation damage to individual lung cells is compounded by a complex cycle of inflammation and altered expression of cytokines, that causes production of reactive oxygen species (ROS) resulting in oxidative damage [7, 27, 44, 70]. Alveolar macrophages, lung fibroblasts, type II pneumocytes and endothelial cells interact via cytokine and growth factor signalling $[8,9]$. There is an increase in levels of intercellular adhesion molecule-1 (ICAM-1) and E-selectin in lung endothelial cells allowing for increased arrest of inflammatory cells in lung capillaries [156]. Many studies have 
documented changes in cytokine expression following irradiation, in particular temporal upregulation of the inflammatory cytokines interleukin-1alpha (IL-1 $\alpha$ ), interleukin-1beta (IL-1 $\beta$ ), transforming growth factor-beta (TGF- $\beta$ ), and tumour necrosis factor-alpha (TNF- $\alpha$ ) have been documented $[6,10,77,84,157]$. Temporal changes in expression depend upon the experimental system, but can be seen as early as one hour following irradiation and continue over the course of development of pneumonitis and fibrosis [11, $15,44,71-74]$.

The severity of side effects following irradiation depends upon volume and region irradiated, dose and fractionation regimen, and concurrent chemotherapy agents. The base of the lung has been shown to be more sensitive than the apex [23, 27-30, 33, 36] and the left lung is more sensitive than the right $[27,28,158]$. In addition to the locoregional response and volume effects, the inclusion of the heart in the radiation field may increase damage seen in the lung $[34,35,159]$; however, this effect was not observed in some other studies $[25,33]$. Previous studies in our lab using partial lung irradiation have shown there is DNA damage in and out of the radiation field [27, 28]. This supports the idea that some DNA damage may be caused by the action of inflammatory cytokines and the resultant production of ROS. Administration of superoxide dismutase (MnSOD, CuZnSOD) lowered the damage seen out of field, demonstrating that oxidative damage can be modified by these agents. Furthermore studies with the manganese-salen SODcatalase mimetic Eukarion-189 (EUK-189) showed that administration at early times following radiation lowered the chronic production of ROS and reduced DNA damage seen during this period [119]. In addition, transgenic mice over expressing extracellular (EC)-SOD in alveolar and airway epithelial cells showed protection from radiation injury 
due to an increased anti-oxidant capacity and decreased inflammatory response [116]. Mice over-expressing a transgene for human MnSOD were also protected against radiation-induced lung injury $[117,118]$.

Our current study investigates the mitigation and treatment potential of the soy isoflavone genistein as a therapeutic agent when combined with radiation. Genistein (4'5,7-trihydroxyisoflavone) has anti-oxidant and anti-inflammatory properties, has low toxicity and is commonly used as a dietary supplement [138-140]. Genistein inhibits protein kinase activity and blocks activation of the transcription factor NF- $\kappa \mathrm{B}$, a critical mediator of immune and inflammatory responses [141]. Genistein has been reported to reduce acute lung injury from inflammation after lipopolysaccharide treatment [142] and administration of genistein doses up to $400 \mathrm{mg} / \mathrm{kg}$ provided a significant increase in survival following whole body irradiation without any toxicity [145]. In addition to radioprotection studies, genistein has been investigated as an anti-cancer therapeutic. Diets high in soy isoflavones have been noted for their role in reducing the incidence of breast and prostate cancers $[147,148]$. Genistein inhibits carcinogenesis in many tumour models through the modulation of genes for cell cycle, survival and apoptosis $[139,146]$ and has been reported to reduce development of metastasis in a breast cancer model [149].

Previous work in our lab examined the protective effects of genistein in rats given following $18 \mathrm{~Gy}$ whole lung irradiation. (Calveley et al, in preparation). In that study the rats were fed a genistein diet of $\sim 10 \mathrm{mg} / \mathrm{kg} /$ day, and demonstrated increased survival during the early phase of pneumonitis and were partially protected against an increase in breathing rate during this time. Genistein did not increase survival during the later 
fibrosis phase and rats showed an increase in breathing rate during this time. However, when examined at 28 weeks the surviving rats on the genistein diet did show reduced levels of collagen in their lungs relative to animals given the control (low soy) diet. The present study was designed to follow up on these findings by investigating the effects of prolonged administration of a genistein diet in mice following a more clinically relevant fractionated irradiation treatment to the lungs and to provide information about the effects of genistein in a different animal model. This study also examined whether tumour might be protected by the genistein treatment.

\subsection{Materials and Methods}

Mice

For the initial short-term experiments examining $\mathrm{MN}$ formation following irradiation both female $\mathrm{C} 57 \mathrm{Bl} / 6 \mathrm{~J}$ and female $\mathrm{C} 3 \mathrm{H} / \mathrm{HeJ}$ mice (JAX Laboratory) aged 7 weeks were used. For the long term studies, only female $\mathrm{C} 3 \mathrm{H} / \mathrm{HeJ}$ mice ages 7 weeks (JAX Laboratory) were used because of their known sensitivity to the development of pneumonitis and later fibrosis whereas $\mathrm{C} 57 \mathrm{Bl} / 6 \mathrm{~J}$ are fibrosis prone but lack the pneumonitis response $[81,86,160]$. The animals were housed at the Ontario Cancer Institute/Princess Margaret Hospital small animal facility, which is accredited by the Canadian Council on Animal Care and were treated in accordance with approved protocols. Mice were randomly assigned to one of four treatment groups: radiation and genistein, radiation and control diet, sham radiation and genistein, sham radiation and control diet. At each experimental time point $(4,8,12,16,20,24$ and 28 weeks) a group 
of four randomly selected mice in each group was sacrificed for analysis unless otherwise indicated.

\section{Irradiation}

Mice were irradiated with a dual headed $100 \mathrm{kVp} \mathrm{X}$-ray unit [161], operating at $10 \mathrm{~mA}$ with a dose-rate of approximately $10.2 \mathrm{~Gy} / \mathrm{min}$. Nine fractions of $3.1 \mathrm{~Gy}$ were given over 30 days (3-4 days apart). This dose had been previously shown to produce a functional deficit equivalent to a $10 \mathrm{~Gy}$ single dose and to be equivalent to more extended fraction schedules in terms of lung damage in rats [39, 40]. The RBE of X-rays compared to Cesium was found to be approximately 1.2 assessed by tumor cell killing in vivo (unpublished data). Day 1 was set as the first day of radiation treatment. Prior to irradiation the mice were anaesthetized by halothane inhalation and placed in customdesigned lucite holding containers. A digital x-ray unit was used to position lead shielding around the lungs to provide a circular field of $2.5 \mathrm{~cm}$ diameter for irradiation.

\section{Genistein Treatment}

During the course of the experiment, mice were provided with sterilized food and water ad libitum. The AIN-76A diet (Harlan Teklad, Madison, WI, ref [162]), a semi purified casein-based diet containing no detectable phytoestrogens (limit of detection, $5 \mathrm{pmol} / \mathrm{mL}$ ) was selected as the control diet. The genistein diet was formulated from the control diet, supplemented with $750 \mathrm{mg} / \mathrm{kg}$ of genistein and has been used by others [149]. This concentration has been shown to yield serum Genistein levels in mice $(\sim 1$ $2 \mu \mathrm{mol} / \mathrm{L})$ similar to those observed in humans consuming a diet containing modest 
amounts of soy products(1-2 servings) [163]. Genistein was chemically synthesized (Toronto Research Chemicals Inc, Toronto, Ontario) and incorporated into the AIN-76A diet at Harlan Teklad. Dietary consumption was monitored to calculate the dose delivered. Mice were monitored for radiation toxicity and were sacrificed when moribund. Mice were weighed weekly following radiation and mice losing $>20 \%$ body weight, or exhibiting signs of distress such as ruffled fur, very rapid breathing, and hunched posture were sacrificed.

\section{Micronucleus Assay}

A well established cytokinesis block micronucleus(MN) assay [27, 28] was used to assess genomic damage following irradiation. Briefly, Alpha MEM medium supplemented with antibiotics (Sigma-Aldrich Canada Ltd, Oakville, Ontario, Canada) was injected into the right ventricle of deeply anaesthetized mice to perfuse the lungs and remove as much blood as possible. The right lungs were then aseptically removed and minced and digested with $0.25 \%$ trypsin and $0.25 \%$ collagenase I (Gibco, Invitrogen Corporation, Burlington, Ont., Canada), at $37^{\circ} \mathrm{C}$ for 2 hours. The digested tissue was filtered, centrifuged and resuspended in Alpha MEM with 10\% fetal calf serum (FCS). The cells were plated in chamber slides and incubated at $37^{\circ} \mathrm{C}$. After 24 hours, culture medium was replaced with complete medium containing cytochalasin B (Sigma-Aldrich Canada Ltd, Oakville, Ontario, Canada) to inhibit cytoplasmic division without interfering with nuclear division. After another 72 hours of incubation, the cells were fixed with $\mathrm{KCl}$ and then methanol. Slides were stained with acridine orange (SigmaAldrich Canada Ltd, Oakville, Ontario, Canada) and scored as the number of MN per 
thousand binucleated $(\mathrm{BN})$ cells. $\mathrm{MN}$ were scored if they were distinguishable from the main two nuclei, less than one third the size of the main nuclei and had similar staining intensity [164]. Background levels of MN were consistently 15-50 MN/1000BN cells.

\section{Lung extraction}

Mice were deeply anaesthetized and using the "Inflation procedure for open lung biopsies"[165] the left lung was injected with $5 \mathrm{ml} 10 \%$ formal saline via the left main bronchus in order to expand the alveoli. The lung was then removed and placed in $10 \%$ formaline saline for 48 hours for fixation. The lungs were embedded in paraffin and sections $5 \mu \mathrm{m}$ thick were cut and placed on slides in preparation for staining.

\section{Immunohistochemistry}

Sections were stained with Haematoxylin and Eosin ( $\mathrm{H}$ and E), Masson's Trichrome for collagen content and the MAC3 antibody for activated macrophages in the Pathology core facility of the Ontario Cancer Institute. Sections were analyzed with the positive pixel algorithm in Aperio ImageScope (Aperio Technologies Inc.) The mean percent positive pixels stained are presented.

\section{Breathing rate}

The breathing rate of mice was measured at $0,4,8,10,11,12,13,14,16,18,20$, 22, 24, 28 weeks following irradiation using a whole body plethysmograph (Columbus Instruments, Columbus, Ohio). Increases in breathing rate have been previously shown during pneumonitis and fibrosis $[23,30,166-168]$. Mice were acclimatized to the 
measurement process three times before the commencement of the experiment. Mice were allowed to acclimatize before each measurement for one minute. Data for each mouse were collected for one minute and at least 3 readings from 4 second periods were selected by hand from regions free of noise due to movement of the mouse in the measurement chamber. Data are represented as the mean $+/-\mathrm{SE}$.

\section{Impact of Genistein on Tumor Response to Radiation}

$\mathrm{C} 3 \mathrm{H} / \mathrm{HeJ}$ female mice were injected intravenously with $2 * 10^{4}$ KHT murine fibrosarcoma cells into the tail vein (IV). The tumor cells then arrest in the lungs and tumors were allowed to grow for either 2 or 10 days (approximate nodule size at 2 days $<1 \mathrm{~mm}$, at 10 days $\sim 3 \mathrm{~mm}$ ). Mice were then treated with a single dose of $5 \mathrm{~Gy}$ while lung radiation combined with a single dose of genistein at $12.5 \mathrm{mg} / \mathrm{kg}$ intraperitoneally (IP). A separate group of mice were put on the genistein diet and irradiated with 9 daily fractions of 3.1Gy whole lung irradiation commencing 8 days following KHT injection. Twentyfour hours following the last fraction, the lungs of the mice were removed aseptically, minced and digested in $0.5 \mathrm{ml}$ trypsin, $4.8 \mathrm{ml}$ PBS and 45 Kunitz units DNase I (SigmaAldrich Canada Ltd, Oakville, Ontario, Canada) for 30 minutes at $37^{\circ} \mathrm{C}$. The tissue was strained and rinsed with PBS and re-digested in $0.5 \mathrm{ml} 0.25 \%$ collagenase I, 45 Kunits DNase I, and $4.4 \mathrm{ml}$ Alpha MEM $+10 \% \mathrm{FCS}$ at $37^{\circ} \mathrm{C}$ for 2 hours. The suspension was strained, centrifuged, and resuspended in alpha MEM $+10 \%$ FCS, cells were counted and plated. Colonies were allowed to grow for 10 days and then fixed with methanol. Tumor cell colonies greater than 50 cells were scored and the number of colonies recovered per lung was calculated. 


\section{Data Analysis}

When comparisons were made between the means of two groups, a two tailed Student's t-test was used, $\mathrm{p}<0.05$. For multiple comparisons an ANOVA was used followed by testing of individual groups via Tukey's test, $\mathrm{p}<0.05$.

\section{$2.4 \quad$ Results}

Normal Tissue Response

Food consumption and toxicity

The mice were weighed to monitor their health and toxicity of treatment (Figure 2.1). The food consumption was also monitored. The average consumption of food per mouse was $2.71( \pm 0.08) \mathrm{g}$ food per mouse per day similar to that reported previously [149]. From the diet formulation the mice were consuming approximately $2.03 \mathrm{mg}$ of genistein per day. The control mice steadily gained weight as they grew during the course of the experiment. The irradiated animals maintained or lost weight during the fractionated treatment but began to gain weight at a similar rate to the controls after radiation treatment was finished. The control animals on the genistein diet were slightly heavier than those on the control diet.

\section{Micronucleus formation}

C57/B16 (F) and C3H/HeJ (F) mice were irradiated with 9 fractions of 3.1Gy over 30 days to the thoracic cavity and given either the control diet or the diet containing genistein starting 2 days before the first fraction. Mice were sacrificed 18 hours post 


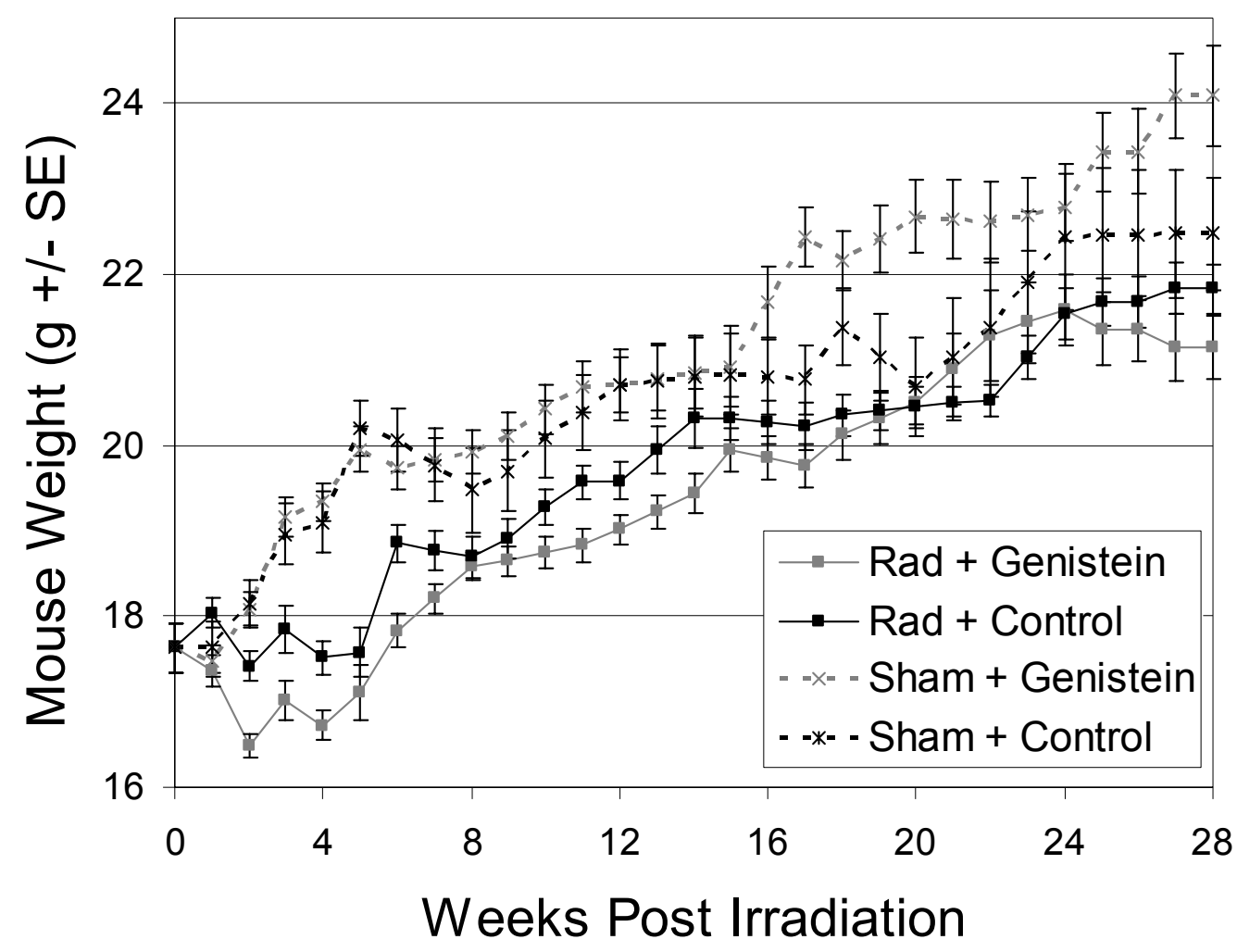

Figure 2-1: Weight of mice following irradiation. The irradiated groups did not gain weight during the irradiation treatments. After irradiation all mice gained weight at roughly the same rate. Weights were used to monitor the health of the mice. This shows no toxicity associated with genistein in the diet. 
irradiation after the $1^{\text {st }}, 3^{\text {rd }}, 6^{\text {th }}$ and $9^{\text {th }}$ fractions. Comparisons were also made between unirradiated controls and mice treated with a 10 Gy single dose. Genistein was effective in reducing the $\mathrm{MN}$ damage observed in normal lung fibroblasts of each irradiated group by an average $47 \%$ in $\mathrm{C} 57 / \mathrm{B} 16$ mice and by $46 \%$ in $\mathrm{C} 3 \mathrm{H} / \mathrm{HEJ}$ mice (Figure 2.2 ). The level of damage observed in the fractionated groups was less than that of a single dose, and increased according to total dose delivered. There was no significant increase in MN formation between the $6^{\text {th }}$ and $9^{\text {th }}$ fractions. The background level of MN is less than 50 MN/1000BN cells.

C57/B16: Mice were analyzed with no treatment ( $\mathrm{n}=4$ per group), post $10 \mathrm{~Gy}$ single dose $(\mathrm{n}=4$ control, $\mathrm{n}=3$ genistein), post fraction $1(\mathrm{n}=4$ control, $\mathrm{n}=3$ genistein), post fraction 3 ( $\mathrm{n}=3$ control, $\mathrm{n}=4$ genistein), post fraction $6(\mathrm{n}=7$ control, $\mathrm{n}=4$ genistein), post fraction 9 ( $\mathrm{n}=7$ control, $\mathrm{n}=4$ genistein). Comparison between control and treated groups: no radiation $\mathrm{p}=\mathrm{ns}, 10 \mathrm{~Gy}$ single dose $\mathrm{p}=0.001$, fraction $1 \mathrm{p}=0.009$, fraction $3 \mathrm{p}=0.001$, fraction $6 \mathrm{p}=0.001$, fraction $9 \mathrm{p}=0.045$. Average reduction in $\mathrm{MN}$ formation by genistein $=47 \%$.

C3H/HEJ: $\mathrm{N}=4$ mice for all groups. Comparison between control and treated groups: no radiation $\mathrm{p}=\mathrm{ns}, 10 \mathrm{~Gy}$ single dose $\mathrm{p}<0.001$, fraction $1 \mathrm{p}=0.003$, fraction $3 \mathrm{p}<0.001$, fraction $6 \mathrm{p}=0.002$, fraction $9 \mathrm{p}=0.048$. Average reduction in $\mathrm{MN}$ formation by genistein $=46 \%$.

C3H/HEJ (F) mice irradiated with 9 fractions of 3.1 Gy were also followed for 28 weeks to examine the long term effects of the genistein diet on radiation damage (Figure 2.3). Following radiation genistein reduced $\mathrm{MN}$ formation to background levels by 16 weeks post irradiation. The irradiated mice on the control diet had sustained levels of MN 
formation between $300-400 \mathrm{MN} / 1000 \mathrm{BN}$ for weeks $12-28$, well above the background levels. $\mathrm{N}=4$ mice for all groups. Comparison between irradiated treated groups: 4 weeks $\mathrm{p}=0.048,8$ weeks $\mathrm{p}=0.021,12$ weeks $\mathrm{p}=0.035,16$ weeks $\mathrm{p}=0.018,20$ weeks $\mathrm{p}=0.009,24$ weeks $p<0.001$, week $28 p=0.001$. There was no significant difference between the sham treatment groups. From weeks $16-28$ there was no significant difference between the irradiated genistein and the sham groups.

\section{Immunohistochemistry}

The left lungs were fixed in formalin and stained for histology and immunohistochemistry. At early times up to 4 weeks there were no visible changes in intra-alveolar thickness, alveolar spaces or inflammatory infiltrate, collagen or activated macrophages (data not shown). For later times from 4-28 weeks post irradiation, representative images of MAC3 staining for activated macrophages are shown in Figure 2.4. Additional images from moribund mice that were sacrificed in weeks 12,14 , and 16 and stained with MAC3 are also shown in Figure 2.5.

MAC3 staining increased gradually over time in the sham groups while the irradiated groups showed a 1.8x increase over the unirradiated controls (Figure 2.6). Genistein caused a significant reduction in macrophage content between the radiation and control diet vs radiation and genistein diet at 28 weeks, and between the sham and control diet vs. sham and genistein diet at 16 weeks. There was an average reduction of $22 \%$ in macrophage content by genistein in the irradiated groups, and $45 \%$ in the sham groups. Macrophage content was also quantified in moribund mice that were sacrificed early 


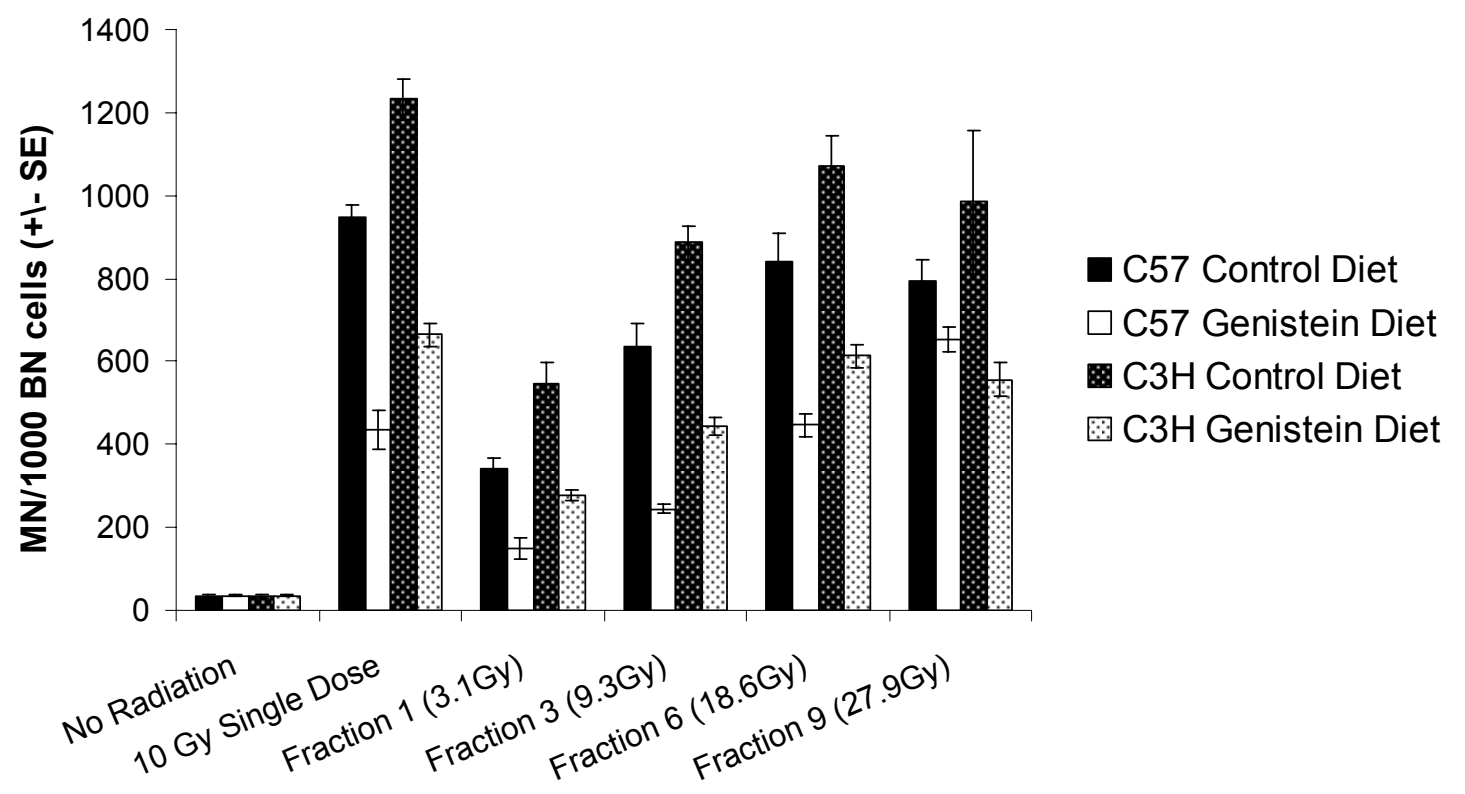

Figure 2-2: Micronucleus yield from whole lung irradiations in C57/B16 and C3H/HEJ mice at various times during fractionated irradiation with genistein treatment. Each bar represents the mean $\pm \mathrm{SE}$. N=3-7 mice per group. Genistein reduced $\mathrm{MN}$ formation in all groups. 


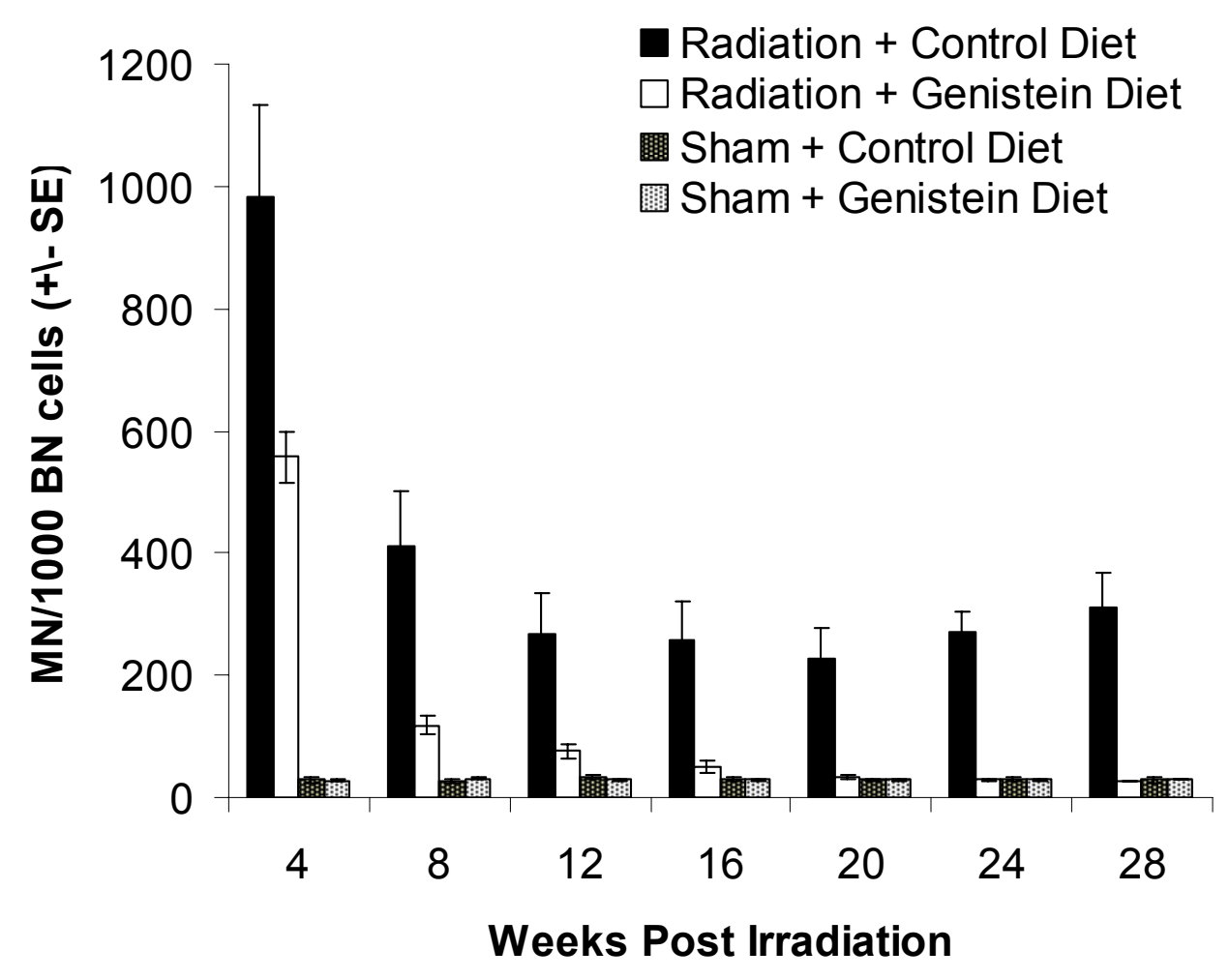

Figure 2-3: Micronucleus formation at various times following fractionated irradiation ( 9 fractions of 3.1 Gy) with genistein treatment. Each bar represents the mean \pm SE. $N=4$ mice per group. Genistein reduced MN formation at late times to background levels by 16 weeks PI. 


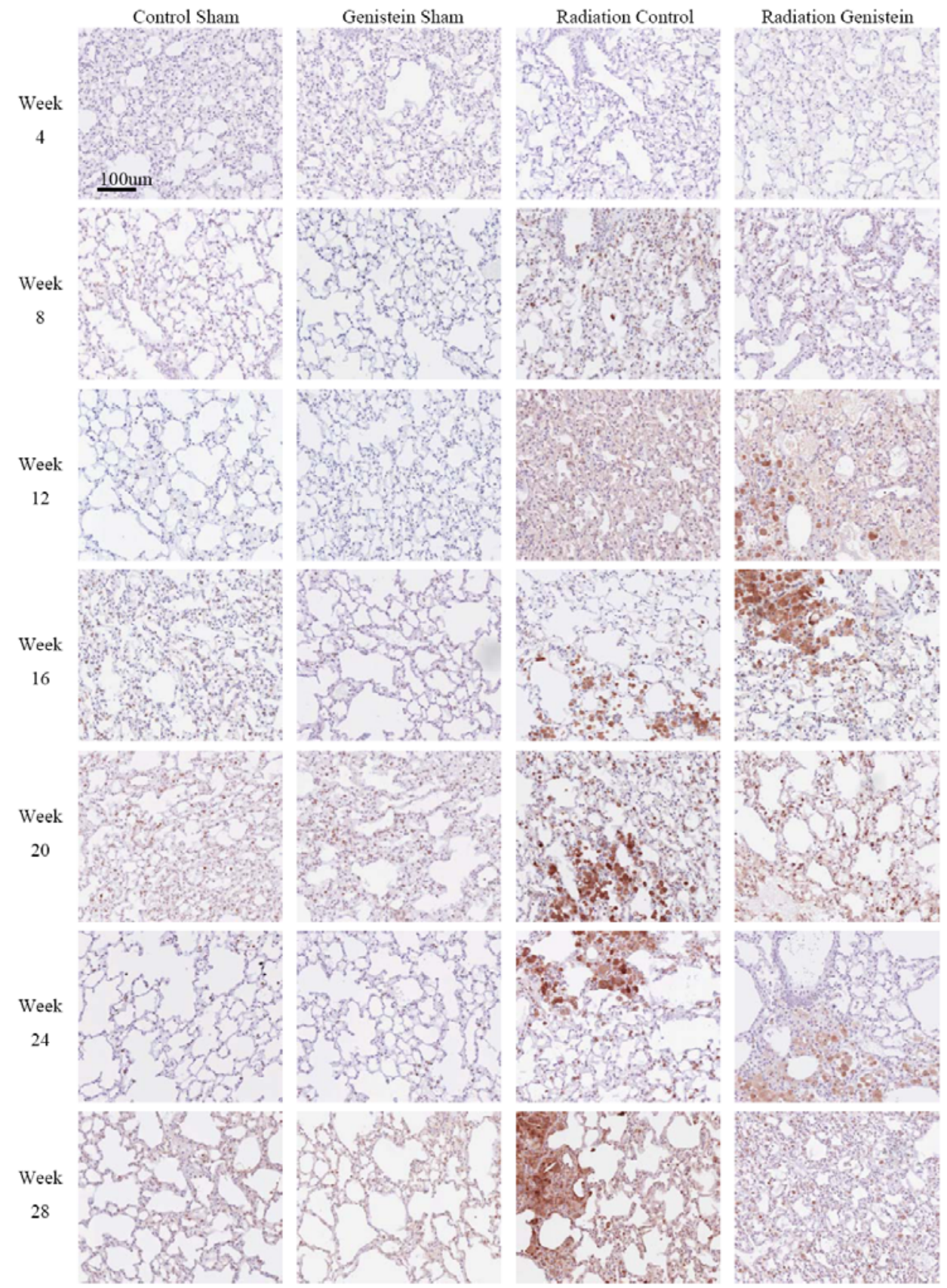

Figure 2-4: Representative images of MAC3 stain at 4 week intervals post irradiation. Black bar represents $100 \mu \mathrm{m}$. Activated macrophages stain brown. Irradiated animals show patchy inflammatory infiltrate into the lung tissue and alveolar air spaces. 


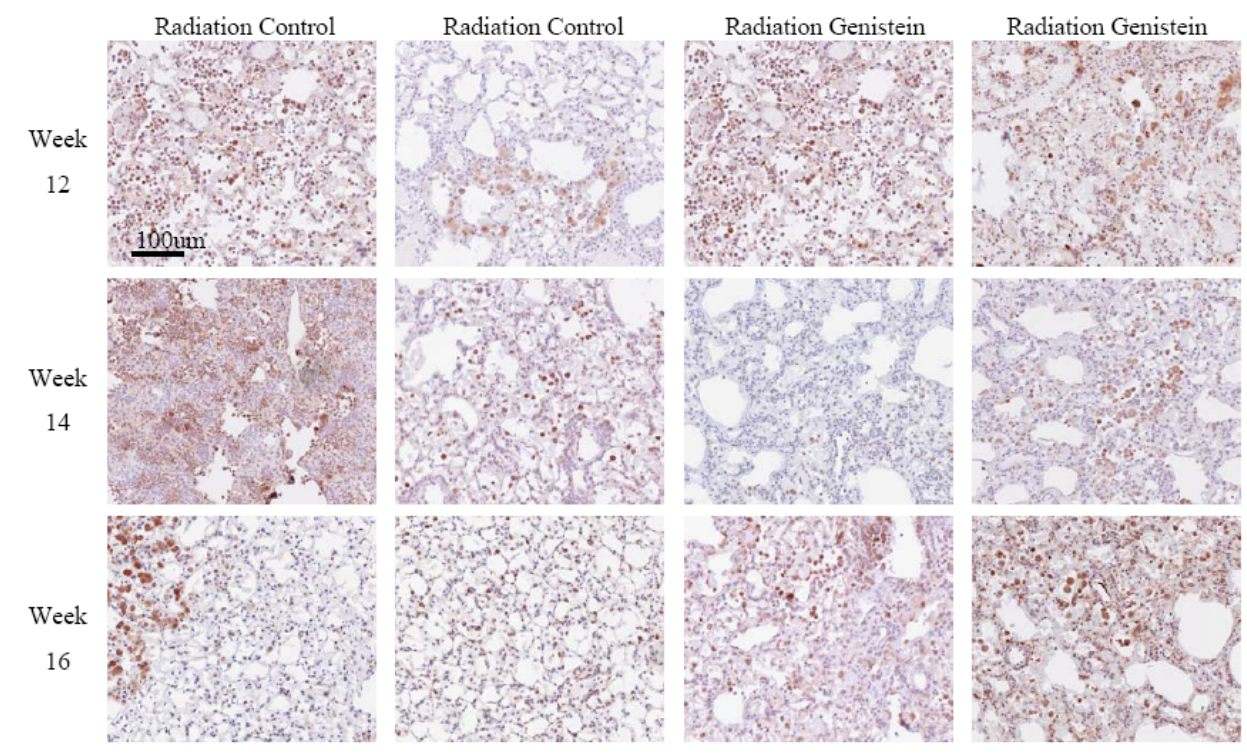

Figure 2-5: Representative images of MAC3 stain at 12, 14, and 16 weeks post irradiation from moribund mice that were sacrificed. Black bar represents $100 \mu \mathrm{m}$. Inflammatory infiltrates completely obliterated much of the normal lung tissue architecture. 


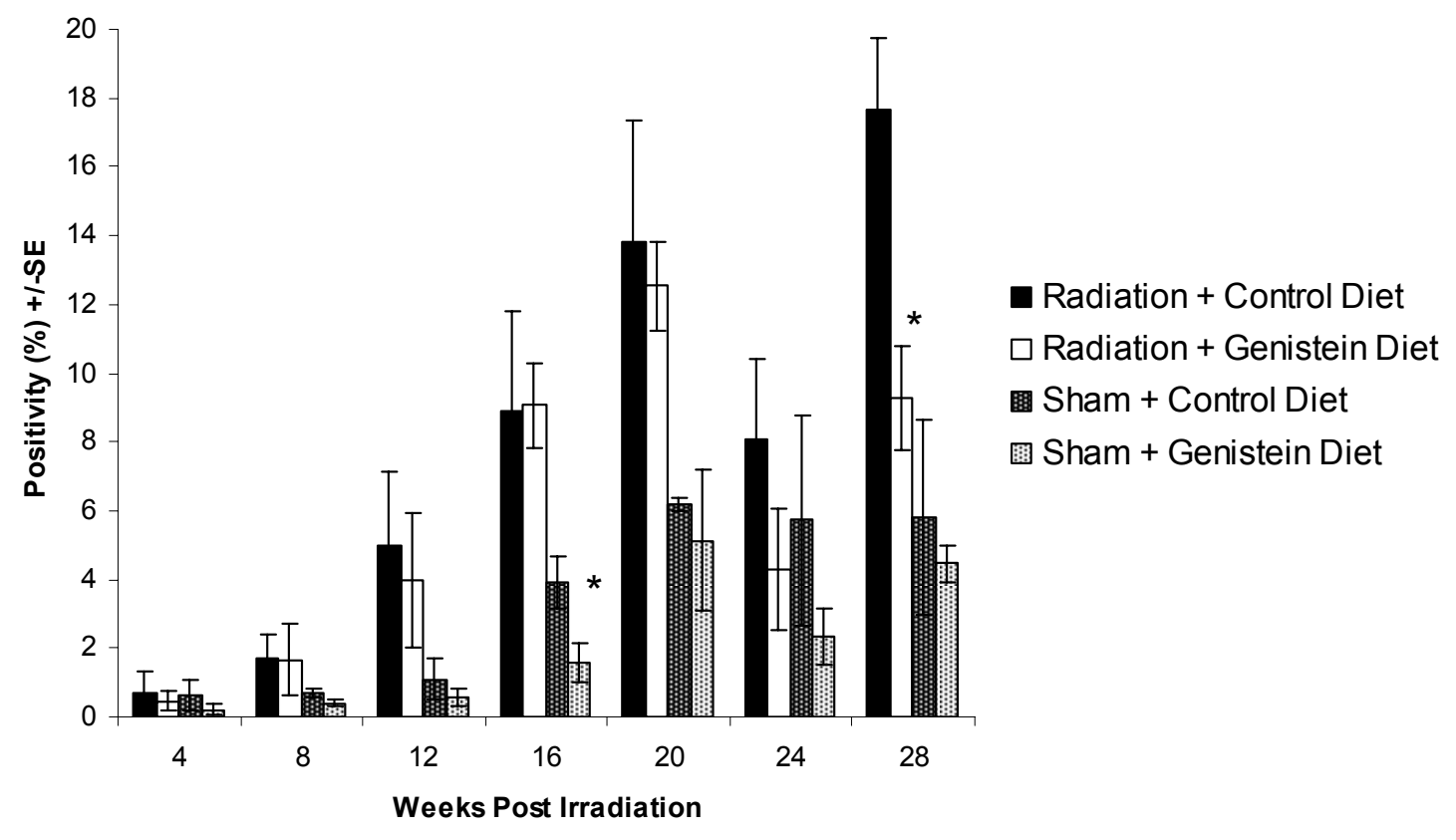

Figure 2-6: Quantification of MAC3 antibody staining (Figure 2-4) for activated macrophages content at 4 week intervals following fractionated irradiation ( $\mathrm{n}=4$ per group). Each bar represents the mean positivity \pm SE. There is an average increase by $1.8 \mathrm{x}$ in macrophage content in the irradiated vs sham groups.

Genistein caused a significant reduction (*) in macrophage content between the Radiation and Control diet vs Radiation and Genistein diet at 28 weeks, and between the Sham and Control diet vs. Sham and Genistein diet at 16 weeks. There was an average reduction of $22 \%$ in macrophage content by Genistein in the irradiated groups, and $45 \%$ in the sham groups. 


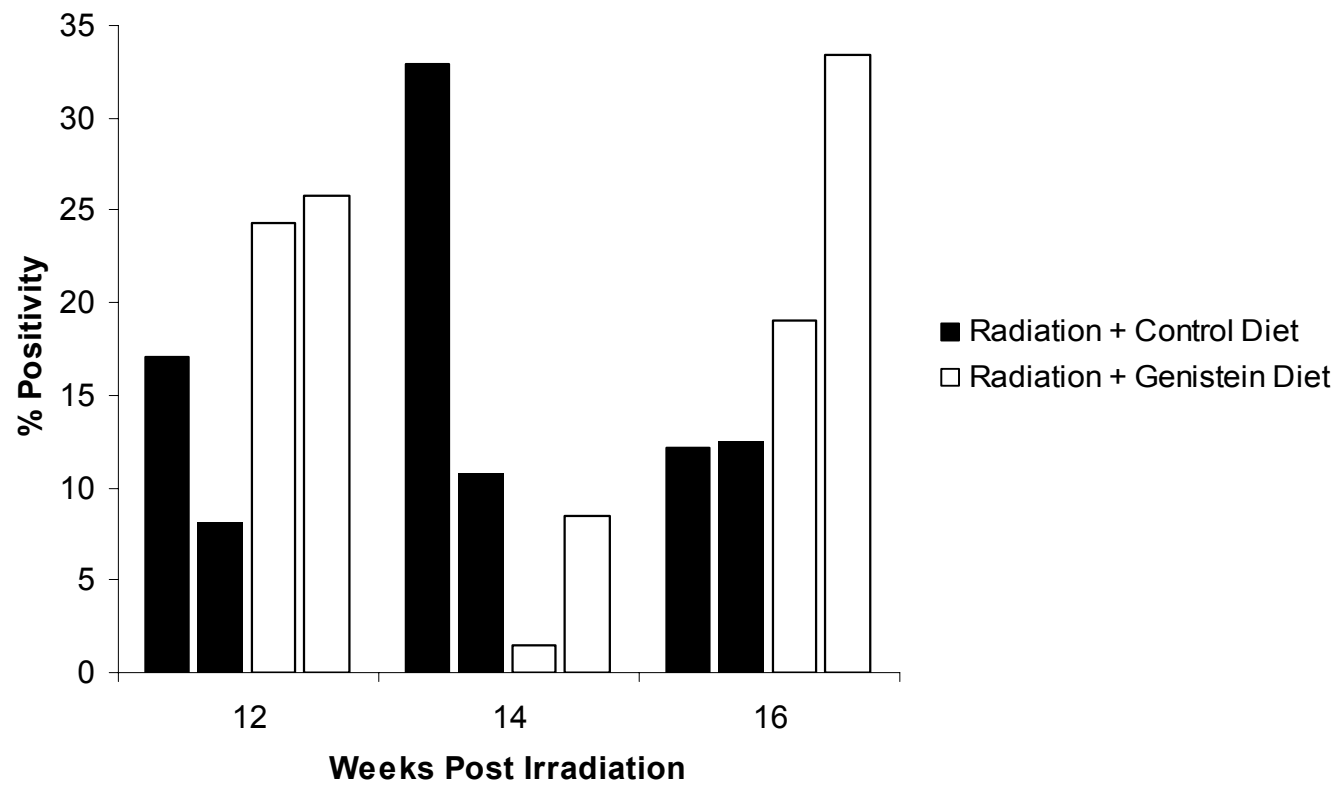

Figure 2-7: Quantification of MAC3 staining for activated macrophages (Figure 2-5) for sacrificed moribund mice from weeks 12, 14 and 16. Mice that were sacrificed early showed much higher levels of macrophages than mice that were healthy at that time(ie mice that were randomly chosen for timepoint analysis as shown in Figure 2-6). Each bar is one mouse. 
during weeks 12, 14, and 16 (Figure 2.7). These mice showed higher macrophage content than mice that were healthy during the same time period.

Collagen content was assessed by Masson's Trichrome staining as shown in Figure 2.8. The levels in the unirradiated mice were fairly constant over the course of the experiment while the irradiated groups showed an average $2.9 \mathrm{x}$ increase over the unirradiated controls (Figure 2.9). The collagen content of the genistein groups was reduced by approximately $28 \%$ from the control diets.

\section{Functional Deficit}

Breathing rate was measured as an indicator of functional deficit caused by radiation damage (Figure 2.10). The irradiated groups both show an increase in breathing rate during weeks 10-16 weeks post irradiation during the pneumonitis phase. Following this time there was a sustained increase in breathing rate during the development of fibrosis in weeks $18-28$ in both irradiated groups with no obvious difference between them.

\section{Morbidity}

Severe morbidity leading to animal sacrifice following the radiation treatment of the mice was also assessed (Figure 2.11). There was no difference between the genistein vs control diet groups with both showing a sharp decrease in survival during the pneumonitis phase. The protection seen against $\mathrm{MN}$ formation in fibroblasts did not extend to increased overall survival. 

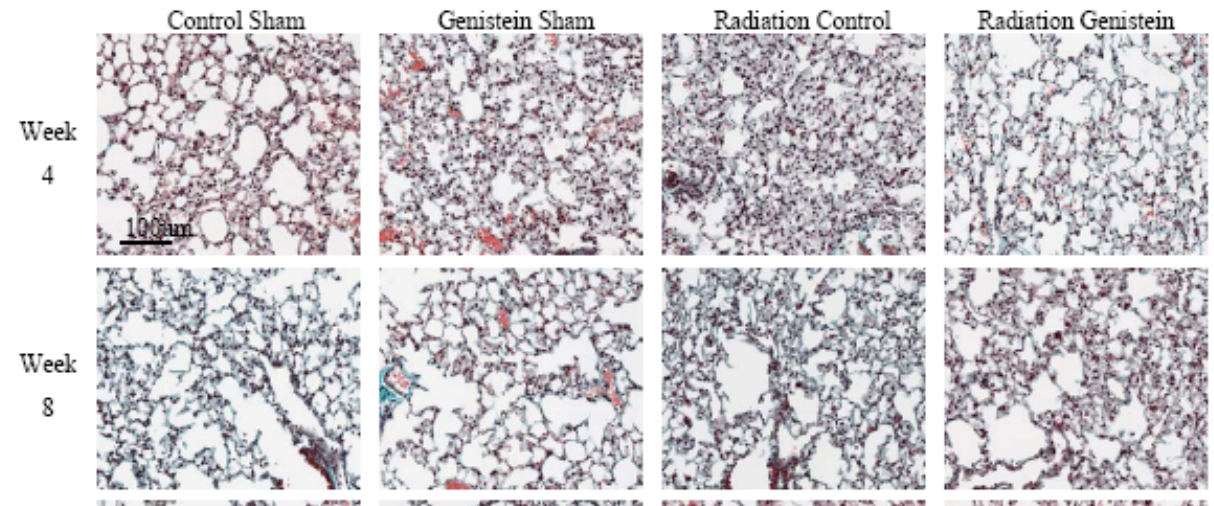

Week
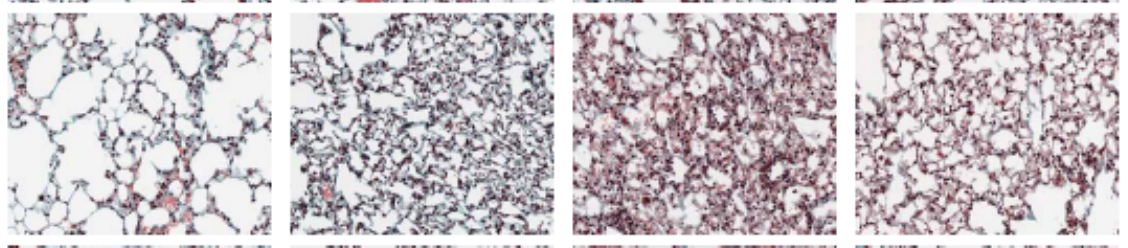

Week
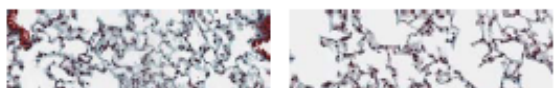

16
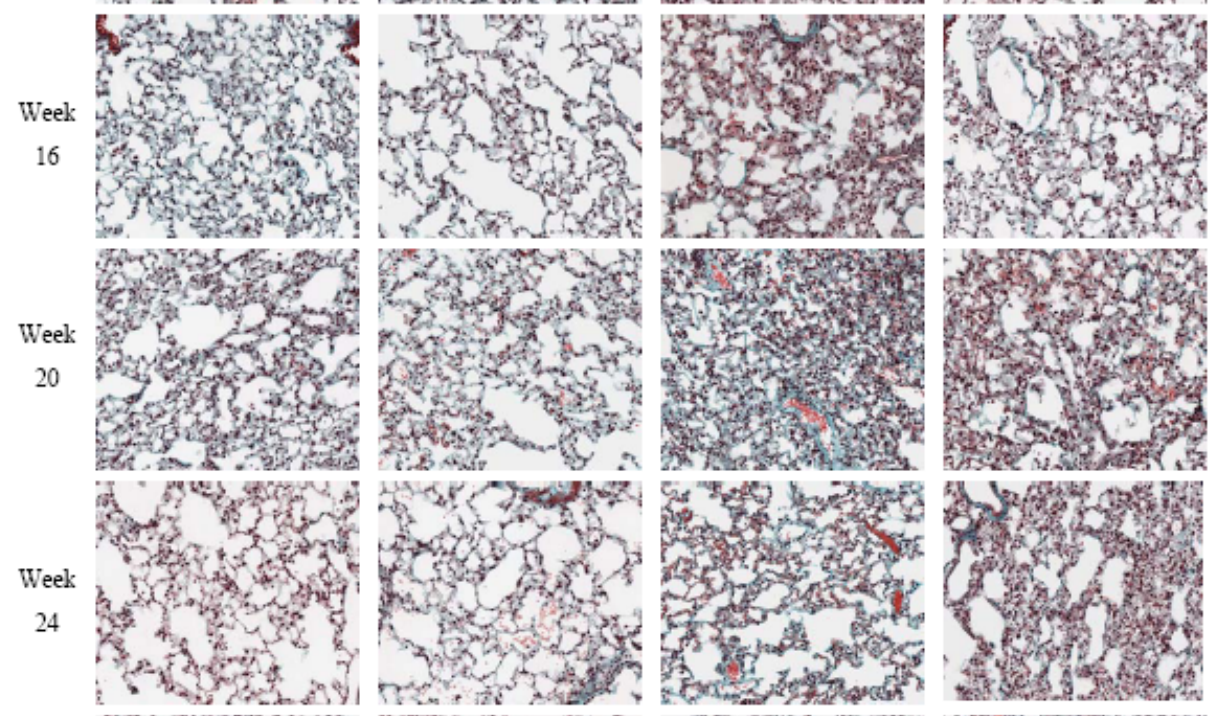

Week
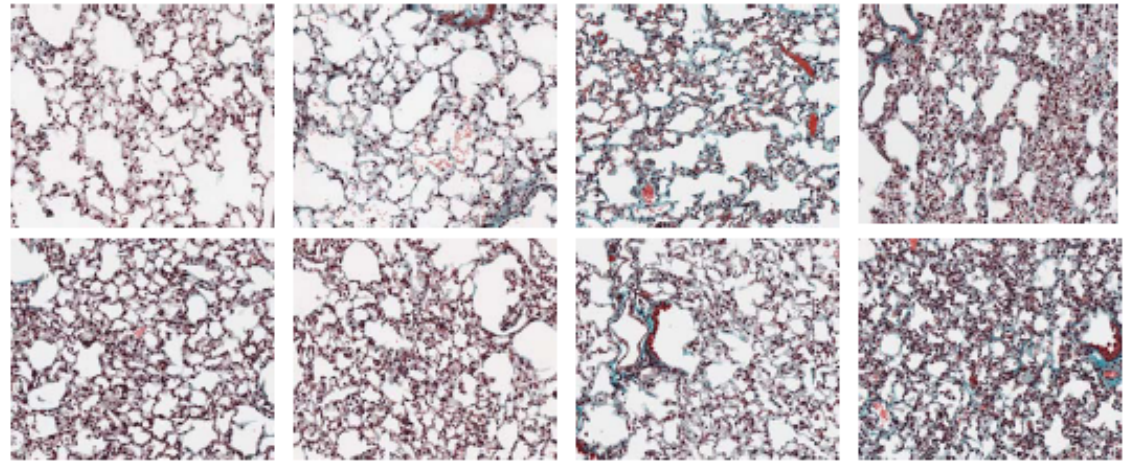

Figure 2-8: Representative images of Masson's Trichrome stain at 4 week intervals post irradiation. Black bar represents $100 \mu \mathrm{m}$. 


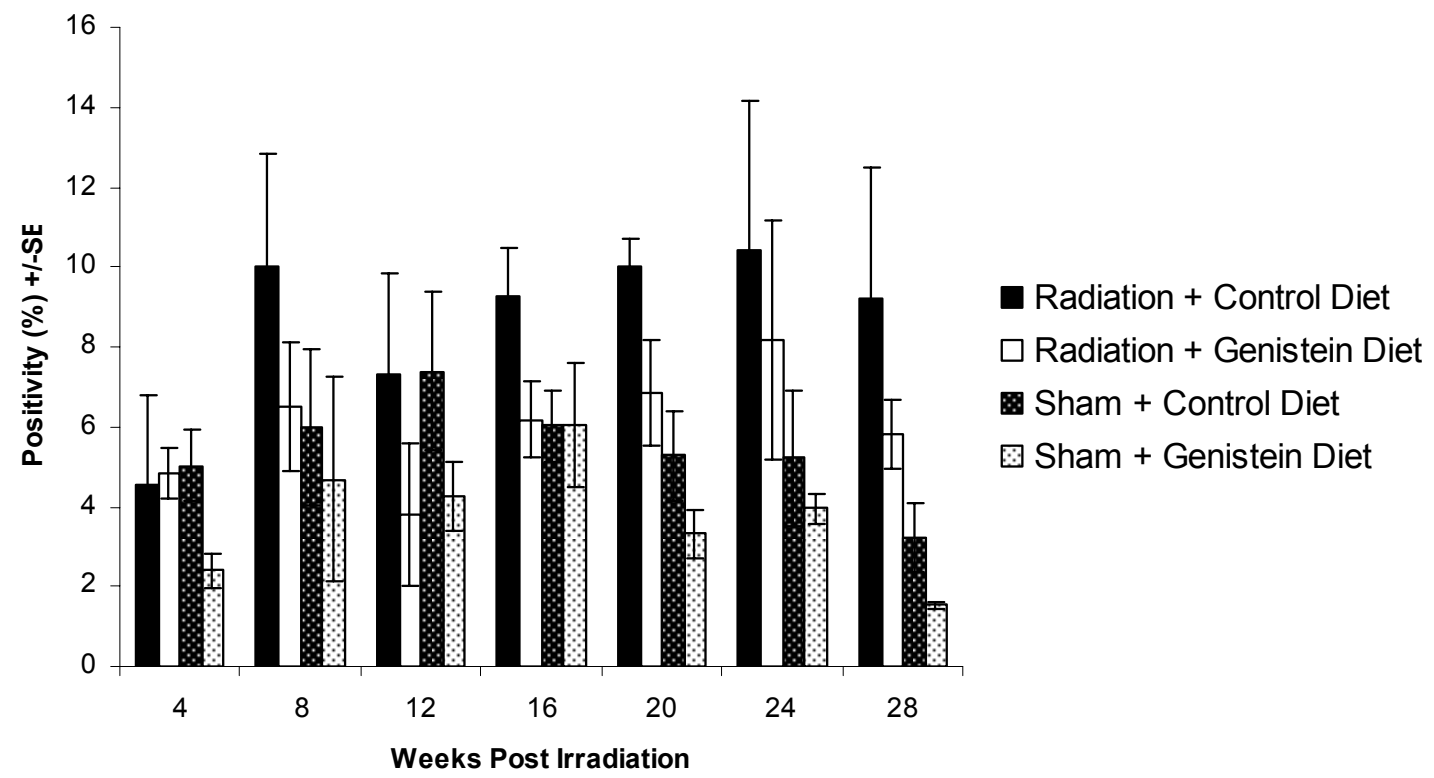

Figure 2-9: Quantification of Masson's Trichrome stain (Figure 4) for collagen content at 4 week intervals following fractionated irradiation ( $\mathrm{n}=4$ per group). Each bar represents the mean positivity $\pm \mathrm{SE}$. There was a trend for reduced collagen content in the irradiated Genistein group compared to the irradiated control group, and in the sham Genistein compared to the sham control group. This trend was not statistically significant; however, there was an average reduction in collagen content by $28 \%$ between the irradiated groups and by $32 \%$ between the sham groups. 


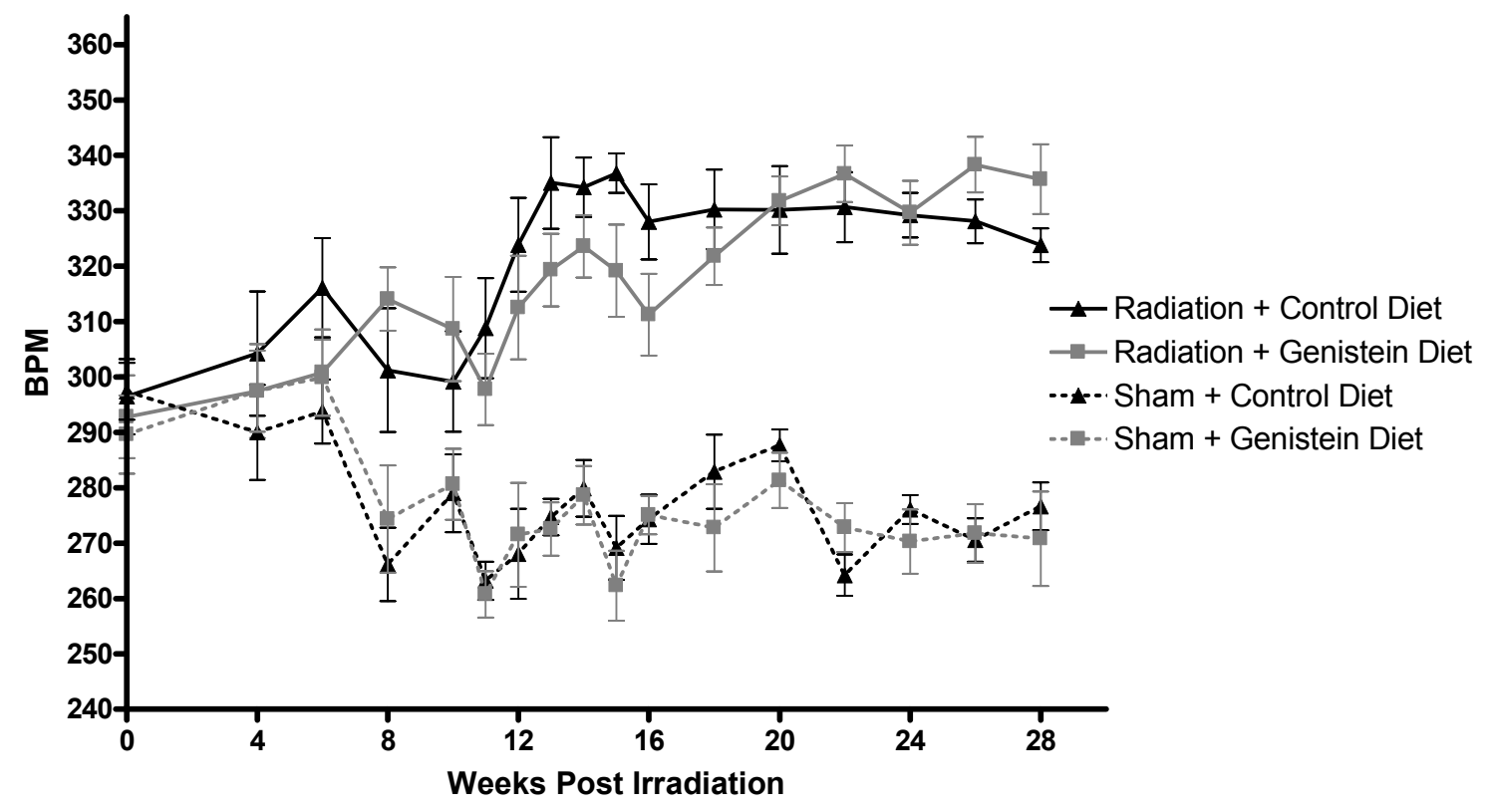

Figure 2-10: Mean Breaths per Minute (BPM) +/- SE of irradiated vs control mice on Genistein and Control diets ( $\mathrm{n}=15-20$ per group). The irradiated groups both show an increase in breathing rate during weeks 10-14 weeks post irradiation during the pneumonitis phase, there is a light decrease from weeks 1416 then a sustained increase over the fibrotic phase in weeks 18-28. Both unirradiated groups have BPM below 300 . 


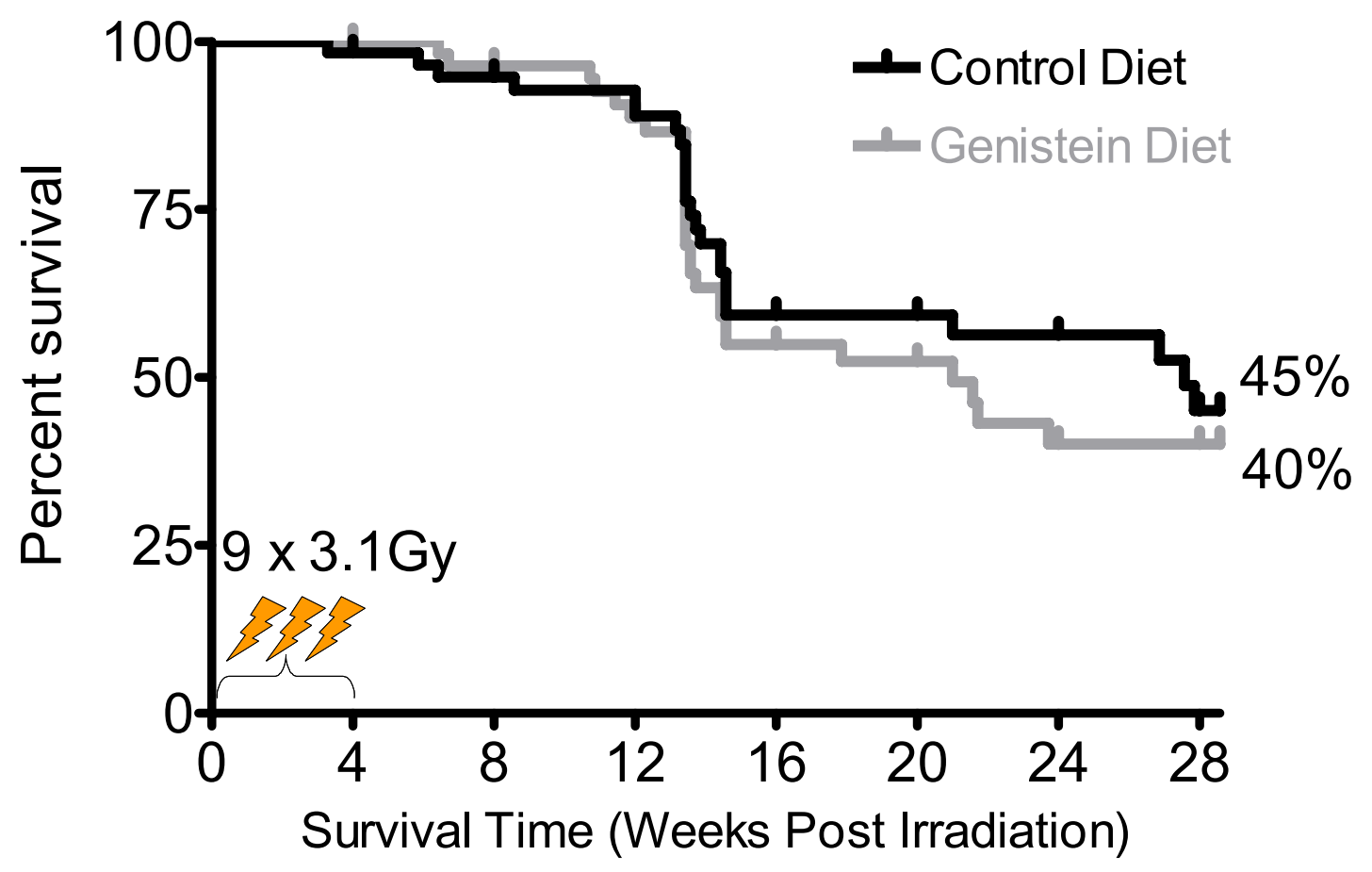

Figure 2-11: Survival of irradiated animals on Genistein vs Control diets ( $\mathrm{n}=60$ for both groups). Both groups had a sharp decrease in survival between 8-16 weeks (2-4 months) during the pneumonitis phase. There was no significant difference between the survival curves (Kaplan-Meier). 


\section{Impact of Genistein on Tumor Response to Radiation}

Mice were injected with KHT tumor cells IV and tumors were allowed to grow in the lungs for 2 or 10 days. The mice were then treated with a single dose of $12.5 \mathrm{mg} / \mathrm{kg}$ genistein and/or 5Gy radiation to the thoracic cavity. Lungs were removed and assessed for clonogenic survival. At 2 days or 10 days there was no difference in tumor cell survival between the groups given a single dose of radiation (data not shown). For fractionated radiation treatment the mice were put on the genistein diet at day 8 after cell injection and maintained on this diet for the remainder of the experiment. The mice were irradiated with 9 daily fractions of $3.1 \mathrm{~Gy}$ starting on Day 8 . There was a significant reduction in colony formation in genistein treated mice in the un-irradiated and irradiated groups (Figure 2.12) suggesting that prolonged treatment with genistein may reduce the growth rate of the lung nodules. Genistein caused a reduction in the number of tumor cells recovered following radiation, but its effect as a radiosensitizer was not statistically significant.

\subsection{Discussion}

Fibrosis and particularly pneumonitis are serious side effects that are dose limiting in radiotherapy involving significant volumes of the lung. This study examined the potential protective effects of genistein on early and late effects post irradiation through comprehensive assessment of DNA damage, immunohistochemical analysis of collagen content and macrophage activation and functional deficit in the whole organism using a mouse model known to be prone to radiation-induced pneumonitis. 


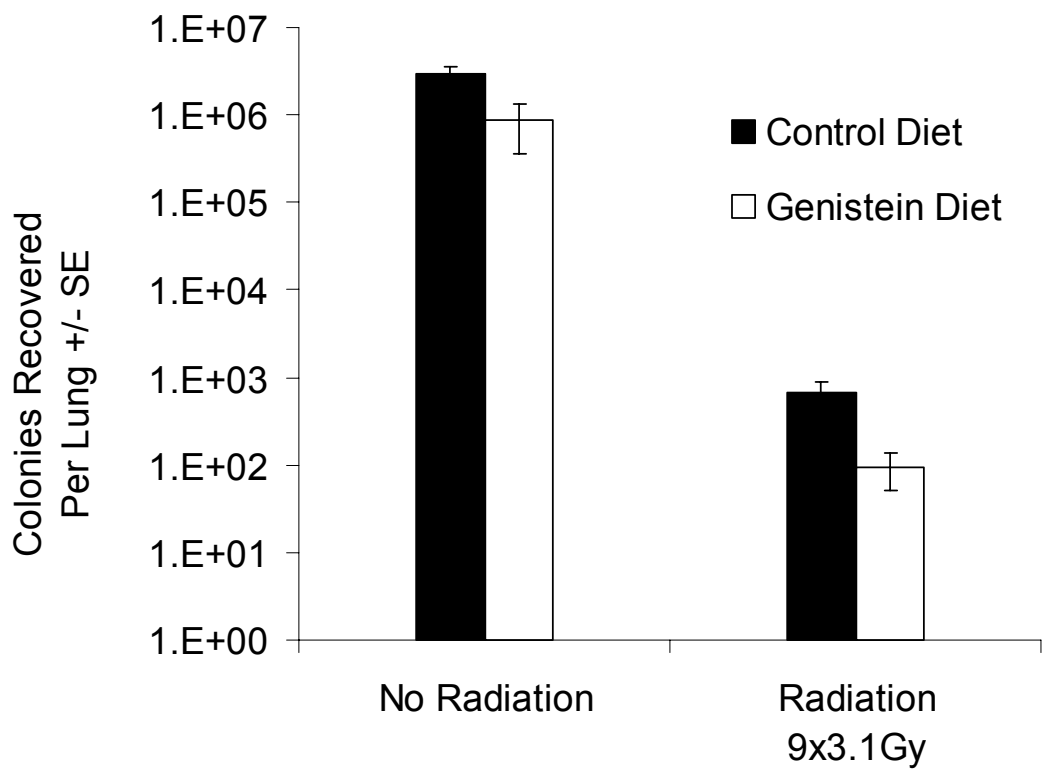

Figure 2-12: Clonogenic assessment of tumor response following in situ irradiation of KHT tumors with $9 \times 3.1 \mathrm{~Gy}$ ( $\mathrm{n}=6$ per group). Genistein significantly reduced tumour formation in both irradiated $(\mathrm{p}=0.021)$ and unirradiated groups $(\mathrm{p}=0.040)$. Effect of radiation vs. effect of Genistein: Genistein did not significantly increase tumor sensitivity to radiation. 
Genistein protected against DNA damage as assessed by MN formation in normal lung fibroblasts by greater than $50 \%$. As the experiment progressed to later times, the MN levels detected were reduced to background levels by 16 weeks post irradiation. Genistein also reduced the macrophage content in lung tissue assessed by MAC3 staining by $\sim 22 \%$ and the deposition of collagen by $\sim 28 \%$ as assessed by Masson's Trichrome staining. However, protection against DNA damage and MN formation did not extend to significant protection against increases in breathing rate or decreased severe morbidity. Both the genistein-treated and control animals treated with radiation showed a large increase in breathing rates and approximately $45 \%$ of the animals manifested severe morbidity during weeks 10-16. Histological samples showed that these mice were suffering from severe pneumonitis.

The data demonstrating that DNA damage can be alleviated by genistein treatment is consistent with our previous work that has shown similar effects in rats with a SOD-Catalase mimetic EUK-189 following lower half lung irradiation [119]. The previous work also showed that there appeared to be some regeneration of damage after EUK-189 treatment and ongoing studies in rats indicate that genistein can partially protect against pneumonitis in a rat model (Calveley et al., in preparation 2008). Similarly, another SOD- catalase mimetic has also been reported to alleviate increases in breathing rate and collagen content following hemithoracic radiation in rats [120-122]. These results suggest that at least some of the DNA damage is caused by oxidative stress induced by the radiation-induced inflammatory response and that DNA damage caused by this mechanism can be scavenged by EUK-189 or genistein when given after irradiation. 
Oxidative stress, inflammatory cell recruitment and cytokine production following radiation to the lung has been examined in many studies and postulated to play a major role in the development of functional lung damage [169]. It was thought that genistein would be an ideal agent to treat radiation-induced lung damage as it has both anti-oxidant and anti-inflammatory properties (blocks activation of NFKB). Furthermore it has been reported to reduce the inflammatory response induced by LPS [141]. Despite this we found that although genistein was effective in reducing DNA damage in lung fibroblasts, this did not relate to the functional outcome in our murine model.

One possible explanation for these results may be the source of ROS causing DNA damage that is detected by the MN assay. There are at least three potential sources of ROS within the irradiated lung, first that which is produced as a direct result of radiation, second that is generated by inflammatory cells $[12,170]$, and third from the mitochondria because of leakage from the electron transport chain [14]. Using whole lung irradiation it is difficult to distinguish between these sources; however, previous studies in our lab using half lung irradiation of rats $[27,28,119]$ showed significant DNA damage both in and out of the radiation field. We also found that MnSOD or CuZnSOD and nitro-L- arginine methyl ester (L-NAME) were effective in protecting against out of field damage. We hypothesized that these results could be explained if out-of-field damage could arise from ROS (or RNOS) created by the induced inflammatory response and in-field DNA damage could be induced by this mechanism as well as by ROS generated primarily from the ionization of water and direct ionization of target molecules [171]. Alternatively or additionally, since we have observed that DNA damage following whole lung irradiation can be regenerated following scavenging by SOD-catalase 
mimetics or genistein [7] (and unpublished observations) the in-field DNA damage observed may also be generated by ROS from the mitochondria. Mitochondrial ROS have not been directly linked to induction of inflammatory responses and might be less important for fibrosis development than extracellular ROS produced by inflammatory cells.

It may also be important that inflammatory cells can produce several orders of magnitude more ROS than would be produced directly by radiation doses of the size we are using $[170,172]$. Thus the levels of genistein used in the current studies may be sufficient to reduce intracellular ROS (RNOS) to low levels but may be insufficient to do this for extracellular ROS produced by the induced inflammatory response. Furthermore, there are other mechanisms that may contribute to the chronic inflammatory response. Mast cells, macrophages and neutrophils, that have been reported to be increased in $\mathrm{C} 3 \mathrm{H}$ mice with alveolitis $[82,173,174]$ have been shown to secrete chemokines such as IL-6, enzyme-rich granules and active amines which promote recruitment and infiltration of other inflammatory cells along with increases in IL- $1 \alpha / \beta$ and TNF- $\alpha$. These cell types are presumably attracted to the irradiated lung by expression of surface adhesion molecules such as ICAM-1 or E-selectin $[47,156]$. It has also been suggested that tissue hypoxia may result from increased oxygen consumption by activated macrophages and decreased perfusion due to vascular injury. Hypoxia may then further enhance oxidative stress by inducing hypoxia inducible factor (HIF)-1 $\alpha$ and downstream genes VEGF and angiotensin II furthering inflammatory cell recruitment [170]. All of these possibilities suggest that the use of higher doses of genistein may be required to achieve significant effects on functional deficits following lung irradiation. 
A further possibility is that DNA damage to the lung fibroblasts is not critical for functional outcome. It has been shown that radiation causes premature terminal differentiation of fibroblasts causing increased synthesis and extracellular deposition of collagen [175]. Since such cells become post mitotic they may harbour DNA damage undetected by the MN assay while still contributing to the progression of tissue remodeling and altering recruitment of inflammatory cells. However, many fibroblasts still retain their ability to divide as we are still able to detect dose dependent DNA damage by the MN assay. Furthermore, studies in rat lungs exposed to internal irradiation showed that deep lung epithelial cells also demonstrated significant levels of $\mathrm{MN}$ as well as fibroblasts, indicating that the presence of DNA damage that can be expressed as micronuclei in irradiated lung is not limited to fibroblasts [176].

An important question is why we observed little or no protection against pneumonitis in the $\mathrm{C} 3 \mathrm{H}$ mice when we had previously seen protection against this endpoint in rats using an identical genistein containing diet. One possibility is the pharmacokinetics of the compound. The amount of food consumed by the mice was monitored and the approximate dose of genistein consumed was in the range of $80 \mathrm{mg} / \mathrm{kg}$ per day (each mouse consumed $2.03 \mathrm{mg} / \mathrm{day}$ per $25 \mathrm{~g}$ ) which has been reported to give a plasma level in the range of $1-2 \mu \mathrm{mol} / \mathrm{L}$ [149]. Studies in rats of plasma values of genistein given a dose of $50 \mathrm{mg} / \mathrm{kg} /$ day gave values of about $11 \mu \mathrm{mol} / \mathrm{L}$ [177], which are significantly higher than the values reported for mice on the diet that we used. However, the technique of genistein measurement and the administration methods are different so it is difficult make a direct comparison. Nevertheless, a recent study of the effect of genistein in bone marrow protection following $9.5 \mathrm{~Gy}$ whole body irradiation showed a 
range of responses according to dose [145]. At least $25 \mathrm{mg} / \mathrm{kg}$ was needed to produce an effect on survival, and $91 \%$ survival was observed at $200 \mathrm{mg} / \mathrm{kg}$ compared to $8 \%$ with saline treated controls. A following study also showed protection against MN formation and collagen deposition [178]. These considerations again suggest the need to test higher doses of genistein. Particularly this may be true because the dose of genistein used in our studies was chosen based on 1) studies in rats to determine the minimum dose which would effectively scavenge all the DNA damage (micronuclei) when given after irradiation. (Calveley et al in preparation) and 2) reports that the median intake of isoflavones is $30-40 \mathrm{mg} /$ day in Asian populations, and that genistein levels in plasma from Asian populations are in the range of 500nmol/L $[179,180]$.

Finally, whenever any protective agent is given in combination with radiation therapy there is a concern that it may protect tumour as well. Consequently this study also investigated the effect of genistein on in situ irradiated KHT tumours. We found that there was no evidence of tumour protection. In fact there was a trend towards tumor sensitization by the reduction in clonogenic cells recovered from unirradiated and irradiated mice with prolonged treatment with genistein. This is consistent with other reports that genistein has shown potential as an anti-cancer agent in several different cancer cell types such as glioma [181], prostate cancer [150], lung cancer [182], cervical cancer [183] and breast cancer [149]. Our results contribute to evidence that even as an anti-oxidant genistein may be used safely as a protective agent for normal tissue in combination with radiation therapy. These findings are encouraging but in the particular case of the use of genistein (at higher doses) as a potential agent to protect lung tissue this 
experiment should be repeated using a human lung carcinoma cell lines to ensure that the result is not cell type specific. 


\section{Chapter 3: Discussion and future directions}




\subsection{Discussion}

Pneumonitis and fibrosis are severe side effects of radiation therapy that can occur following irradiation of the lung. The probability of normal tissue complications is a dose limiting factor for radiation that can be delivered. Reducing or preventing of side effects would allow for dose escalation and better local control of the tumor. An agent, such as genistein, may be beneficial to the treatment strategy by protecting against the development of radiation pneumonitis and fibrosis in lung. New treatment regimes using hypofractionation use 1-5 very large fraction sizes of up to $20 \mathrm{~Gy}$ versus traditional 30 fractions of 2 Gy daily. These potentially produce greater side effects, and minimizing them would be highly beneficial.

The exact mechanisms of radiation induced lung damage are unclear. It is hypothesized that oxidative stress, inflammatory cell recruitment and cytokine production following radiation to the lung play a major role in the development of functional lung damage. Genistein is an ideal agent that acts as an anti-oxidant by scavenging ROS, and as an anti-inflammatory by blocking activation of NF- $\kappa$ B. This study examined the protective effects of genistein on early and late effects post irradiation through assessment of DNA damage by MN assay, immunohistochemical analysis of collagen content and macrophage activation and functional deficit using a mouse model known to be prone to radiation-induced pneumonitis.

This study extended previous work in rat lung to a mouse model which had not been used for long term studies before. This study also moved to a fractionated irradiation schedule to investigate protection against a more clinically relevant treatment. Previous work in rats used a $18 \mathrm{~Gy}$ (at a dose rate of $0.4-05 \mathrm{~Gy} / \mathrm{min}$ ) whole lung 
irradiation which was the approximate LD50. This current study based the fractionated treatment schedule on equivalent dose experiments $[39,40]$ and aimed to deliver a dose equivalent to $10 \mathrm{~Gy}$, the $\mathrm{LD} 50$ for $\mathrm{C} 3 \mathrm{H}$ mice. The current study used $100 \mathrm{kVp}$-rays at a dose rate of $\sim 10.2 \mathrm{~Gy} / \mathrm{min}$. The dose equivalence studies were performed in rats but the overall survival in this experiment with the $\mathrm{C} 3 \mathrm{H}$ mice was indeed close to $50 \%$ showing that this fractionated treatment was closely equivalent in dose as expected.

The effectiveness of genistein in blocking DNA damage was assessed by levels of $\mathrm{MN}$ formation. It was shown that genistein reduced $\mathrm{MN}$ formation by $50 \%$ in lung fibroblasts over the course of fractionated treatment. Fractionation should allow for repair of damage between doses, but measurements following the first, third, sixth and ninth fractions all showed damage roughly half that of the untreated animals, and damage increased with dose. The damage produced by each fraction was additive, and there were high levels of $\mathrm{MN}$ formation following the 9 treatments comparable to damage seen following a 10Gy single dose. The $\%$ reduction of MN formation was lowest after the $9^{\text {th }}$ fraction.

Lung fibroblasts from mice sacrificed at 4 week intervals post irradiation (PI) showed decrease in MN formation over time to background levels by 16 weeks PI. Previous studies with genistein in our lab showed that doses as low as $12.5 \mathrm{mg} / \mathrm{kg}$ genistein given intraperitoneally (IP) either 1 hour pre or 5 minutes post irradiation was sufficient to reduce MN formation in rat lung to background levels in animals sacrificed 18hrs PI (Calveley, unpublished data). The genistein diet was formulated based upon the results of these studies and aimed to deliver a dose of $12.5 \mathrm{mg} / \mathrm{kg}$ absorbed. It was also thought that providing genistein in the diet would provide better protection as it would be 
consumed at many times during the day and would give a more steady concentration versus a single injection that has a half life of approximately 8 hours. The genistein diet formulation was not as effective in fully blocking $\mathrm{MN}$ formation (only a $50 \%$ reduction was observed following each fraction) as the IP injections, suggesting that for maximal protection the dose of genistein being consumed in the diet should be increased. The time course study of MN formation at 4 week intervals also provided insight into levels of damage occurring over time. Another previous study of 10Gy lower half lung irradiation in rats saw fluctuating levels of MN over time[15] but that effect was not seen in this experiment. Calveley (in preparation) also saw a reduction of $\mathrm{MN}$ to background levels at the 28 weeks time point, but time course data was not collected. The ability of genistein to reduce $\mathrm{MN}$ formation at late times was similar in the rat single dose and mouse fractionated dose models.

The impact of genistein on the inflammatory response was also investigated. Genistein also reduced the macrophage content in lung tissue assessed by MAC3 staining by $\sim 22 \%$ and the deposition of collagen by $\sim 28 \%$ as assessed by Masson's Trichrome staining. However, protection against DNA damage and MN formation did not extend to significant protection against increases in breathing rate or decreased severe morbidity. Histology confirmed that animals that were sick in the 12-16 week time window had developed severe pneumonitis, and portions of the lung were completely obliterated by inflammatory infiltrate. Previous studies with genistein in our lab in rats monitored breathing rate (Figure 3.1, Calveley, in preparation) and survival (Figure 3.2 Calveley, in preparation) but did not examine histology except at 28 weeks PI. In rats following a single dose of radiation genistein reduced breathing rates during pneumonitis, but this 
effect was lost during fibrosis as breathing rates increased again. Genistein also increased the median survival time, most of the treated rats survived during pneumonitis, but later died during the fibrotic phase. Together these results show that Genistein is having an effect on the inflammatory response, but this effect was not significant enough to affect mortality. These results of previous work in rats are quite similar to those observed in this study. Further studies using higher doses of genistein may show larger protective effects. Studies of various doses of genistein following whole body irradiation showed a range of responses, with protection increasing according to doses up to $400 \mathrm{mg} / \mathrm{kg}$ without toxicity [145]. This supports the idea for future studies that an increase in dose may be required to have complete protection against severe pneumonitis and fibrosis causing lethality.

The timing of genistein doses is also important. Langan et al. [119] investigated the effects of delivering doses for shorter time periods following irradiation, and for longer sustained treatments. Langan et al. showed protective effects when given 1 or 2 weeks PI. Perhaps larger doses given for a shorter period of time following irradiation or at critical time periods, during pneumonitis, would provide more protection to the lung. However, other studies have shown that long term administration of protective agents provided protection but short term administration did not [94, 122]. The best timing for administration is still unclear. Other studies in our lab are investigating the effects of $\sim 50 \mathrm{mg} / \mathrm{kg}$ genistein delivered by implanted subcutaneous osmotic pumps for 12 weeks, and may provide more insight into this matter. A combination of agents, such as genistein plus EUK-189 may also produce synergistic effects. Higher doses of genistein 

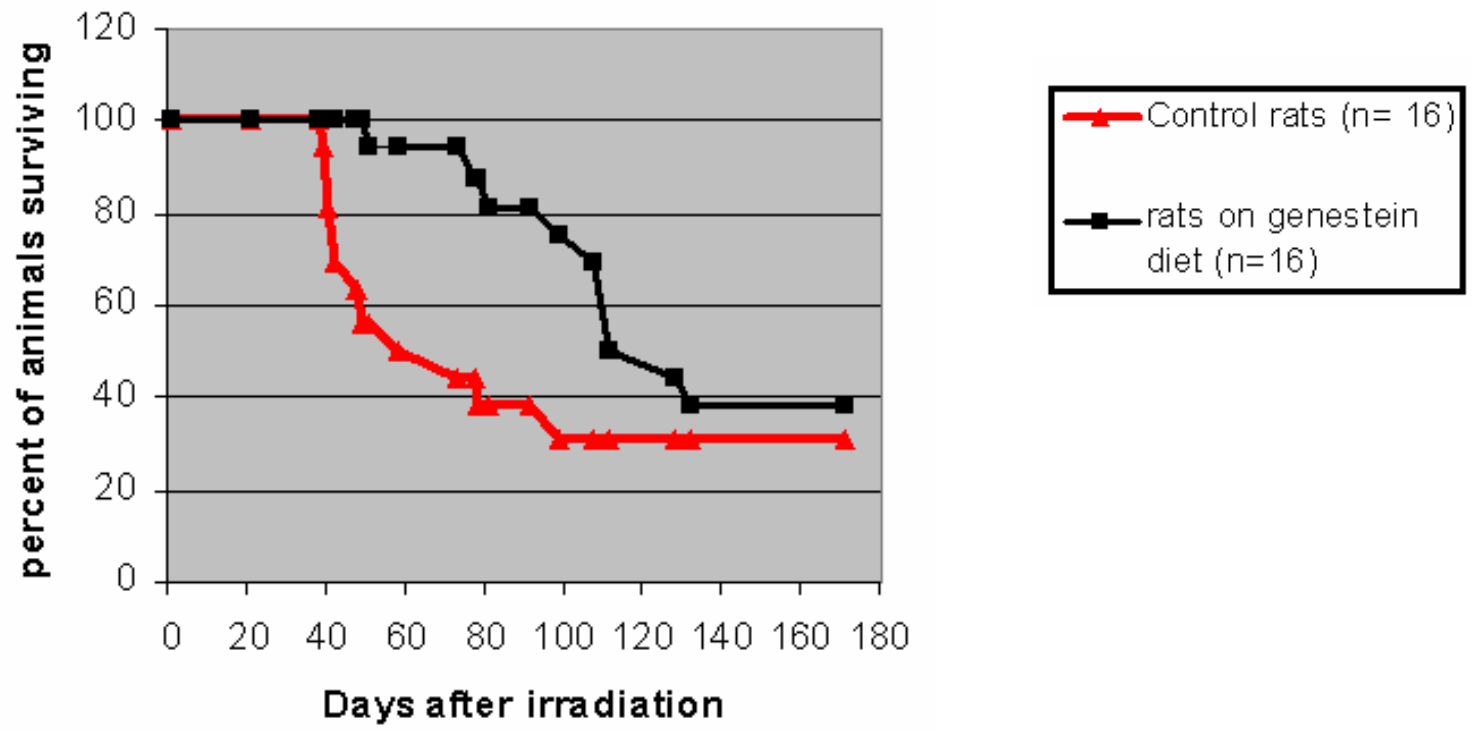

Figure 3-1: Survival data from previous experiments in rats, 18Gy Whole lung irradiation (Calveley, in preparation). Rats fed the genistein diet survived better than rats fed the control diet during pneumonitis but later succumbed to fibrosis. 


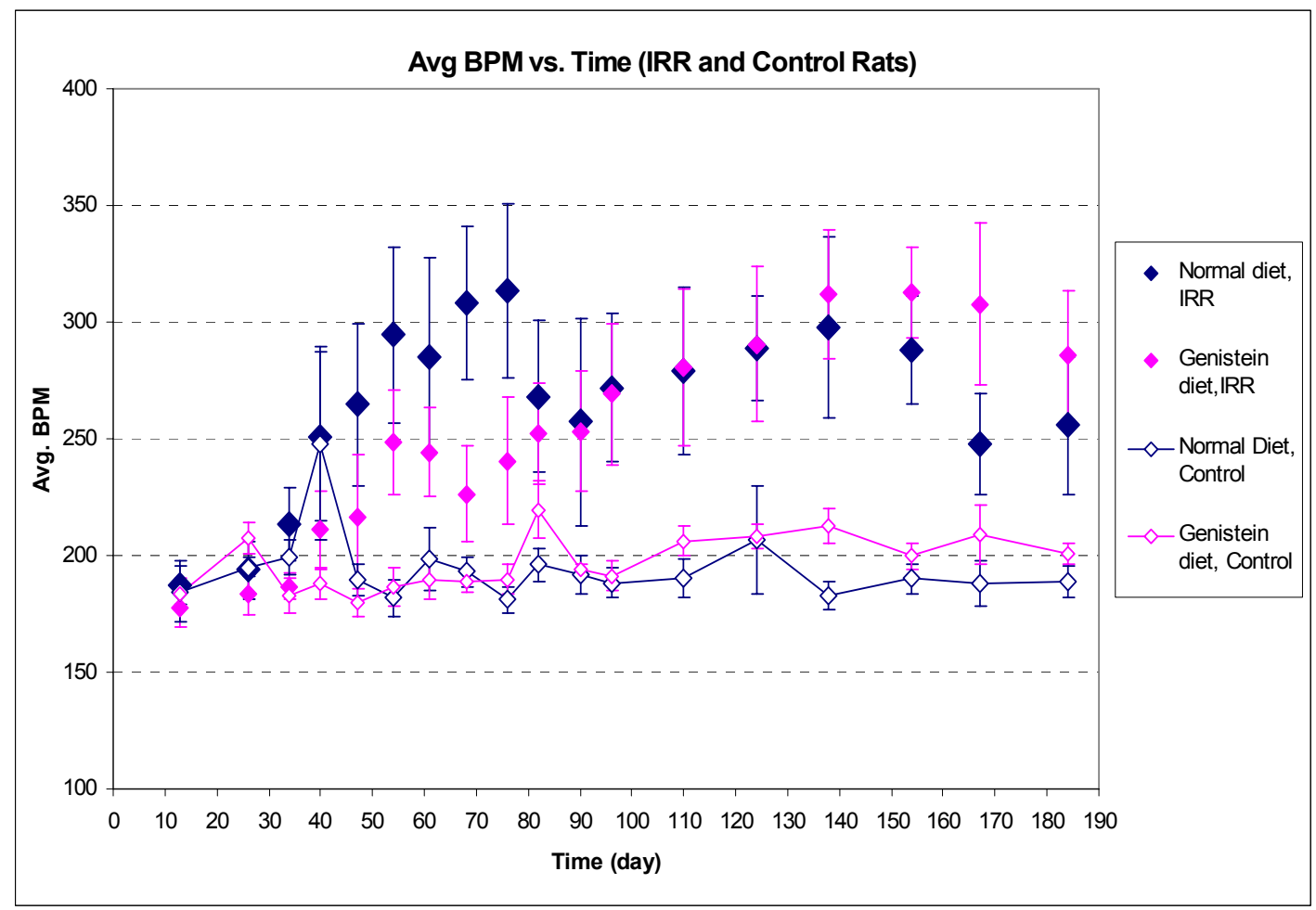

Figure 3-2: Breathing rate data from previous experiments in rats, 18Gy Whole lung irradiation (Calveley, in preparation). Genistein provided protection against early increases in breathing rate during pneumonitis, but this effect was lost later during fibrosis. 
may protect against pneumonitis while another agent may be given to protect against fibrosis.

Whenever any protective agent is given in combination with radiation therapy there is a concern that it may protect tumour as well. There is considerable debate as to whether to give antioxidants during radiotherapy [184-190]. There is concern that increasing the antioxidant capacity of cells, particularly tumor cells would lessen the effect of radiation that kills tumor cells via oxidative damage. However, this study showed that genistein did not impact upon tumor radiosensitivity in KHT tumors in vivo. This effect should be examined in other tumor models to ensure that this effect was not cell specific, and at higher doses of genistein. Several studies have also shown antimetastatic potential of anti-oxidants and genistein that would support their use during or after radiation therapy. The importance of timing doses would be important if they were as effective given after therapy as during then there would not be interaction directly with tumor cell kill during radiation.

\subsection{Future Directions}

The current study provided great insight into the effects of genistein following fractionated lung irradiation in mice. Genistein showed some protective effects against MN formation and inflammation, but future studies should investigate higher doses to try to provide complete protection and prevent lethality. The dose may be increased in the diet or supplemented with osmotic pumps, or injections. The increased dose may only need to be delivered during critical time periods, but the exact timing merits further investigation. If genistein proves to be more effective in blocking pneumonitis and not 
fibrosis then perhaps a combination with agents such as EUK-189 may have synergistic protective effects.

In this study tissue samples were taken at 4 week intervals that could be analyzed for RNA expression of various inflammatory cytokines. However, in rats Calveley (in preparation) did not see an effect of genistein using the same diet on cytokine expression in tissue samples except for TNF- $\alpha$. If genistein did not impact upon cytokine expression, high pro-inflammatory cytokine levels would still allow for perpetuation of the inflammatory response. Likely a larger dose of genistein may be required to impact upon cytokine levels as well as DNA damage.

Blood samples were also taken from the mice and are available to measure plasma concentration of genistein to confirm the expected calculated dose, and possibly compare with levels in rat plasma too. There may be differences in bioavailability of genistein between rats and mice, and between different strains of mice.

There is a disconnect between the levels of MN damage observed and the functional deficit and survival observed. The MN assay has been used previously to assess regional damage in lung quadrants, and provided great insight into out-of-field effects. In the current experiment there did not appear to be a correlation with the reduced MN formation and DNA damage in genistein-treated animals and increased survival. The MN assay may be reflective of ROS levels within the cell as opposed to levels of ROS produced by inflammation outside the cell which may play a larger role in the development of severe symptoms. Perhaps investigation of other assays of DNA or cell damage such as 8-oxoguanine or lipid peroxidation assays may provide 
measurements of oxidative damage that are more relevant to survival outcome than $\mathrm{MN}$ formation.

This study focused on inflammatory macrophages present in the lung tissue. Examining levels of macrophages and inflammatory mediators present in bronchiolar lavage fluid (BALF) may also provide insight into inflammatory processes and timing of expression following lung irradiation.

Genistein did not impact upon tumor response in KHT fibrosarcoma cells irradiated in situ. This effect should be examined at higher doses as well, and in other cell lines such as human lung carcinoma H460 to ensure that this effect is not cell type specific before applying this agent to clinical use. It is important that any therapeutic agent not interfere with the effectiveness of radiation killing of tumor cells.

\subsection{Conclusion}

Studies examining DNA damage, lung inflammation and protective agents are necessary to better understand the mechanisms of radiation-induced lung damage. Radiation pneumonitis and fibrosis are damaging side effects that limit the amount of radiation that can be delivered to treat cancer of the lung and surrounding tissues. This study examined the anti-oxidant and anti-inflammatory agent genistein to determine if blocking oxidative damage and the inflammatory response can impact upon the development of radiation pneumonitis and fibrosis. A greater understanding of the mechanisms leading to development of side effects is needed to successfully mitigate and treat them. Further work investigating the role of chronic oxidative stress and inflammation following lung irradiation will contribute to the development of therapies in 
this field to allow larger doses of radiation to be delivered to improve treatment outcomes. 


\section{References}

1. Canadian Cancer Society/National Cancer Institute of Canada-Canadian Cancer Statistics 2007. 2007 [cited; Available from: www.cancer.ca.

2. $\quad$ National Cancer Institute Fact Sheet. 2007.

3. MT Milano, LS Constine, and P Okunieff, Normal tissue tolerance dose metrics for radiation therapy of major organs. Semin Radiat Oncol, 2007. 17(2): p. 13140.

4. $\quad$ LB Marks, X Yu, Z Vujaskovic, W Small, Jr., R Folz, and MS Anscher, Radiation-induced lung injury. Semin Radiat Oncol, 2003. 13(3): p. 333-45.

5. E Hall, Radiobiology for the Radiobiologist. 5th ed. 2000, Philadelphia: Lippincott

6. A Burger, H Loffler,M Bamberg, H.P Rodemann, Molecular and cellular basis of radiation fibrosis. International Journal of Radiation Biology, 1998 73(4): p. 401408.

7. EL Travis, Organizational response of normal tissues to irradiation. Semin Radiat Oncol, 2001. 11(3): p. 184-96.

8. P Rubin, J Finkelstein, and D Shapiro, Molecular biology mechanisms in the radiation induction of pulmonary injury syndromes: interrelationship between the alveolar macrophage and the septal fibroblast. Int J Radiat Oncol Biol Phys, 1992. 24(1): p. 93-101.

9. HP Rodemann and M Bamberg, Cellular basis of radiation-induced fibrosis. Radiother Oncol, 1995. 35(2): p. 83-90.

10. P Rubin, CJ Johnston, JP Williams, S McDonald, and JN Finkelstein, A perpetual cascade of cytokines postirradiation leads to pulmonary fibrosis. Int J Radiat Oncol Biol Phys, 1995. 33(1): p. 99-109.

11. JH Hong, CS Chiang, CY Tsao, PY Lin, WH McBride, and CJ Wu, Rapid induction of cytokine gene expression in the lung after single and fractionated doses of radiation. Int J Radiat Biol, 1999. 75(11): p. 1421-7.

12. EJ Swindle, JA Hunt, and JW Coleman, A comparison of reactive oxygen species generation by rat peritoneal macrophages and mast cells using the highly sensitive real-time chemiluminescent probe pholasin: inhibition of antigeninduced mast cell degranulation by macrophage-derived hydrogen peroxide. $\mathrm{J}$ Immunol, 2002. 169(10): p. 5866-73.

13. ME Robbins and $\mathrm{W} Z$ Zhao, Chronic oxidative stress and radiation-induced late normal tissue injury: a review. Int J Radiat Biol, 2004. 80(4): p. 251-9.

14. W Zhao, DI Diz, and ME Robbins, Oxidative damage pathways in relation to normal tissue injury. Br J Radiol, 2007. 80 Spec No 1: p. S23-31.

15. VL Calveley, MA Khan, IWT Yeung, J Van Dyk, and RP Hill, Partial volume rat lung irradiation: Temporal fluctuations of in-field and out-of-field DNA damage and inflammatory cytokines following irradiation. International Journal of Radiation Biology, 2005. 81(12): p. 887 - 899. 
16. I Madani, K De Ruyck, H Goeminne, W De Neve, H Thierens, and J Van Meerbeeck, Predicting risk of radiation-induced lung injury. J Thorac Oncol, 2007. 2(9): p. 864-74.

17. E Scherer, C Streffer, K Trott, and W Alberti, Radiopathology of organs and tissues. 1991: Springer.

18. S McDonald, P Rubin, TL Phillips, and LB Marks, Injury to the lung from cancer therapy: clinical syndromes, measurable endpoints, and potential scoring systems. Int J Radiat Oncol Biol Phys, 1995. 31(5): p. 1187-203.

19. HB Stone, CN Coleman, MS Anscher, and WH McBride, Effects of radiation on normal tissue: consequences and mechanisms. Lancet Oncol, 2003. 4(9): p. 52936.

20. JN Finkelstein, CJ Johnston, R Baggs, and P Rubin, Early alterations in extracellular matrix and transforming growth factor beta gene expression in mouse lung indicative of late radiation fibrosis. Int J Radiat Oncol Biol Phys, 1994. 28(3): p. 621-31.

21. JW Hopewell and KR Trott, Volume effects in radiobiology as applied to radiotherapy. Radiother Oncol, 2000. 56(3): p. 283-8.

22. HR Withers, JM Taylor, and B Maciejewski, Treatment volume and tissue tolerance. Int J Radiat Oncol Biol Phys, 1988. 14(4): p. 751-9.

23. ZX Liao, EL Travis, and SL Tucker, Damage and morbidity from pneumonitis after irradiation of partial volumes of mouse lung. Int J Radiat Oncol Biol Phys, 1995. 32(5): p. 1359-70.

24. A Novakova-Jiresova, P van Luijk, H van Goor, HH Kampinga, and RP Coppes, Changes in expression of injury after irradiation of increasing volumes in rat lung. Int J Radiat Oncol Biol Phys, 2007. 67(5): p. 1510-8.

25. VA Semenenko, RC Molthen, C Li, NV Morrow, R Li, SN Ghosh, MM Medhora, and XA Li, Irradiation of varying volumes of rat lung to same mean lung dose: a little to a lot or a lot to a little? Int J Radiat Oncol Biol Phys, 2008. 71(3): p. 83847.

26. P Ghafoori, LB Marks, Z Vujaskovic, and CR Kelsey, Radiation-induced lung injury. Assessment, management, and prevention. Oncology (Williston Park), 2008. 22(1): p. 37-47; discussion 52-3.

27. MA Khan, J Van Dyk, IWT Yeung, and RP Hill, Partial volume rat lung irradiation; assessment of early DNA damage in different lung regions and effect of radical scavengers. Radiother Oncol, 2003. 66(1): p. 95-102.

28. MA Khan, RP Hill, and J Van Dyk, Partial volume rat lung irradiation: An evaluation of early DNA damage. Int J Radiat Oncol Biol Phys, 1998. 40(2): p. 467-476.

29. SL Tucker, Z-X Liao, and EL Travis, Estimation of the spatial distribution of target cells for radiation pneumonitis in mouse lung. Int J Radiat Oncol Biol Phys, 1997. 38(5): p. 1055-1066.

30. EL Travis, ZX Liao, and SL Tucker, Spatial heterogeneity of the volume effect for radiation pneumonitis in mouse lung. Int J Radiat Oncol Biol Phys, 1997. 38(5): p. 1045-54. 
31. M Yamada, S Kudoh, K Hirata, T Nakajima, and J Yoshikawa, Risk Factors of Pneumonitis Following Chemoradiotherapy for Lung Cancer. European Journal of Cancer, 1998. 34(1): p. 71-75.

32. S Wang, Z Liao, X Wei, HH Liu, SL Tucker, C-s Hu, R Mohan, JD Cox, and R Komaki, Analysis of clinical and dosimetric factors associated with treatmentrelated pneumonitis (TRP) in patients with non-small-cell lung cancer (NSCLC) treated with concurrent chemotherapy and three-dimensional conformal radiotherapy (3D-CRT). Int J Radiat Oncol Biol Phys, 2006. 66(5): p. 1399-1407.

33. ED Yorke, A Jackson, KE Rosenzweig, L Braban, SA Leibel, and CC Ling, Correlation of dosimetric factors and radiation pneumonitis for non-small-cell lung cancer patients in a recently completed dose escalation study. Int J Radiat Oncol Biol Phys, 2005. 63(3): p. 672-82.

34. A Novakova-Jiresova, P van Luijk, H van Goor, HH Kampinga, and RP Coppes, Pulmonary radiation injury: identification of risk factors associated with regional hypersensitivity. Cancer Res, 2005. 65(9): p. 3568-76.

35. P van Luijk, A Novakova-Jiresova, H Faber, JM Schippers, HH Kampinga, H Meertens, and RP Coppes, Radiation damage to the heart enhances early radiation-induced lung function loss. Cancer Res, 2005. 65(15): p. 6509-11.

36. VV Moiseenko, JJ Battista, RP Hill, EL Travis, and J Van Dyk, In-field and outof-field effects in partial volume lung irradiation in rodents: Possible correlation between early dna damage and functional endpoints. Int J Radiat Oncol Biol Phys, 2000. 48(5): p. 1539-1548.

37. GD Wilson, Cell kinetics. Clin Oncol (R Coll Radiol), 2007. 19(6): p. 370-84.

38. J Van Dyk, K Mah, and TJ Keane, Radiation-induced lung damage: dose-timefractionation considerations. Radiother Oncol, 1989. 14(1): p. 55-69.

39. CK Haston, RP Hill, CH Newcomb, and J Van Dyk, Radiation-induced lung damage in rats: the influence of fraction spacing on effect per fraction. Int $\mathbf{J}$ Radiat Oncol Biol Phys, 1994. 28(3): p. 633-40.

40. CH Newcomb, J Van Dyk, and RP Hill, Evaluation of isoeffect formulae for predicting radiation-induced lung damage. Radiother Oncol, 1993. 26(1): p. 5163.

41. K Mah, J Van Dyk, T Keane, and PY Poon, Acute radiation-induced pulmonary damage: a clinical study on the response to fractionated radiation therapy. Int $\mathrm{J}$ Radiat Oncol Biol Phys, 1987. 13(2): p. 179-88.

42. PG Giri, BF Kimler, UP Giri, GG Cox, and EK Reddy, Comparison of single, fractionated and hyperfractionated irradiation on the development of normal tissue damage in rat lung. Int J Radiat Oncol Biol Phys, 1985. 11(3): p. 527-34.

43. JD Down, NJ Tarbell, M Warhol, and P Mauch, Dose-limiting complications from upper half body irradiation in C3H mice. Int J Radiat Oncol Biol Phys, 1988. 14(3): p. 483-9.

44. CE Rube, F Wilfert, J Palm, J Konig, S Burdak-Rothkamm, L Liu, A Schuck, N Willich, and C Rube, Irradiation induces a biphasic expression of proinflammatory cytokines in the lung. Strahlenther Onkol, 2004. 180(7): p. 442-8.

45. JP Williams, E Hernady, CJ Johnston, CM Reed, B Fenton, P Okunieff, and JN Finkelstein, Effect of administration of lovastatin on the development of late 
pulmonary effects after whole-lung irradiation in a murine model. Radiat Res, 2004. 161(5): p. 560-7.

46. L Papiez and $\mathrm{R}$ Timmerman, Hypofractionation in radiation therapy and its impact. Med Phys, 2008. 35(1): p. 112-8.

47. DE Hallahan and S Virudachalam, Intercellular adhesion molecule 1 knockout abrogates radiation induced pulmonary inflammation. Proc Natl Acad Sci U S A, 1997. 94(12): p. 6432-7.

48. CL Fattman, LY Chang, TA Termin, L Petersen, JJ Enghild, and TD Oury, Enhanced bleomycin-induced pulmonary damage in mice lacking extracellular superoxide dismutase. Free Radic Biol Med, 2003. 35(7): p. 763-71.

49. JHG Cranshaw, M.J.D., Inflammatory processes in the acute respiratory distress syndrome. Current Anaesthesia and Critical Care, 2003. 14(2): p. 66-73.

50. M Bhatia and S Moochhala, Role of inflammatory mediators in the pathophysiology of acute respiratory distress syndrome. J Pathol, 2004. 202(2): p. 145-56.

51. AB Weinacker and LT Vaszar, Acute respiratory distress syndrome: physiology and new management strategies. Annu Rev Med, 2001. 52: p. 221-37.

52. JL Balibrea and J Arias-Diaz, Acute respiratory distress syndrome in the septic surgical patient. World J Surg, 2003. 27(12): p. 1275-84.

53. TS Blackwell and JW Christman, The role of nuclear factor-kappa B in cytokine gene regulation. Am J Respir Cell Mol Biol, 1997. 17(1): p. 3-9.

54. P Wang, P Wu, MI Siegel, RW Egan, and MM Billah, Interleukin (IL)-10 inhibits nuclear factor kappa B (NF kappa B) activation in human monocytes. IL-10 and IL-4 suppress cytokine synthesis by different mechanisms. J Biol Chem, 1995. 270(16): p. 9558-63.

55. M Nys, G Deby-Dupont, Y Habraken, S Legrand-Poels, S Kohnen, D Ledoux, JL Canivet, P Damas, and M Lamy, Bronchoalveolar lavage fluids of ventilated patients with acute lung injury activate NF-kappaB in alveolar epithelial cell line: role of reactive oxygen/nitrogen species and cytokines. Nitric Oxide, 2003. 9(1): p. 33-43.

56. WY Park, RB Goodman, KP Steinberg, JT Ruzinski, F Radella, 2nd, DR Park, J Pugin, SJ Skerrett, LD Hudson, and TR Martin, Cytokine balance in the lungs of patients with acute respiratory distress syndrome. Am J Respir Crit Care Med, 2001. 164(10 Pt 1): p. 1896-903.

57. TM Siler, JE Swierkosz, TM Hyers, AA Fowler, and RO Webster, Immunoreactive interleukin-1 in bronchoalveolar lavage fluid of high-risk patients and patients with the adult respiratory distress syndrome. Exp Lung Res, 1989. 15(6): p. 881-94.

58. RB Goodman, RM Strieter, DP Martin, KP Steinberg, JA Milberg, RJ Maunder, SL Kunkel, A Walz, LD Hudson, and TR Martin, Inflammatory cytokines in patients with persistence of the acute respiratory distress syndrome. Am J Respir Crit Care Med, 1996. 154(3 Pt 1): p. 602-11.

59. GU Meduri, G Kohler, S Headley, E Tolley, F Stentz, and A Postlethwaite, Inflammatory cytokines in the BAL of patients with ARDS. Persistent elevation over time predicts poor outcome. Chest, 1995. 108(5): p. 1303-14. 
60. FJ Wiedermann, AJ Mayr, P Hobisch-Hagen, D Fuchs, and W Schobersberger, Association of endogenous G-CSF with anti-inflammatory mediators in patients with acute respiratory distress syndrome. J Interferon Cytokine Res, 2003. 23(12): p. 729-36.

61. R Fudala, A Krupa, D Stankowska, TC Allen, and AK Kurdowska, Antiinterleukin-8 autoantibody:interleukin-8 immune complexes in acute lung injury/acute respiratory distress syndrome. Clin Sci (Lond), 2008. 114(6): p. 40312.

62. CJ Lo, M Fu, and HG Cryer, Interleukin 10 inhibits alveolar macrophage production of inflammatory mediators involved in adult respiratory distress syndrome. J Surg Res, 1998. 79(2): p. 179-84.

63. L Armstrong and AB Millar, Relative production of tumour necrosis factor alpha and interleukin 10 in adult respiratory distress syndrome. Thorax, 1997. 52(5): p. 442-6.

64. H Schmal, BJ Czermak, AB Lentsch, NM Bless, B Beck-Schimmer, HP Friedl, and PA Ward, Soluble ICAM-1 activates lung macrophages and enhances lung injury. J Immunol, 1998. 161(7): p. 3685-93.

65. D Hallahan, J Kuchibhotla, and C Wyble, Cell adhesion molecules mediate radiation-induced leukocyte adhesion to the vascular endothelium. Cancer Res, 1996. 56(22): p. 5150-5.

66. K Tsujino, A Kodama, N Kanaoka, T Maruta, and M Kono, Expression of pulmonary $m R N A$ encoding ICAM-1, VCAM-1, and P-selectin following thoracic irradiation in mice. Radiat Med, 1999. 17(4): p. 283-7.

67. Y Ishii and S Kitamura, Soluble intercellular adhesion molecule-1 as an early detection marker for radiation pneumonitis. Eur Respir J, 1999. 13(4): p. 733-8.

68. A Kawana, S Shioya, H Katoh, C Tsuji, M Tsuda, and Y Ohta, Expression of intercellular adhesion molecule-1 and lymphocyte function-associated antigen-1 on alveolar macrophages in the acute stage of radiation-induced lung injury in rats. Radiat Res, 1997. 147(4): p. 431-6.

69. DE Hallahan, L Geng, and Y Shyr, Effects of intercellular adhesion molecule 1 (ICAM-1) null mutation on radiation-induced pulmonary fibrosis and respiratory insufficiency in mice. J Natl Cancer Inst, 2002. 94(10): p. 733-41.

70. CJ Johnston, JP Williams, A Elder, E Hernady, and JN Finkelstein, Inflammatory cell recruitment following thoracic irradiation. Exp Lung Res, 2004. 30(5): p. 369-82.

71. C Linard, C Marquette, J Mathieu, A Pennequin, D Clarencon, and D Mathe, Acute induction of inflammatory cytokine expression after gamma-irradiation in the rat: effect of an NF-kappaB inhibitor. Int J Radiat Oncol Biol Phys, 2004. 58(2): p. 427-34.

72. CE Rube, F Wilfert, D Uthe, KW Schmid, R Knoop, N Willich, A Schuck, and C Rube, Modulation of radiation-induced tumour necrosis factor alpha (TNFalpha) expression in the lung tissue by pentoxifylline. Radiother Oncol, 2002. 64(2): p. 177-87.

73. CE Rube, D Uthe, KW Schmid, KD Richter, J Wessel, A Schuck, N Willich, and $\mathrm{C}$ Rube, Dose-dependent induction of transforming growth factor beta (TGF- 
beta) in the lung tissue of fibrosis-prone mice after thoracic irradiation. Int $\mathrm{J}$ Radiat Oncol Biol Phys, 2000. 47(4): p. 1033-42.

74. CE Rube, D Uthe, F Wilfert, D Ludwig, K Yang, J Konig, J Palm, A Schuck, N Willich, K Remberger, and C Rube, The bronchiolar epithelium as a prominent source of pro-inflammatory cytokines after lung irradiation. Int J Radiat Oncol Biol Phys, 2005. 61(5): p. 1482-92.

75. MW Epperly, CA Sikora, SJ DeFilippi, JE Gretton, D Bar-Sagi, H Archer, T Carlos, H Guo, and JS Greenberger, Pulmonary irradiation-induced expression of VCAM-I and ICAM-I is decreased by manganese superoxide dismutaseplasmid/liposome (MnSOD-PL) gene therapy. Biol Blood Marrow Transplant, 2002. 8(4): p. 175-87.

76. JP Hart, G Broadwater, Z Rabbani, BJ Moeller, R Clough, D Huang, GA Sempowski, M Dewhirst, SV Pizzo, Z Vujaskovic, and MS Anscher, Cytokine profiling for prediction of symptomatic radiation-induced lung injury. Int J Radiat Oncol Biol Phys, 2005. 63(5): p. 1448-54.

77. CJ Johnston, B Piedboeuf, P Rubin, JP Williams, R Baggs, and JN Finkelstein, Early and persistent alterations in the expression of interleukin-1 alpha, interleukin-1 beta and tumor necrosis factor alpha mRNA levels in fibrosisresistant and sensitive mice after thoracic irradiation. Radiat Res, 1996. 145(6): p. 762-7.

78. AJ Franko, J Sharplin, WF Ward, and JM Hinz, The genetic basis of straindependent differences in the early phase of radiation injury in mouse lung. Radiat Res, 1991. 126(3): p. 349-56.

79. CK Haston and EL Travis, Murine susceptibility to radiation-induced pulmonary fibrosis is influenced by a genetic factor implicated in susceptibility to bleomycininduced pulmonary fibrosis. Cancer Res, 1997. 57(23): p. 5286-91.

80. CK Haston, X Zhou, L Gumbiner-Russo, R Irani, R Dejournett, X Gu, M Weil, CI Amos, and EL Travis, Universal and radiation-specific loci influence murine susceptibility to radiation-induced pulmonary fibrosis. Cancer Res, 2002. 62(13): p. 3782-8.

81. TJ O'Brien, S Letuve, and CK Haston, Radiation-induced strain differences in mouse alveolar inflammatory cell apoptosis. Can J Physiol Pharmacol, 2005. 83(1): p. 117-22.

82. CK Haston, M Begin, G Dorion, and SM Cory, Distinct loci influence radiationinduced alveolitis from fibrosing alveolitis in the mouse. Cancer Res, 2007. 67(22): p. 10796-803.

83. WF Ward, J Sharplin, AJ Franko, and JM Hinz, Radiation-induced pulmonary endothelial dysfunction and hydroxyproline accumulation in four strains of mice. Radiat Res, 1989. 120(1): p. 113-20.

84. CJ Johnston, TW Wright, P Rubin, and JN Finkelstein, Alterations in the expression of chemokine $m R N A$ levels in fibrosis-resistant and-sensitive mice after thoracic irradiation. Exp Lung Res, 1998. 24(3): p. 321-37.

85. AJ Franko, J Sharplin, WF Ward, and JM Taylor, Evidence for two patterns of inheritance of sensitivity to induction of lung fibrosis in mice by radiation, one of which involves two genes. Radiat Res, 1996. 146(1): p. 68-74. 
86. EL Travis, Genetic susceptibility to late normal tissue injury. Semin Radiat Oncol, 2007. 17(2): p. 149-55.

87. CL Dileto and EL Travis, Fibroblast radiosensitivity in vitro and lung fibrosis in vivo: comparison between a fibrosis-prone and fibrosis-resistant mouse strain. Radiat Res, 1996. 146(1): p. 61-7.

88. WH McBride, Cytokine cascades in late normal tissue radiation responses. Int $\mathrm{J}$ Radiat Oncol Biol Phys, 1995. 33(1): p. 233-4.

89. ZN Rabbani, MS Anscher, X Zhang, L Chen, TV Samulski, CY Li, and Z Vujaskovic, Soluble TGFbeta type II receptor gene therapy ameliorates acute radiation-induced pulmonary injury in rats. Int J Radiat Oncol Biol Phys, 2003. 57(2): p. 563-72.

90. MS Anscher, FM Kong, K Andrews, R Clough, LB Marks, G Bentel, and RL Jirtle, Plasma transforming growth factor betal as a predictor of radiation pneumonitis. Int J Radiat Oncol Biol Phys, 1998. 41(5): p. 1029-35.

91. MS Anscher, FM Kong, and RL Jirtle, The relevance of transforming growth factor beta 1 in pulmonary injury after radiation therapy. Lung Cancer, 1998. 19(2): p. 109-20.

92. MS Anscher, FM Kong, LB Marks, GC Bentel, and RL Jirtle, Changes in plasma transforming growth factor beta during radiotherapy and the risk of symptomatic radiation-induced pneumonitis. Int J Radiat Oncol Biol Phys, 1997. 37(2): p. 2538.

93. MH Barcellos-Hoff and AL Brooks, Extracellular signaling through the microenvironment: a hypothesis relating carcinogenesis, bystander effects, and genomic instability. Radiat Res, 2001. 156(5 Pt 2): p. 618-27.

94. MS Anscher, B Thrasher, L Zgonjanin, ZN Rabbani, MJ Corbley, K Fu, L Sun, WC Lee, LE Ling, and Z Vujaskovic, Small molecular inhibitor of transforming growth factor-beta protects against development of radiation-induced lung injury. Int J Radiat Oncol Biol Phys, 2008. 71(3): p. 829-37.

95. C Linard, A Ropenga, MC Vozenin-Brotons, A Chapel, and D Mathe, Abdominal irradiation increases inflammatory cytokine expression and activates $N F-k a p p a B$ in rat ileal muscularis layer. Am J Physiol Gastrointest Liver Physiol, 2003. 285(3): p. G556-65.

96. A Beetz, RU Peter, T Oppel, W Kaffenberger, RA Rupec, M Meyer, D van Beuningen, $\mathrm{P}$ Kind, and G Messer, NF-kappaB and AP-1 are responsible for inducibility of the IL-6 promoter by ionizing radiation in HeLa cells. Int J Radiat Biol, 2000. 76(11): p. 1443-53.

97. MG Haase, A Klawitter, P Geyer, H Alheit, M Baumann, TM Kriegel, M Kasper, and GB Baretton, Sustained elevation of NF-kappaB DNA binding activity in radiation-induced lung damage in rats. Int J Radiat Biol, 2003. 79(11): p. 863-77.

98. D Zhou, SA Brown, T Yu, G Chen, S Barve, BC Kang, and JS Thompson, A high dose of ionizing radiation induces tissue-specific activation of nuclear factorkappaB in vivo. Radiat Res, 1999. 151(6): p. 703-9.

99. JE White, HY Lin, FB Davis, PJ Davis, and MF Tsan, Differential induction of tumor necrosis factor alpha and manganese superoxide dismutase by endotoxin in human monocytes: role of protein tyrosine kinase, mitogen-activated protein kinase, and nuclear factor kappaB. J Cell Physiol, 2000. 182(3): p. 381-9. 
100. P Renard and M Raes, The proinflammatory transcription factor NFkappaB: a potential target for novel therapentical strategies. Cell Biol Toxicol, 1999. 15(6): p. 341-4.

101. A Meng, T Yu, G Chen, SA Brown, Y Wang, JS Thompson, and D Zhou, Cellular origin of ionizing radiation-induced NF-kappaB activation in vivo and role of NF-kappaB in ionizing radiation-induced lymphocyte apoptosis. Int $\mathbf{J}$ Radiat Biol, 2003. 79(11): p. 849-61.

102. A Bowie and LA O'Neill, Oxidative stress and nuclear factor-kappaB activation: a reassessment of the evidence in the light of recent discoveries. Biochem Pharmacol, 2000. 59(1): p. 13-23.

103. J Fan, RD Ye, and AB Malik, Transcriptional mechanisms of acute lung injury. Am J Physiol Lung Cell Mol Physiol, 2001. 281(5): p. L1037-50.

104. K Enesa, K Ito, A Luong le, I Thorbjornsen, C Phua, Y To, J Dean, DO Haskard, J Boyle, I Adcock, and PC Evans, Hydrogen peroxide prolongs nuclear localization of NF-kappaB in activated cells by suppressing negative regulatory mechanisms. J Biol Chem, 2008. 283(27): p. 18582-90.

105. CH Lee, YT Jeon, SH Kim, and YS Song, NF-kappaB as a potential molecular target for cancer therapy. Biofactors, 2007. 29(1): p. 19-35.

106. WF Morgan and MB Sowa, Non-targeted bystander effects induced by ionizing radiation. Mutat Res, 2007. 616(1-2): p. 159-64.

107. N Hamada, H Matsumoto, T Hara, and Y Kobayashi, Intercellular and intracellular signaling pathways mediating ionizing radiation-induced bystander effects. J Radiat Res (Tokyo), 2007. 48(2): p. 87-95.

108. WF Morgan, Is there a common mechanism underlying genomic instability, bystander effects and other nontargeted effects of exposure to ionizing radiation? Oncogene, 2003. 22(45): p. 7094-9.

109. M Pollycove and LE Feinendegen, Radiation-induced versus endogenous DNA damage: possible effect of inducible protective responses in mitigating endogenous damage. Hum Exp Toxicol, 2003. 22(6): p. 290-306; discussion 307, 315-7, 319-23.

110. N Azad, Y Rojanasakul, and V Vallyathan, Inflammation and lung cancer: roles of reactive oxygen/nitrogen species. J Toxicol Environ Health B Crit Rev, 2008. 11(1): p. 1-15.

111. D Salvemini, DP Riley, and S Cuzzocrea, SOD mimetics are coming of age. Nat Rev Drug Discov, 2002. 1(5): p. 367-74.

112. JA Cook, D Gius, DA Wink, MC Krishna, A Russo, and JB Mitchell, Oxidative stress, redox, and the tumor microenvironment. Semin Radiat Oncol, 2004. 14(3): p. 259-66.

113. D Salvemini, C Muscoli, DP Riley, and S Cuzzocrea, Superoxide dismutase mimetics. Pulm Pharmacol Ther, 2002. 15(5): p. 439-47.

114. F Gao, VL Kinnula, M Myllarniemi, and TD Oury, Extracellular superoxide dismutase in pulmonary fibrosis. Antioxid Redox Signal, 2008. 10(2): p. 343-54.

115. SK Kang, ZN Rabbani, RJ Folz, ML Golson, H Huang, D Yu, TS Samulski, MW Dewhirst, MS Anscher, and Z Vujaskovic, Overexpression of extracellular superoxide dismutase protects mice from radiation-induced lung injury. Int J Radiat Oncol Biol Phys, 2003. 57(4): p. 1056-66. 
116. ZN Rabbani, MS Anscher, RJ Folz, E Archer, H Huang, L Chen, ML Golson, TS Samulski, MW Dewhirst, and Z Vujaskovic, Overexpression of extracellular superoxide dismutase reduces acute radiation induced lung toxicity. BMC Cancer, 2005. 5(1): p. 59.

117. M Epperly, J Bray, S Kraeger, R Zwacka, J Engelhardt, E Travis, and J Greenberger, Prevention of late effects of irradiation lung damage by manganese superoxide dismutase gene therapy. Gene Ther, 1998. 5(2): p. 196-208.

118. MW Epperly, JA Bray, S Krager, LM Berry, W Gooding, JF Engelhardt, R Zwacka, EL Travis, and JS Greenberger, Intratracheal injection of adenovirus containing the human MnSOD transgene protects athymic nude mice from irradiation-induced organizing alveolitis. Int J Radiat Oncol Biol Phys, 1999. 43(1): p. 169-81.

119. AR Langan, MA Khan, IW Yeung, J Van Dyk, and RP Hill, Partial volume rat lung irradiation: the protective/mitigating effects of Eukarion-189, a superoxide dismutase-catalase mimetic. Radiother Oncol, 2006. 79(2): p. 231-8.

120. Z Vujaskovic, I Batinic-Haberle, ZN Rabbani, Q-f Feng, SK Kang, I Spasojevic, TV Samulski, I Fridovich, MW Dewhirst, and MS Anscher, A small molecular weight catalytic metalloporphyrin antioxidant with superoxide dismutase (SOD) mimetic properties protects lungs from radiation-induced injury. Free Radical Biology and Medicine, 2002. 33(6): p. 857-863.

121. ZN Rabbani, FK Salahuddin, P Yarmolenko, I Batinic-Haberle, BA Thrasher, B Gauter-Fleckenstein, MW Dewhirst, MS Anscher, and Z Vujaskovic, Low molecular weight catalytic metalloporphyrin antioxidant AEOL 10150 protects lungs from fractionated radiation. Free Radic Res, 2007. 41(11): p. 1273-82.

122. ZN Rabbani, I Batinic-Haberle, MS Anscher, J Huang, BJ Day, E Alexander, MW Dewhirst, and Z Vujaskovic, Long-term administration of a small molecular weight catalytic metalloporphyrin antioxidant, AEOL 10150, protects lungs from radiation-induced injury. Int J Radiat Oncol Biol Phys, 2007. 67(2): p. 573-80.

123. B Gauter-Fleckenstein, K Fleckenstein, K Owzar, C Jiang, I Batinic-Haberle, and Z Vujaskovic, Comparison of two Mn porphyrin-based mimics of superoxide dismutase in pulmonary radioprotection. Free Radic Biol Med, 2008. 44(6): $\mathrm{p}$. 982-9.

124. Z Vujaskovic, QF Feng, ZN Rabbani, MS Anscher, TV Samulski, and DM Brizel, Radioprotection of lungs by amifostine is associated with reduction in profibrogenic cytokine activity. Radiat Res, 2002. 157(6): p. 656-60.

125. Z Vujaskovic, QF Feng, ZN Rabbani, TV Samulski, MS Anscher, and DM Brizel, Assessment of the protective effect of amifostine on radiation-induced pulmonary toxicity. Exp Lung Res, 2002. 28(7): p. 577-90.

126. EL Travis, CS Parkins, SJ Holmes, JD Down, and JF Fowler, WR-2721 protection of pneumonitis and fibrosis in mouse lung after single doses of $x$ rays. Int J Radiat Oncol Biol Phys, 1984. 10(2): p. 243-51.

127. EL Travis, RA Newman, and SJ Helbing, WR 2721 modification of type II cell and endothelial cell function in mouse lung after single doses of radiation. Int $\mathrm{J}$ Radiat Oncol Biol Phys, 1987. 13(9): p. 1355-9. 
128. WF Ward, A Molteni, CH Ts'ao, and JM Hinz, Captopril reduces collagen and mast cell accumulation in irradiated rat lung. Int J Radiat Oncol Biol Phys, 1990. 19(6): p. 1405-9.

129. WF Ward, A Molteni, CH Ts'ao, YT Kim, and JM Hinz, Radiation pneumotoxicity in rats: modification by inhibitors of angiotensin converting enzyme. Int J Radiat Oncol Biol Phys, 1992. 22(3): p. 623-5.

130. WF Ward, PJ Lin, PS Wong, R Behnia, and N Jalali, Radiation pneumonitis in rats and its modification by the angiotensin-converting enzyme inhibitor captopril evaluated by high-resolution computed tomography. Radiat Res, 1993. 135(1): $\mathrm{p}$. 81-7.

131. L Nguyen, WF Ward, CH Ts'ao, and A Molteni, Captopril inhibits proliferation of human lung fibroblasts in culture: a potential antifibrotic mechanism. Proc Soc Exp Biol Med, 1994. 205(1): p. 80-4.

132. EP Cohen, A Molteni, P Hill, BL Fish, WF Ward, JE Moulder, and FA Carone, Captopril preserves function and ultrastructure in experimental radiation nephropathy. Lab Invest, 1996. 75(3): p. 349-60.

133. A Molteni, JE Moulder, EF Cohen, WF Ward, BL Fish, JM Taylor, LF Wolfe, L Brizio-Molteni, and P Veno, Control of radiation-induced pneumopathy and lung fibrosis by angiotensin-converting enzyme inhibitors and an angiotensin II type 1 receptor blocker. Int J Radiat Biol, 2000. 76(4): p. 523-32.

134. B Ozturk, I Egehan, S Atavci, and M Kitapci, Pentoxifylline in prevention of radiation-induced lung toxicity in patients with breast and lung cancer: a doubleblind randomized trial. Int J Radiat Oncol Biol Phys, 2004. 58(1): p. 213-9.

135. WF Ward, YT Kim, A Molteni, C Ts'ao, and JM Hinz, Pentoxifylline does not spare acute radiation reactions in rat lung and skin. Radiat Res, 1992. 129(1): $\mathrm{p}$. $107-11$.

136. WJ Koh, KJ Stelzer, LM Peterson, BL Staker, WF Ward, KJ Russell, and TW Griffin, Effect of pentoxifylline on radiation-induced lung and skin toxicity in rats. Int J Radiat Oncol Biol Phys, 1995. 31(1): p. 71-7.

137. L Zhao, K Sheldon, M Chen, MS Yin, JA Hayman, GP Kalemkerian, D Arenberg, SE Lyons, JL Curtis, M Davis, KB Cease, D Brenner, MS Anscher, TS Lawrence, and FM Kong, The predictive role of plasma TGF-betal during radiation therapy for radiation-induced lung toxicity deserves further study in patients with non-small cell lung cancer. Lung Cancer, 2008. 59(2): p. 232-9.

138. JF Weiss and MR Landauer, Protection against ionizing radiation by antioxidant nutrients and phytochemicals. Toxicology, 2003. 189(1-2): p. 1-20.

139. FH Sarkar and Y Li, Soy isoflavones and cancer prevention. Cancer Invest, 2003. 21(5): p. 744-57.

140. I Kruk, HY Aboul-Enein, T Michalska, K Lichszteld, and A Kladna, Scavenging of reactive oxygen species by the plant phenols genistein and oleuropein. Luminescence, 2005. 20(2): p. 81-9.

141. JL Kang, HW Lee, HS Lee, IS Pack, Y Chong, V Castranova, and Y Koh, Genistein prevents nuclear factor-kappa B activation and acute lung injury induced by lipopolysaccharide. Am J Respir Crit Care Med, 2001. 164(12): p. 2206-12. 
142. JL Kang, HW Lee, HS Lee, IS Pack, V Castranova, and Y Koh, Time course for inhibition of lipopolysaccharide-induced lung injury by genistein: relationship to alteration in nuclear factor-kappaB activity and inflammatory agents. Crit Care Med, 2003. 31(2): p. 517-24.

143. C Choi, H Cho, J Park, C Cho, and Y Song, Suppressive effects of genistein on oxidative stress and NFkappaB activation in RAW 264.7 macrophages. Biosci Biotechnol Biochem, 2003. 67(9): p. 1916-22.

144. O Tabary, S Escotte, JP Couetil, D Hubert, D Dusser, E Puchelle, and J Jacquot, Genistein inhibits constitutive and inducible NFkappaB activation and decreases IL-8 production by human cystic fibrosis bronchial gland cells. Am J Pathol, 1999. 155(2): p. 473-81.

145. MR Landauer, V Srinivasan, and TM Seed, Genistein treatment protects mice from ionizing radiation injury. J Appl Toxicol, 2003. 23(6): p. 379-85.

146. MH Ravindranath, S Muthugounder, N Presser, and S Viswanathan, Anticancer therapeutic potential of soy isoflavone, genistein. Adv Exp Med Biol, 2004. 546: p. 121-65.

147. $\mathrm{AH} \mathrm{Wu}, \mathrm{MC} \mathrm{Yu}, \mathrm{CC}$ Tseng, and MC Pike, Epidemiology of soy exposures and breast cancer risk. Br J Cancer, 2008. 98(1): p. 9-14.

148. GA Sonn, W Aronson, and MS Litwin, Impact of diet on prostate cancer: $a$ review. Prostate Cancer Prostatic Dis, 2005. 8(4): p. 304-10.

149. SA Vantyghem, SM Wilson, CO Postenka, W Al-Katib, AB Tuck, and AF Chambers, Dietary genistein reduces metastasis in a postsurgical orthotopic breast cancer model. Cancer Res, 2005. 65(8): p. 3396-403.

150. M Lakshman, L Xu, V Ananthanarayanan, J Cooper, CH Takimoto, I Helenowski, JC Pelling, and RC Bergan, Dietary genistein inhibits metastasis of human prostate cancer in mice. Cancer Res, 2008. 68(6): p. 2024-32.

151. GG Hillman, Y Wang, O Kucuk, M Che, DR Doerge, M Yudelev, MC Joiner, B Marples, JD Forman, and FH Sarkar, Genistein potentiates inhibition of tumor growth by radiation in a prostate cancer orthotopic model. Mol Cancer Ther, 2004. 3(10): p. 1271-9.

152. H Yamashita, K Nakagawa, N Nakamura, H Koyanagi, M Tago, H Igaki, K Shiraishi, N Sasano, and K Ohtomo, Exceptionally high incidence of symptomatic grade 2-5 radiation pneumonitis after stereotactic radiation therapy for lung tumors. Radiat Oncol, 2007. 2: p. 21.

153. G Rodrigues, M Lock, D D'Souza, E Yu, and J Van Dyk, Prediction of radiation pneumonitis by dose-volume histogram parameters in lung cancer--a systematic review. Radiother Oncol, 2004. 71(2): p. 127-138.

154. JD Bradley, A Hope, I El Naqa, A Apte, PE Lindsay, W Bosch, J Matthews, W Sause, MV Graham, and JO Deasy, A nomogram to predict radiation pneumonitis, derived from a combined analysis of RTOG 9311 and institutional data. Int J Radiat Oncol Biol Phys, 2007. 69(4): p. 985-92.

155. Z Kocak, GR Borst, J Zeng, S Zhou, DR Hollis, J Zhang, ES Evans, RJ Folz, T Wong, D Kahn, JS Belderbos, JV Lebesque, and LB Marks, Prospective assessment of dosimetric/physiologic-based models for predicting radiation pneumonitis. Int J Radiat Oncol Biol Phys, 2007. 67(1): p. 178-86. 
156. DE Hallahan and S Virudachalam, Ionizing radiation mediates expression of cell adhesion molecules in distinct histological patterns within the lung. Cancer Res, 1997. 57(11): p. 2096-9.

157. CJ Johnston, B Piedboeuf, R Baggs, P Rubin, and JN Finkelstein, Differences in correlation of mRNA gene expression in mice sensitive and resistant to radiationinduced pulmonary fibrosis. Radiat Res, 1995. 142(2): p. 197-203.

158. EM Wiegman, H Meertens, AW Konings, HH Kampinga, and RP Coppes, Locoregional differences in pulmonary function and density after partial rat lung irradiation. Radiother Oncol, 2003. 69(1): p. 11-9.

159. P van Luijk, H Faber, H Meertens, JM Schippers, JA Langendijk, S Brandenburg, HH Kampinga, and RP Coppes, The impact of heart irradiation on dose-volume effects in the rat lung. Int J Radiat Oncol Biol Phys, 2007. 69(2): p. 552-9.

160. CJ Johnston, JP Williams, P Okunieff, and JN Finkelstein, Radiation-induced pulmonary fibrosis: examination of chemokine and chemokine receptor families. Radiat Res, 2002. 157(3): p. 256-65.

161. RG Bristow, PA Hardy, and RP Hill, Comparison between in vitro radiosensitivity and in vivo radioresponse of murine tumor cell lines. I: Parameters of in vitro radiosensitivity and endogenous cellular glutathione levels. Int J Radiat Oncol Biol Phys, 1990. 18(1): p. 133-45.

162. Report of the American Institute of Nurtition ad hoc Committee on Standards for Nutritional Studies. J Nutr, 1977. 107(7): p. 1340-8.

163. MJ Messina and CL Loprinzi, Soy for breast cancer survivors: a critical review of the literature. J Nutr, 2001. 131(11 Suppl): p. 3095S-108S.

164. M Fenech, The in vitro micronucleus technique. Mutat Res, 2000. 455(1-2): p. 8195.

165. A Churg, An inflation procedure for open lung biopsies. Am J Surg Pathol, 1983. 7(1): p. 69-71.

166. EL Travis, B Vojnovic, EE Davies, and DG Hirst, A plethysmographic method for measuring function in locally irradiated mouse lung. Br J Radiol, 1979. 52(613): p. 67-74.

167. EL Travis, JD Down, L Hall, B Vojnovic, and SJ Holmes, Factors affecting the breathing rate of mice as used for studies of radiation damage to lungs. $\mathrm{Br} \mathrm{J}$ Radiol, 1981. 54(637): p. 50-3.

168. NJ Gross, Pulmonary effects of radiation therapy. Ann Intern Med, 1977. 86(1): p. 81-92.

169. K Fleckenstein, B Gauter-Fleckenstein, IL Jackson, Z Rabbani, M Anscher, and Z Vujaskovic, Using biological markers to predict risk of radiation injury. Semin Radiat Oncol, 2007. 17(2): p. 89-98.

170. K Fleckenstein, L Zgonjanin, L Chen, Z Rabbani, IL Jackson, B Thrasher, J Kirkpatrick, WM Foster, and Z Vujaskovic, Temporal onset of hypoxia and oxidative stress after pulmonary irradiation. Int J Radiat Oncol Biol Phys, 2007. 68(1): p. 196-204.

171. PA Riley, Free radicals in biology: oxidative stress and the effects of ionizing radiation. Int J Radiat Biol, 1994. 65(1): p. 27-33.

172. JF Ward, DNA damage as the cause of ionizing radiation-induced gene activation. Radiat Res, 1994. 138(1 Suppl): p. S85-8. 
173. JH Hong, SM Jung, TC Tsao, CJ Wu, CY Lee, FH Chen, CH Hsu, WH McBride, and CS Chiang, Bronchoalveolar lavage and interstitial cells have different roles in radiation-induced lung injury. Int J Radiat Biol, 2003. 79(3): p. 159-67.

174. CS Chiang, WC Liu, SM Jung, FH Chen, CR Wu, WH McBride, CC Lee, and JH Hong, Compartmental responses after thoracic irradiation of mice: strain differences. Int J Radiat Oncol Biol Phys, 2005. 62(3): p. 862-71.

175. HP Rodemann and MA Blaese, Responses of normal cells to ionizing radiation. Semin Radiat Oncol, 2007. 17(2): p. 81-8.

176. AL Brooks, S Bao, PW Harwood, BH Wood, WB Chrisler, MA Khan, RA Gies, and FT Cross, Induction of micronuclei in respiratory tract following radon inhalation. Int J Radiat Biol, 1997. 72(5): p. 485-95.

177. R Michael McClain, E Wolz, A Davidovich, F Pfannkuch, JA Edwards, and J Bausch, Acute, subchronic and chronic safety studies with genistein in rats. Food Chem Toxicol, 2006. 44(1): p. 56-80.

178. RM Day, M Barshishat-Kupper, SR Mog, EA McCart, PG Prasanna, TA Davis, and MR Landauer, Genistein Protects Against Biomarkers of Delayed Lung Sequelae in Mice Surviving High-Dose Total Body Irradiation. J Radiat Res (Tokyo), 2008.

179. MS Morton, O Arisaka, N Miyake, LD Morgan, and BA Evans, Phytoestrogen concentrations in serum from Japanese men and women over forty years of age. $\mathrm{J}$ Nutr, 2002. 132(10): p. 3168-71.

180. S Yamamoto, T Sobue, S Sasaki, M Kobayashi, Y Arai, M Uehara, H Adlercreutz, S Watanabe, T Takahashi, Y Iitoi, Y Iwase, M Akabane, and S Tsugane, Validity and reproducibility of a self-administered food-frequency questionnaire to assess isoflavone intake in a japanese population in comparison with dietary records and blood and urine isoflavones. J Nutr, 2001. 131(10): p. 2741-7.

181. F Schmidt, CB Knobbe, B Frank, H Wolburg, and M Weller, The topoisomerase II inhibitor, genistein, induces G2/M arrest and apoptosis in human malignant glioma cell lines. Oncol Rep, 2008. 19(4): p. 1061-6.

182. H Zou, S Zhan, and K Cao, Apoptotic activity of genistein on human lung adenocarcinoma SPC-A-1 cells and preliminary exploration of its mechanisms using microarray. Biomed Pharmacother, 2008.

183. JI Shin, JH Shim, KH Kim, HS Choi, JW Kim, HG Lee, BY Kim, SN Park, OJ Park, and DY Yoon, Sensitization of the apoptotic effect of gamma-irradiation in genistein-pretreated CaSki cervical cancer cells. J Microbiol Biotechnol, 2008. 18(3): p. 523-31.

184. C Borek, Antioxidants and radiation therapy. J Nutr, 2004. 134(11): p. 3207S3209S.

185. K Camphausen, D Citrin, MC Krishna, and JB Mitchell, Implications for tumor control during protection of normal tissues with antioxidants. J Clin Oncol, 2005. 23(24): p. 5455-7.

186. KN Prasad, Multiple dietary antioxidants enhance the efficacy of standard and experimental cancer therapies and decrease their toxicity. Integr Cancer Ther, 2004. 3(4): p. 310-22. 
187. C Borek, Dietary antioxidants and human cancer. Integr Cancer Ther, 2004. 3(4): p. 333-41.

188. KI Block, Antioxidants and cancer therapy: furthering the debate. Integr Cancer Ther, 2004. 3(4): p. 342-8.

189. GM D'Andrea, Use of antioxidants during chemotherapy and radiotherapy should be avoided. CA Cancer J Clin, 2005. 55(5): p. 319-21.

190. RW Moss, Should patients undergoing chemotherapy and radiotherapy be prescribed antioxidants? Integr Cancer Ther, 2006. 5(1): p. 63-82. 